\title{
Biosynthesis of Diverse Antimicrobial and Antiproliferative Acyloins in Anaerobic Bacteria
}

Sebastian Schieferdecker ${ }^{a, \dagger}, G$ (ulimila Shabuer ${ }^{a, \dagger}$, Anne-Catrin Letzel ${ }^{a}$, Barbara Urbansky ${ }^{a}$, Mie Ishida-Ito ${ }^{a}$, Keishi Ishida ${ }^{a}$, Michael Cyrulies ${ }^{b}$, Hans-Martin Dahse ${ }^{d}$, Sacha Pidot $^{c}$, and Christian Hertweck $^{\mathrm{a}, \mathrm{e}^{*}}$

a Department of Biomolecular Chemistry, Leibniz Institute for Natural Product Research and Infection Biology (HKI), Beutenbergstr. 11a, 07745 Jena, Germany.

${ }^{b}$ BioPilot Plant, Leibniz Institute for Natural Product Research and Infection Biology (HKI), Beutenbergstr. 11a, 07745 Jena, Germany.

${ }^{c}$ Department of Infection Biology, Leibniz Institute for Natural Product Research and Infection Biology (HKI), Beutenbergstr. 11a, 07745 Jena, Germany.

d Department of Microbiology and Immunology, The Peter Doherty Institute for Infection and Immunity, University of Melbourne, 792 Elizabeth Street, Victoria 3010, Australia.

${ }^{\text {e }}$ Faculty of Biological Sciences, Friedrich Schiller University Jena, 07743 Jena, Germany.

${ }^{\dagger}$ Both authors have contributed equally to this work 


\section{Table of Contents}

\section{Experimental Section}

General experimental procedures

Fermentation of C. beijerinckii, extraction and isolation of acyloins

Genome sequencing and annotation

Construction of sattazolin synthase (Cbei2730) expression plasmid

In vivo sattazolin production

Sattazolin purification from E. coli (DE3) pET28a-cbei2730 culture

Production and purification of His6-Cbei2730

In vitro sattazolin production by His6-Cbei2730

Reversed-phase HPLC analysis for in vivo and in vitro sattazolin production

Cloning and overexpression of clostrocyloin synthase gene (CbeiHKI805_0381)

Production and purification of clostrocyloin synthase (CbeiHKI805_0381)

Enzyme assay of clostrocyloin synthase (CbeiHKI805_0381)

Preparation of methyl 2-((tert-butyldimethylsilyl)oxy)propanoate (32)

Preparation of 2-((tert-butyldimethylsilyl)oxy)- $N$-methoxy- $N$-methylpropanamide (33)

Preparation of 2-hydroxy-5-methylhexan-3-one (35)

Preparation of MTPA esters of (S)- and racemic 2-hydroxy-5-methylhexan-3-one

HPLC analysis of MPTA esters

Phylogenetic analysis

Agar diffusion assay

Evaluation of antiproliferative and cytotoxic effects

Supporting references 


\section{Tables}

Table S1. Antimicrobial activity of compounds 1-6 in an agar diffusion assay [mm inhibition zone].

Table S2. Antiproliferative and cytotoxic activity of compounds 1-6.

Table S3. Optical rotation of compounds 1-6.

Table S4. ${ }^{1} \mathrm{H}(600 \mathrm{MHz})$ and ${ }^{13} \mathrm{C}$ NMR $(150 \mathrm{MHz})$ data of 1.

Table S5. ${ }^{1} \mathrm{H}(500 \mathrm{MHz})$ and ${ }^{13} \mathrm{C}$ NMR $(125 \mathrm{MHz})$ data of 2.

Table S6. ${ }^{1} \mathrm{H}(300 \mathrm{MHz})$ and ${ }^{13} \mathrm{C}$ NMR $(75 \mathrm{MHz})$ data of 3.

Table S7. ${ }^{1} \mathrm{H}(500 \mathrm{MHz})$ and ${ }^{13} \mathrm{C}$ NMR $(125 \mathrm{MHz})$ data of 4.

Table S8. ${ }^{1} \mathrm{H}(500 \mathrm{MHz})$ and ${ }^{13} \mathrm{C}$ NMR $(125 \mathrm{MHz})$ data of 5.

Table s9. ${ }^{1} \mathrm{H}(600 \mathrm{MHz})$ and ${ }^{13} \mathrm{C}$ NMR $(150 \mathrm{MHz})$ data of 6.

Table S10. ThDP-dependent enzymes used in the phylogenetic tree.

Figures

Figure S1. COSY (bold lines) and HMBC correlations (arrows) of compound 1.

Figure S2. COSY (bold lines) and HMBC correlations (arrows) of compound 2.

Figure S3. COSY (bold lines) and HMBC correlations (arrows) of compound 3.

Figure S4. COSY (bold lines) and HMBC correlations (arrows) of compound 4.

Figure S5. COSY (bold lines) and HMBC correlations (arrows) of compound 5.

Figure S6. COSY (bold lines) and HMBC correlations (arrows) of compound 6.

Figure S7. A: Preparation of synthetic standards and MPTA diastereomers 7 and 8.

Figure S8. SDS-PAGE analysis of heterologously produced $\mathrm{His}_{6}-\mathrm{Cbei2730.}$

Figure S9. SDS-PAGE of CbeiHKI805_0381.

Figure S10. Maximum likelihood phylogenetic tree for acyloin synthases and related ThDP-dependent enzymes.

Figure S11. Acyloin synthases used in the phylogenetic tree.

Figure S12. ThDP-dependent enzymes used in the phylogenetic tree. SHCHC, 2succinyl-5-enolpyruvyl-6-hydroxy-3-cyclohexadiene-1-carboxylate.

Figure S13. ${ }^{1} \mathrm{H}$ spectrum of compound 1.

Figure S14. ${ }^{13} \mathrm{C}$ spectrum of compound 1. 
Figure S15. COSY spectrum of compound 1.

Figure S16. HSQC spectrum of compound 1.

Figure S17. HMBC spectrum of compound 1.

Figure S18. ${ }^{1} \mathrm{H}$ spectrum of compound 2.

Figure S19. ${ }^{13} \mathrm{C}$ spectrum of compound 2.

Figure S20. COSY spectrum of compound 2.

Figure S21. HSQC spectrum of compound 2.

Figure S22. HMBC spectrum of compound 2.

Figure S23. ${ }^{1} \mathrm{H}$ spectrum of compound 3.

Figure S24. ${ }^{13} \mathrm{C}$ spectrum of compound 3 .

Figure S25. COSY spectrum of compound 3.

Figure S26. HSQC spectrum of compound 3.

Figure S27. HMBC spectrum of compound 3.

Figure S28. ${ }^{1} \mathrm{H}$ spectrum of compound 4.

Figure S29. ${ }^{13} \mathrm{C}$ spectrum of compound 4 .

Figure S30. COSY spectrum of compound 4.

Figure S30. COSY spectrum of compound 4.

Figure S32. HMBC spectrum of compound 4.

Figure S33. ${ }^{1} \mathrm{H}$ spectrum of compound 5.

Figure S34. ${ }^{13} \mathrm{C}$ spectrum of compound 5 .

Figure S35. COSY spectrum of compound $\mathbf{5}$.

Figure S36. HSQC spectrum of compound 5.

Figure S37. HMBC spectrum of compound 5.

Figure S38. ${ }^{1} \mathrm{H}$ spectrum of compound 6.

Figure $539 .{ }^{13} \mathrm{C}$ spectrum of compound 6 .

Figure S40. COSY spectrum of compound 6.

Figure S41. HSQC spectrum of compound 6.

Figure S42. HMBC spectrum of compound 6.

Figure S43. ${ }^{1} \mathrm{H}$ NMR spectrum of methyl 2-((tert-butyldimethylsilyl)oxy)propanoate (32). 
Figure S44. ${ }^{13} \mathrm{C}$ NMR spectrum of methyl 2-((tert-butyldimethylsilyl)oxy)propanoate (32).

Figure S45. ${ }^{1} \mathrm{H}$ NMR spectrum of 2-((tert-butyldimethylsilyl)oxy)- $N$-methoxy- $N$ methylpropanamide (33).

Figure S46. ${ }^{13} \mathrm{C}$ NMR spectrum of 2-((tert-butyldimethylsilyl)oxy)- $N$-methoxy- $N$ methylpropanamide (33).

Figure S47. ${ }^{1} \mathrm{H}$ NMR spectrum of 2-hydroxy-5-methylhexan-3-one (35).

Figure S48. ${ }^{13} \mathrm{C}$ NMR spectrum of 2-hydroxy-5-methylhexan-3-one (35).

Figure S49. ESI-HR-MS spectrum of compound 1 measured in positive mode.

Figure S50. ESI-HR-MS spectrum of compound 1 measured in negative mode.

Figure S51. ESI-HR-MS spectrum of compound 2 measured in positive mode.

Figure S52. ESI-HR-MS spectrum of compound 2 measured in negative mode.

Figure S53. ESI-HR-MS spectrum of compound 3 measured in positive mode.

Figure S54. ESI-HR-MS spectrum of compound 3 measured in negative mode.

Figure S55. ESI-HR-MS spectrum of compound 4 measured in positive mode.

Figure S56. ESI-HR-MS spectrum of compound 4 measured in negative mode.

Figure S57. ESI-HR-MS spectrum of compound 5 measured in positive mode.

Figure S58. ESI-HR-MS spectrum of compound 5 measured in negative mode.

Figure S59. ESI-HR-MS spectrum of compound 6 measured in positive mode.

Figure S60. ESI-HR-MS spectrum of 6 measured in negative mode.

Figure S61. ESI-HR-MS spectrum of ${ }^{13} \mathrm{C}$-labeled 6 measured in positive mode.

Figure S62. ESI-HR-MS spectrum of ${ }^{13} \mathrm{C}$-labeled 6 measured in negative mode.

Figure S63. HR-ESI-MS spectrum of 13 measured in negative mode.

Figure S64. ESI-HR-MS spectrum of compound 14 measured in negative mode.

Figure S65. HR-ESI-MS spectrum of 2-hydroxy-2-isobutyl-4,4-dimethyl-3-oxopentanoic acid (15) measured in negative mode.

Figure S66. HR-ESI-MS spectrum of 2-hydroxy-2-isobutyl-4-methyl-3-oxohexanoic acid (16) measured in negative mode.

Figure S67. HR-ESI-MS spectrum of 2-hydroxy-2-isobutyl-4-methyl-3-oxopentanoic acid (17) measured in negative mode.

\section{Supporting References}




\section{Experimental Procedures}

\section{General experimental procedures}

NMR data were recorded on AVANCE III $300 \mathrm{MHz}, 500 \mathrm{MHz}$ and $600 \mathrm{MHz}$ instruments. LCHRMS measurements were performed using an Exactive Q Orbitrap high performance benchtop device with an electrospray ion source and an Accela HPLC system (Thermo Fisher Scientific, Bremen, Germany) consisting of an Autosampler equipped with a column oven, a 1250 Pump and a PDA Detector.

\section{Fermentation of $C$. beijerinckii, extraction and isolation of acyloins}

C. beijerinckii HKI805 was grown in P2 medium ${ }^{1}$ in bioreactors (20 L, BIOSTAT UD, U20K, Braun Biotech International) at $37^{\circ} \mathrm{C}$. After 3 days of fermentation, the fermentation broth was extracted twice with $20 \mathrm{~L}$ ethyl acetate. The organic layers were combined, residual water dried with $\mathrm{Na}_{2} \mathrm{SO}_{4}$ and the solvent removed under reduced pressure. The crude extract was chromatographed on a Shimadzu Prominence preparative HPLC system equipped with a diode array detector and a $\mathrm{C}_{18} \mathrm{Htec} 21 \times 250 \mathrm{~mm}, 5 \mu \mathrm{m}$ column (Macherey Nagel). Chromatographic conditions were as follows: $10 \% \mathrm{MeOH}$ in $\mathrm{H}_{2} \mathrm{O}$ with $0.1 \%$ TFA for 5 min followed by a linear gradient to $100 \% \mathrm{MeOH}$ in $30 \mathrm{~min}$ and an additional isocratic step at $100 \% \mathrm{MeOH}$ for $10 \mathrm{~min}$.

\section{Genome sequencing and annotation}

Clostridial genomes (C. beijerrinckii DSM51, DSM53) were sequenced using Illumina based sequencing. DNA libraries were created using the Nextera XT DNA preparation kit (Illumina) and whole genome sequencing was performed on the NextSeq platform (Illumina) with $2 \times 150 \mathrm{bp}$ paired-end chemistry. A sequencing depth of $>50 \times$ was targeted for each sample. Genomes were assembled with SPAdes (v 3.10.1) and annotated with Prokka v 1.12. ${ }^{2-3}$

\section{Construction of sattazolin synthase (Cbei2730) expression plasmid}

Genomic DNA of C. beijerinckii NCIMB 8052 was purified by using Epicentre MasterPure ${ }^{\text {TM }}$ DNA Purification Kit. The Cbei2730 gene was amplified with primer pair cbei2730_Ndel_fw (5'-GGT CAT ATG AGA AAC ATA GCA TCT ATT TTA-3') and cbei2730_BamHI_rv (5'-GGT GGA TCC CTA TCC CCT TTT CAT AGT TGG-3') by Phusion polymerase (New England Biolabs). The amplicon obtained from agarose gel was purified by illustra GFX PCR DNA and Gel Band Purification Kit (GE Healthcare), and the recovered DNA was subcloned into pJET1.2 (Thermo Fisher Scientific). The resulting plasmid pJET1.2-cbei2730 was restricted with Ndel and BamHI, 
and the gene fragment was subcloned into pET28a(+) vector (Novagen), which was restricted by Ndel and BamHI to yield pET28a-cbei2730. This plasmid was finally introduced into E. coli BL21 (DE3).

\section{In vivo sattazolin production}

E. coli BL21 (DE3) pET28a-cbei2730 was cultured at $37{ }^{\circ} \mathrm{C}$ overnight and these pre-cultured cells $(300 \mu \mathrm{L})$ were inoculated in $30 \mathrm{~mL}$ of LB medium containing $50 \mu \mathrm{g} \mathrm{mL}^{-1}$ kanamycin and cultured at $37^{\circ} \mathrm{C}$ until $O_{600}=0.5-0.7$. After cells were cooled on ice for $30 \mathrm{~min}$, isopropyl-ß-Dthiogalactopyranosid (IPTG) was added for induction (final conc. $0.5 \mathrm{mM}$ ) and the two a-keto acids indole-3-pyruvic acid and calcium 4-methyl-2-oxovalerate (final conc. each $5 \mathrm{mM}$ ) were added to the culture. Afterwards, the induced E. coli cells were further cultivated at $24{ }^{\circ} \mathrm{C}$ overnight. The culture broth was extracted with $30 \mathrm{~mL}$ ethyl acetate twice and the extracts were dried over $\mathrm{Na}_{2} \mathrm{SO}_{4}$. After the removal of solvent under reduced pressure, the residue was dissolved in $300 \mu \mathrm{L}$ methanol and analyzed by HR-LC-MS.

\section{Sattazolin purification from E. coli (DE3) pET28a-cbei2730 culture}

Three $\mathrm{mL}$ of overnight preculture E. coli BL21 (DE3) pET28a-cbei2730 was inoculated in $300 \mathrm{~mL}$ LB medium in $1 \mathrm{~L}$ flasks containing $25 \mu \mathrm{g} \mathrm{mL}{ }^{-1}$ kanamycin and were incubated at $37^{\circ} \mathrm{C}$ with shaken. When $\mathrm{OD}_{600}$ reached approximately 0.7 , IPTG was added to a final concentration of 0.5 $\mathrm{mM}$. Indole-3-pyruvic acid and calcium 4-methyl-2-oxovalerate hydrate were added at final concentrations of $5 \mathrm{mM}$ each. This IPTG induced culture was further incubated at $24{ }^{\circ} \mathrm{C}$ with shaking for 18 hours. The culture broth was extracted with $300 \mathrm{~mL}$ ethyl acetate three times and organic phases were combined. After drying over $\mathrm{Na}_{2} \mathrm{SO}_{4}$, the solvent was concentrated under reduced pressure. The residue was subjected to silca gel SPE column chromatography (500 mg, CHROMABOND) using a chloroform/methanol system. The fraction eluted with chloroform/methanol (49:1) was subjected to reversed-phase HPLC (Kromasil 100-5C18, $20 \times$ $250 \mathrm{~mm}$, Labor und Datentechnik $\mathrm{GmbH}$ ) with a gradient system; solvent A (water containing $0.1 \%$ TFA), solvent B ( $83 \%$ acetonitrile), $30 \%$ B for $10 \mathrm{~min}$, to $100 \%$ B for $35 \mathrm{~min}$, and 100\% B

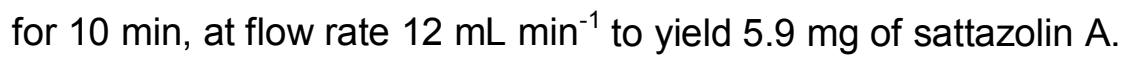

\section{Production and purification of $\mathrm{His}_{6}-\mathrm{Cbei2730}$}

One hundredth volume of the overnight preculture of E. coli BL21 (DE3) pET28a-cbei2730 was inoculated in LB medium containing kanamycin $\left(25 \mu \mathrm{g} \mathrm{mL} \mathrm{m}^{-1}\right)$ at $37^{\circ} \mathrm{C}$ until OD $600=0.5-0.8$. Cells were cooled on ice for $30 \mathrm{~min}$, then further cultivated $18^{\circ} \mathrm{C}$ overnight after induction $(0.5$ 
mM IPTG). Cells were harvested using centrifugation and resuspended with lysis buffer (50 mM Tris- $\mathrm{HCl} \mathrm{pH}$ 7.5), $250 \mathrm{mM} \mathrm{NaCl}, 20 \%$ glycerol, $1 \mathrm{mM}$ DTT, $1 \mathrm{mM}$ EDTA). The resuspended solution was incubated at $37^{\circ} \mathrm{C}$ for $30 \mathrm{~min}$ in the presence of lysozyme $\left(1 \mathrm{mg} \mathrm{mL}{ }^{-1}\right)$. Cells were disrupted using a sonicator (SONOPULS HD 2200, BANDELIN) and the cell debris was removed by centrifugation at $9,500 \times \mathrm{g}$ for $45 \mathrm{~min}$ at $4{ }^{\circ} \mathrm{C}$. Supernatants were loaded onto $\mathrm{Ni}-$ NTA agarose resin (Qiagen) using the batch method. The resin was washed with buffer A (50 m Tris- $\mathrm{HCl}$ (pH 7.5), $0.5 \mathrm{M} \mathrm{NaCl}, 1 \mathrm{mM}$ EDTA, $1 \mathrm{mM}$ DTT) containing $10 \mathrm{mM}$ imidazole and same buffer with $30 \mathrm{mM}$ imidazole. The proteins were eluted with buffer A containing $500 \mathrm{mM}$ imidazole. Fractions containing $\mathrm{His}_{6}-\mathrm{Cbei} 2730$ were analyzed using SDS-PAGE and dialyzed against $50 \mathrm{mM}$ Tris- $\mathrm{HCl}(\mathrm{pH} 7.5), 50 \mathrm{mM} \mathrm{NaCl}$. The band which was corresponding to the expected molecular weight was analyzed and confirmed by MALDI-TOF-MS using in-gel tryptic (Promega) digestion method (Data not shown). Purified His ${ }_{6}-\mathrm{Cbei2730}$ was concentrated using centrifugal filters (Amicon Ultra-15; 50 kDa MWCO) (Merck Millipore). The concentrations of protein solutions were determined using a Nanodrop (Thermo Scientific).

\section{In vitro sattazolin production by $\mathrm{His}_{6}-\mathrm{Cbei2730}$}

The enzyme activity was assayed by acyloin condensation of indole-3-pyruvic acid and calcium 4-methyl-2-oxovalerate hydrate. Assay mix (total volume $1 \mathrm{~mL}$ ) consisted of thiamine pyrophosphate (TPP; final conc. $1 \mathrm{mM}$ ), $\mathrm{MgCl}_{2}$ (final conc. $3 \mathrm{mM}$ ), $\mathrm{NaCl}$ (final conc. $200 \mathrm{mM}$ ), enzyme (final conc. $286 \mu \mathrm{g} \mathrm{mL} \mathrm{m}^{-1}$ ), indole-3-pyruvic acid (final conc. $9 \mathrm{mM}$ ), and calcium 4methyl-2-oxovalerate hydrate (final conc. $9 \mathrm{mM}$ ) in $50 \mathrm{mM}$ HEPES ( $\mathrm{pH} 8.0$ ). This mixture was incubated at $28{ }^{\circ} \mathrm{C}$ with shaken at $500 \mathrm{rpm}$ overnight. The resulting mixture was extracted with ethyl acetate $(1 \mathrm{~mL})$ twice and dried over $\mathrm{Na}_{2} \mathrm{SO}_{4}$. After the solvent was removed under the reduced pressure, the residue was dissolved in $100 \mu \mathrm{l}$ methanol.

\section{Reversed-phase HPLC analysis for in vivo and in vitro sattazolin production}

The $20 \mu \mathrm{L}$ extracts were analyzed by reversed-phase HPLC (Eurosphere 100-7C18, $4 \times 250$ $\mathrm{mm}$, Knauer) as a gradient system; solvent A (water containing $0.5 \%$ TFA), solvent $B$ (acetonitrile), $20 \%$ B for $5 \mathrm{~min}$, to $100 \% \mathrm{~B}$ for $30 \mathrm{~min}, 100 \% \mathrm{~B}$ for $1 \mathrm{~min}$, at flow rate $1 \mathrm{~mL} \mathrm{~min}{ }^{-1}$. These extracts were also analyzed by Orbitrap HPLC-HRMS.

\section{Cloning and overexpression of clostrocyloin synthase gene (CbeiHKI805_0381)}

The gene CbeiHKI805_0381 (1650 bp product) from C. beijerinckii HKI805 was amplified by PCR from genomic DNA of $C$. beijerinckii HKI805 using the primer pair (100 pmol) 
Cbei_0381_BamHI_fw: 5'-AAA AGG ATC CAT GAG AAA CAT AGC ATC TAT TTT AGT ATC3‘; Cbei_0381_Sall_v: 5’-TTT TGT CGA CCT ATC TCC TTT TCA TAG TTG GTG-3' using Finnzymes Phusion High-Fidelity DNA Polymerase (Biozym Scientific $\mathrm{GmbH}$, Oldendorf, Deutschland); Thermal cycling condition were as following: $98^{\circ} \mathrm{C} 2 \mathrm{~min}, 98^{\circ} \mathrm{C} 30 \mathrm{sec}, 55^{\circ} \mathrm{C} 30$ sec, $72{ }^{\circ} \mathrm{C}$ for $1 \mathrm{~min}$ per $\mathrm{kb}$ of PCR product, $30 \mathrm{x}, 72{ }^{\circ} \mathrm{C} 10 \mathrm{~min}, 4^{\circ} \mathrm{C}$ hold. The resulting PCR product was cloned into pJET1.2 (Thermo Scientific) and sequenced. The desired fragment of the gene was cloned into the BamHI-Sall site of the expressions plasmid pET28a(+) (Novagen) to give pET28-cbei381. The plasmid was introduced into E. coli Rosetta DE3. Colonies were selected by growth on LB agar containing kanamycin and chloramphenicol, respectively.

\section{Production and purification of clostrocyloin synthase (CbeiHKI805_0381)}

E. coli Rosetta DE3 strain carrying the expression vector $\mathrm{pET} 28$-cbei381 was used. A single bacterial colony was inoculated in $10 \mathrm{~mL} 2 \mathrm{YT}$ medium (16 g Bacto Tryptone, $10 \mathrm{~g}$ Bacto Yeast Extract, $5 \mathrm{~g} \mathrm{NaCl}$ and distilled water $1,000 \mathrm{~mL}$ ) in a $100 \mathrm{~mL}$ flask that contained $20 \mu \mathrm{L}$ kanamycin $\left(50 \mathrm{mg} \mathrm{mL}^{-1}\right)$ and $20 \mu \mathrm{L}$ chloramphenicol $\left(25 \mathrm{mg} \mathrm{mL}^{-1}\right)$. The culture was shaken at $200 \mathrm{rpm}$ and $30{ }^{\circ} \mathrm{C}$ overnight. $1 \%$ of the overnight culture was transferred to a $1 \mathrm{~L}$ baffled Erlenmeyer flask with $400 \mathrm{~mL}$ of $2 \mathrm{YT}$ medium containing $400 \mu \mathrm{L}$ kanamycin $\left(50 \mathrm{mg} \mathrm{mL}^{-1}\right)$ and $400 \mu \mathrm{L}$ chloramphenicol $\left(25 \mathrm{mg} \mathrm{mL}^{-1}\right)$. The culture was shaken at $180 \mathrm{rpm}$ at $27^{\circ} \mathrm{C}$ for $4-5 \mathrm{~h}$ until an OD600 $=0.4-0.6$ was reached. Protein expression was induced by addition of $1 \mathrm{mM}$ IPTG with further cultivation for $15 \mathrm{~h}$ at $16{ }^{\circ} \mathrm{C}$ with shaking at $200 \mathrm{rpm}$. After cell disruption, the soluble fraction was dissolved in $50 \mathrm{mM}$ phosphate buffer $(\mathrm{pH}$ 7.4) supplemented with $300 \mathrm{mM}$ $\mathrm{NaCl}$. For protein purification we used the batch/gravity-flow method. The soluble fraction was incubated with $3 \mathrm{~mL}$ TALON Superflow on a shaker at low speed for 1 hour. After the incubation the fraction was loaded to a PD-10 column and the flow-through was collected. The Talon beads on the column were washed with 2 bed volumes of wash buffer ( $50 \mathrm{mM}$ sodium phosphate, 300 $\mathrm{mM} \mathrm{NaCl}, \mathrm{pH} 7.4$ ). Then, the protein was eluted with 4 bed volumes of elution buffer (50 mM sodium phosphate, $300 \mathrm{mM} \mathrm{NaCl}, 150 \mathrm{mM}$ Imidazol, $\mathrm{pH}$ 7.4). The collected fractions were used for SDS-PAGE (12\%). For concentration of the protein, we used the Amicons Ultra 15 filtration units (Merck Milipore). To store the purified protein, we used the assay buffer (50 mM HEPES, $25 \mathrm{mM} \mathrm{NaCl}, \mathrm{pH} 7.5)$.

\section{Enzyme assay of clostrocyloin synthase (CbeiHKI805_0381)}

The enzyme activity was assayed by acyloin condensation of pyruvate with 3-methyl-2oxobutyric acid. The assay master mix consisted of purified enzyme CbeiHKI805_0381 $25 \mu \mathrm{L}$ (2 
$\left.\mu \mathrm{g} \mu \mathrm{L}^{-1}\right)$, potassium phosphate buffer $\left(100 \mu \mathrm{L}\right.$ of $500 \mathrm{mM}, \mathrm{pH}$ 6.8) $\mathrm{MgCl}_{2}(30 \mu \mathrm{L}, 100 \mathrm{mM})$ thiamine pyrophosphate (TPP, $25 \mu \mathrm{L}, 50 \mathrm{mM})$, water $(250 \mu \mathrm{L})$ and substrates: pyruvate and 3methyl-2-oxobutyric acid. The control consisted of the assay master mix without enzyme but water. All samples were shaken at $1,000 \mathrm{rpm}$ and $28^{\circ} \mathrm{C}$ overnight. The reaction was terminated by addition of aqueous $\mathrm{HCl}(1 \mathrm{M})$ and methanol. The enzyme assay solution was subsequently extracted three times with dichloromethane, the organic layers were combined and dried under reduced pressure. After dissolving in a small volume of acetonitrile, $20 \mu \mathrm{L}$ of a saturated solution of freshly recrystallized 2,4-dinitrophenyl hydrazine in acetonitrile and $20 \mu \mathrm{L} 6 \mathrm{~N} \mathrm{HCl}$ was added and the mixture was incubated at $40^{\circ} \mathrm{C}$ for $1 \mathrm{~h}$. A sample of synthetic 2-hydroxy-5-methylhexan3-one was treated the same way. All samples were directly analysed by HR-LC-MS.

\section{Preparation of methyl 2-((tert-butyldimethylsilyl)oxy)propanoate (32)}

To an ice water bath cooled solution of $2 \mathrm{mmol}$ of $\mathrm{L}$ or D/L-lactic acid methyl ester in dry dichloromethane, 1.5 equivalents of imidazole and 1.2 equivalents of tertbutyl(chloro)dimethylsilane were added. The solution was allowed to warm up to room temperature and stirred for $16 \mathrm{~h}$. Subsequently, the solution was diluted with dichloromethane and washed with brine. The organic layer was separated, dried with $\mathrm{Na}_{2} \mathrm{SO}_{4}$, evaporated under reduced pressure and the crude product purified by silica column chromatography using $n$ hexane:ethyl acetate $97: 3$ as a mobile phase.

Colorless oil; ${ }^{1} \mathrm{H}$ NMR (300 MHz, $\left.\mathrm{CDCl}_{3}\right): \delta=4.29(\mathrm{q}, J=6.7 \mathrm{~Hz}, 1 \mathrm{H}), 3.68(\mathrm{~s}, 3 \mathrm{H}), 1.36(\mathrm{~d}, J=$ $6.7 \mathrm{~Hz}, 3 \mathrm{H}), 0.86(\mathrm{~s}, 9 \mathrm{H}), 0.06(\mathrm{~s}, 3 \mathrm{H}), 0.03(\mathrm{~s}, 3 \mathrm{H}) ;{ }^{13} \mathrm{C} \mathrm{NMR}\left(75 \mathrm{MHz}, \mathrm{CDCl}_{3}\right): \delta=174.7,68.4$, $51.8,25.8,21.3,18.3,-5.0,-5.3$.

\section{Preparation of 2-((tert-butyldimethylsilyl)oxy)-N-methoxy-N-methylpropanamide (33)}

To an ice water bath cooled solution of $1.5 \mathrm{mmol}$ of $S$ - or racemic 2-((tertbutyldimethylsilyl)oxy)propanoate in dry dichloromethane, 1.2 equivalents of $\mathrm{Me}_{3} \mathrm{Al}$ and 1.2 equivalents of $\mathrm{N}, \mathrm{O}$-dimethylhydroxylamine hydrochloride were added. The solution was allowed to reach room temperature and stirred for additional 4 hours. Afterwards, the solution was diluted with dichloromethane and washed with saturated Rochelle salt solution. After separation of the organic phase, residual water was removed by the addition of $\mathrm{Na}_{2} \mathrm{SO}_{4}$ and the solvent was removed under reduced pressure. The crude product was purified by silica column chromatography using a gradient of dichloromethane:ethyl acetate $1: 1 \rightarrow$ ethyl acetate:methanol 9:1 as a mobile phase. 
Colorless oil; ${ }^{1} \mathrm{H}$ NMR (600 MHz, $\mathrm{CDCl}_{3}$ ): $\delta=4.68$ (bs, 3H), 3.71 (s, 3H), 3.22 (bs, 3H), 1.37 (d, $J$ $=6.7 \mathrm{~Hz}, 3 \mathrm{H}), 0.92(\mathrm{~s}, 9 \mathrm{H}), 0.12(\mathrm{~s}, 3 \mathrm{H}), 0.09(\mathrm{~s}, 3 \mathrm{H}) ;{ }^{13} \mathrm{C} \mathrm{NMR}\left(150 \mathrm{MHz}, \mathrm{CDCl}_{3}\right): \delta=175.0$, $66.4,61.1,32.6,25.8,20.9,18.3,-4.7,-5.0$.

\section{Preparation of 2-hydroxy-5-methylhexan-3-one (35)}

To a solution of $1 \mathrm{mmol}$ of $S$ - or racemic 2-((tert-butyldimethylsilyl)oxy)- $N$-methoxy- $N$ methylpropanamide in dry diethyl ether, three equivalents of isobutylmagnesium bromide were added and the solution was stirred at room temperature for $16 \mathrm{~h}$. Subsequently the reaction was quenched by the careful addition of $0.1 \mathrm{M} \mathrm{HCl}$, diluted with diethyl ether and washed with $0.1 \mathrm{M}$ $\mathrm{HCl}$ and brine. Residual water was removed by $\mathrm{Na}_{2} \mathrm{SO}_{4}$ addition and the solvent removed under reduced pressure. The crude product was dissolved in THF, cooled to $0{ }^{\circ} \mathrm{C}$ with an ice water bath and 1 equivalent of TBAF was added. The solution was stirred at $0{ }^{\circ} \mathrm{C}$ for additional two hours. Afterwards, the solvent was removed under reduced pressure and the crude product purified by silica column chromatography with dichloromethane as mobile phase.

Colorless oil; ${ }^{1} \mathrm{H}$ NMR (500 MHz, $\mathrm{CD}_{2} \mathrm{Cl}_{2}$ ): $\delta=4.21$ (qd, $\left.J=4.7,7.0 \mathrm{~Hz}, 1 \mathrm{H}\right), 3.48(\mathrm{~d}, \mathrm{~J}=4.7 \mathrm{~Hz}$, $3 \mathrm{H}$ ), 2.40 (dd, $J=13.7,16.6 \mathrm{~Hz}, 1 \mathrm{H}$ ), 2.38 (dd, $J=13.2,16.6 \mathrm{~Hz}, 1 \mathrm{H}$ ), 2.21 (qui, $J=6.8 \mathrm{~Hz}, 1 \mathrm{H}$ ), $1.37(\mathrm{~d}, J=7.0 \mathrm{~Hz}, 3 \mathrm{H}), 0.97(\mathrm{~d}, J=6.8 \mathrm{~Hz}, 3 \mathrm{H}), 0.96(\mathrm{~d}, J=6.8 \mathrm{~Hz}, 3 \mathrm{H}) ;{ }^{13} \mathrm{C} \mathrm{NMR}(125 \mathrm{MHz}$, $\left.\mathrm{CD}_{2} \mathrm{Cl}_{2}\right): \delta=213.0,73.5,46.9,25.0,22.9,22.8,20.1$.

\section{Preparation of MTPA esters of (S)- and racemic 2-hydroxy-5-methylhexan-3-one}

To a solution of $0.01 \mathrm{mmol}$ of 2-hydroxy-5-methylhexan-3-one dissolved in dichloromethane, two equivalents of $(R)$ - $\alpha$-Methoxy- $\alpha$-trifluoromethylphenylacetyl chloride and two equivalents of pyridine were added and the solution was stirred at room temperature for $16 \mathrm{~h}$. The crude products were directly used without purification.

\section{HPLC analysis of MTPA esters}

HPLC analysis was done on an Agilent Infinity 1260 HPLC equipped with a diode array detector and a single quadrupole mass spectrometer. The samples were chromatographed on a $50 \times 4.6$ mm Poroshell 120 EC-C18 $2.7 \mu \mathrm{m}$ HPLC column (Agilent) using $1 \mathrm{~mL} \mathrm{~min}^{-1}$ flow of a gradient of $10 \%$ methanol in water $+0.1 \%$ formic acid to $90 \%$ methanol in water $+0.1 \%$ formic acid in 12 min to $100 \%$ methanol in $1 \mathrm{~min}$ and a isocratic step at $100 \%$ methanol for $5 \mathrm{~min}$. 


\section{Phylogenetic analysis}

The ThDP-dependent enzymes were extracted from the NCBI server (https://www.ncbi.nlm.nih.gov/) using UniProtKB/Swiss-Prot and the protein data bank (PDB: https://www.rcsb.org/). The amino acid sequences of these proteins were aligned using the MAFFT server (https://mafft.cbrc.jp/alignment/server/) ${ }^{4}$ with MAFFT ver. 7 using the default setting besides Scoring matrix for amino acid sequences; JTT100, Mafft-homologs; ON. Unrooted fast maximum-likelihood-based tree was generated using IQ-TREE (https://www.hiv.lanl.gov/content/sequence/IQTREE/iqtree.html) ${ }^{5}$ with automatic model selection mode (ModelFinder ${ }^{6}$ ) resulting in the amino acid replacement model LG+R5. Phylogenetic bootstrap analysis was performed by ultrafast approximate bootstrap. ${ }^{7}$ The tree was displayed using MEGA7.

\section{Agar diffusion assay}

Antimicrobial activities were determined in a primary screen against Bacillus subtilis ATCC 6633, Staphylococcus aureus SG511, Mycobacterium vaccae IMET 10670, Pseudomonas aeruginosa K799/61, Escherichia coli SG458, Sporobolomyces salmonicolor SBUG 549, Candida albicans ATCC14053 and Penicillium notatum JP 36. To this end, holes with $7 \mathrm{~mm}$ diameter were aseptically punched in the respective agar medium. Subsequently, the agar plates were inoculated with the test organisms. $0.5 \mathrm{mg}$ of every test compound was dissolved in $1 \mathrm{~mL}$ of methanol, and $50 \mathrm{~mL}$ of this solution was transferred to a single hole. Ciprofloxacin and amphotericin B served as positive controls. After evaporation of the solvent, the agar plates were incubated depending on the growth conditions of the test organisms.

\section{Evaluation of antiproliferative and cytotoxic effects}

The test substances were dissolved in DMSO before being diluted in the respective medium. The adherent cells were harvested at the logarithmic growth phase after soft trypsinization using $0.25 \%$ trypsin in phosphate buffered saline (PBS) containing $0.02 \%$ ethylenediaminetetraacetic acid (EDTA). For each experiment, approximately 10,000 cells were seeded with $0.1 \mathrm{~mL}$ culture medium per well of the 96-well microplates. HeLa cells were pre-incubated for $48 \mathrm{~h}$ prior to the addition of the test compounds, which were carefully diluted on the subconfluent monolayers. Incubation was then conducted in a humidified atmosphere at $37^{\circ} \mathrm{C}$ and $5 \% \mathrm{CO}_{2}$. In case of $\mathrm{K}$ 562 cells, the number of viable cells in every well was determined using the CellTiter-Blue assay. The adherent HUVEC and HeLa cells were fixed by glutaraldehyde and stained with a $0.05 \%$ solution of methylene blue for $10 \mathrm{~min}$. After gently washing, the stain was eluted with 0.2 
$\mathrm{mL}$ of $0.33 \mathrm{~N} \mathrm{HCl}$ in the wells. The optical densities were measured at $660 \mathrm{~nm}$ in a SUNRISE microplate reader (TECAN). 
Table S1. Antimicrobial activities of compounds 1-6 in an agar diffusion assay [mm inhibition zone].

\begin{tabular}{lllllllll}
\hline cmp & $\begin{array}{l}B . \\
\text { subtilis }\end{array}$ & $\begin{array}{l}S . \\
\text { aureus }\end{array}$ & $\begin{array}{l}E . \\
\text { coli }\end{array}$ & $\begin{array}{l}P . \\
\text { aeruginosa }\end{array}$ & $\begin{array}{l}\text { M. } \\
\text { vaccae }\end{array}$ & $\begin{array}{l}S . \\
\text { salmonicolor }\end{array}$ & $\begin{array}{l}C . \\
\text { albicans }\end{array}$ & $\begin{array}{l}P . \\
\text { notatum }\end{array}$ \\
\hline $\mathbf{1}$ & 0 & 13 & 0 & 0 & 18 & 0 & 0 & 17 \\
$\mathbf{2}$ & 20 & 18 & 0 & 0 & 21 & 0 & 14 & 22 \\
$\mathbf{3}$ & 13 & 13 & 0 & 0 & 19 & 0 & 0 & 15 \\
$\mathbf{4}$ & 0 & 0 & 0 & 0 & 0 & 0 & 0 & 14 \\
$\mathbf{5}$ & 0 & 11 & 0 & 0 & 19 & 0 & 0 & 15 \\
$\mathbf{6}$ & 10 & 0 & 0 & 0 & 11 & 17 & 0 & 19 \\
\hline
\end{tabular}

Table S2. Antiproliferative and cytotoxic activities of compounds 1-6.

\begin{tabular}{llll}
\hline $\mathrm{cmp}$ & $\begin{array}{l}\mathrm{HUVEC} \\
\mathrm{GI}_{50}\left[\mu \mathrm{g} \mathrm{mL} \mathrm{mL}^{-1}\right]\end{array}$ & $\begin{array}{l}\mathrm{K}-562 \\
\mathrm{GI}_{50}\left[\mu \mathrm{mL}^{-1}\right]\end{array}$ & $\begin{array}{l}\mathrm{HeLa} \\
\mathrm{CC}_{50}\left[\mu \mathrm{mL}^{-1}\right]\end{array}$ \\
\hline $\mathbf{1}$ & $>50$ & $>50$ & $46.9( \pm 1.9)$ \\
$\mathbf{2}$ & $35.1( \pm 1.9)$ & $34.1( \pm 1.3)$ & $40.3( \pm 1.3)$ \\
$\mathbf{3}$ & $29.9( \pm 1.2)$ & $19.4( \pm 0.3)$ & $31.3( \pm 0.9)$ \\
$\mathbf{4}$ & $5.2( \pm 0.5)$ & $4.4( \pm 0.4)$ & $7.7( \pm 1.8)$ \\
$\mathbf{5}$ & $>50$ & $>50$ & $>50$ \\
$\mathbf{6}$ & $>50$ & $>50$ & $44.1( \pm 0.3)$ \\
\hline
\end{tabular}

Table S3. Optical rotation of compounds 1-6.

\begin{tabular}{ll}
\hline $\mathrm{cmp}$ & {$[\mathrm{\alpha}]_{\mathrm{D}}\left(\mathrm{c} 1.0, \mathrm{CHCl}_{3}\right)$} \\
\hline $\mathbf{1}$ & +58 \\
$\mathbf{2}$ & +64 \\
$\mathbf{3}$ & n.d. \\
$\mathbf{4}$ & +52 \\
$\mathbf{5}$ & +61 \\
$\mathbf{6}$ & +71 \\
\hline
\end{tabular}




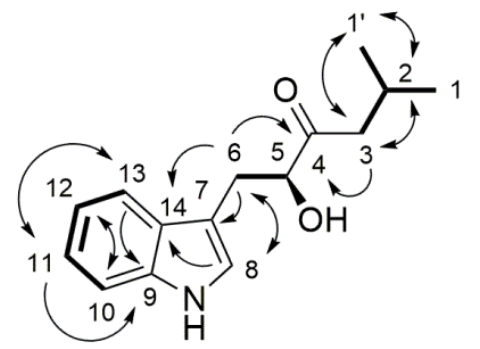

Figure S1. COSY (bold lines) and HMBC correlations (arrows) of compound 1.

Table S4. ${ }^{1} \mathrm{H}(600 \mathrm{MHz})$ and ${ }^{13} \mathrm{C}$ NMR $(150 \mathrm{MHz})$ data of 1.

\begin{tabular}{|c|c|c|c|c|}
\hline & $\delta_{\mathrm{H}}$ mult $(\mathrm{J}$ in $\mathrm{Hz})$ & $\delta_{C}$ & COSY & HMBC \\
\hline 1 & $0.81 \mathrm{~d}(6.6)$ & 22.9 & 2 & $1 ', 2,3$ \\
\hline $1^{\prime}$ & $0.81 \mathrm{~d}(6.6)$ & 22.8 & 2 & $1,2,3$ \\
\hline 2 & 2.02 qui (6.6) & 25.1 & $1,1^{\prime}, 3$ & $1,1^{\prime}, 3$ \\
\hline 3 & $2.33 \mathrm{~d}(7.0)$ & 48.7 & 2 & $1,1^{\prime}, 2,4$ \\
\hline 4 & & 214.8 & & \\
\hline 5 & $4.37 \mathrm{dd}(7.1,5.4)$ & 78.4 & 6 & 4,7 \\
\hline 6 & $\begin{array}{l}\text { a) } 3.01 \mathrm{dd}(14.8,5.4) \\
\text { b) } 3.16 \mathrm{dd}(14.8,7.1)\end{array}$ & 30.9 & $\begin{array}{l}5 \\
5\end{array}$ & $\begin{array}{l}4,5,7,8,14 \\
4,5,7,8,14\end{array}$ \\
\hline 7 & & 111.1 & & \\
\hline 8 & $7.08 \mathrm{~s}$ & 124.6 & & 6,14 \\
\hline 9 & & 138.2 & & \\
\hline 10 & $7.31 \mathrm{ddd}(8.1,2.0,1.0)$ & 112.2 & 11 & 12,14 \\
\hline 11 & 7.55 ddd $(7.9,2.0,1.0)$ & 119.4 & 10,12 & 9,13 \\
\hline 12 & 6.99 ddd $(8.1,7.0,1.1)$ & 119.7 & 11,13 & 10,14 \\
\hline 13 & 7.07 ddd $(8.1,7.0,1.1)$ & 122.3 & 12 & 9,11 \\
\hline 14 & & 128.9 & & \\
\hline
\end{tabular}

Chemical shifts in $\mathrm{CD}_{3} \mathrm{OD}$. 


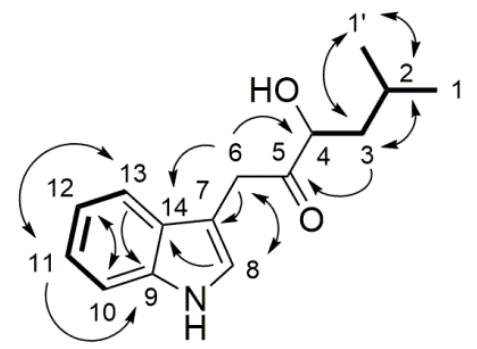

Figure S2. COSY (bold lines) and HMBC correlations (arrows) of compound 2.

Table S5. ${ }^{1} \mathrm{H}(500 \mathrm{MHz})$ and ${ }^{13} \mathrm{C}$ NMR $(125 \mathrm{MHz})$ data of 2.

\begin{tabular}{|c|c|c|c|c|}
\hline & $\bar{\delta}_{\mathrm{H}}$ mult $(\mathrm{J}$ in $\mathrm{Hz})$ & $\delta_{C}$ & COSY & HMBC \\
\hline 1 & $0.93 \mathrm{~d}(6.8)$ & 23.8 & 2 & $1^{\prime}, 2,3$ \\
\hline $1^{\prime}$ & $0.91 \mathrm{~d}(6.8)$ & 21.5 & 2 & $1,2,3$ \\
\hline 2 & $1.82 \mathrm{~m}$ & 25.5 & $1,1^{\prime}, 3$ & $1,1^{\prime}, 3,4$ \\
\hline \multirow[t]{2}{*}{3} & a) $1.61 \mathrm{ddd}(12.7,10.0,3.2)$ & 43,4 & 2,4 & $1,1^{\prime}, 2,4,5$ \\
\hline & b) $1.42 \mathrm{ddd}(13.4,10.0,4.6)$ & & 2,4 & $1,1^{\prime}, 2,4,5$ \\
\hline 4 & $4.25 \mathrm{dd}(10.0,3.2)$ & 75.5 & 3 & $2,3,5$ \\
\hline 5 & & 212.3 & & \\
\hline 6 & $3.96 \mathrm{q}(17.0)$ & 35.3 & & $5,7,8,14$ \\
\hline 7 & & 108.6 & & \\
\hline 8 & $7.16 \mathrm{~s}$ & 125.0 & & $5,6,7,14$ \\
\hline 9 & & 137.3 & & \\
\hline 10 & $7.40 \mathrm{~d}(8.0)$ & 112.4 & 11 & 12,14 \\
\hline 11 & $7.14 \mathrm{td}(8.0,1.0)$ & 122.6 & 10,12 & $9,10,13$ \\
\hline 12 & 7.05 td $(8.0,1.0)$ & 120.0 & 11,13 & $9,10,11,13,14$ \\
\hline 13 & $7.45 \mathrm{~d}(8.0)$ & 119.5 & 12 & $7,9,10,11,14$ \\
\hline 14 & & 128.5 & & \\
\hline
\end{tabular}




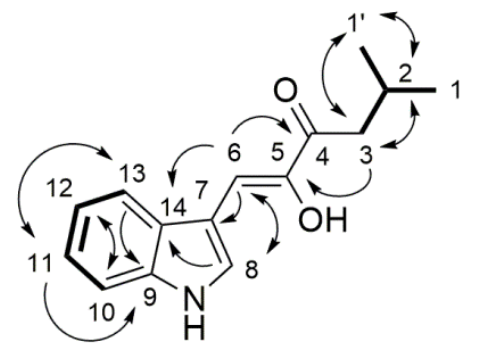

Figure S3. COSY (bold lines) and HMBC correlations (arrows) of compound 3.

Table S6. ${ }^{1} \mathrm{H}(300 \mathrm{MHz})$ and ${ }^{13} \mathrm{C}$ NMR $(75 \mathrm{MHz})$ data of 3.

\begin{tabular}{lllll}
\hline & $\delta_{\mathrm{H}}$ mult $(\mathrm{J}$ in Hz) & $\delta_{\mathrm{C}}$ & $\mathrm{COSY}$ & $\mathrm{HMBC}$ \\
\hline 1 & $1.03, \mathrm{~d}, 6.64 \mathrm{~Hz}$ & 23.0 & 2 & $1^{\prime}, 2,3$ \\
$1^{\prime}$ & $1.03, \mathrm{~d}, 6.64 \mathrm{~Hz}$ & 23.0 & 2 & $1,2,3$ \\
2 & $2.25, \mathrm{~m}$ & 27.9 & $1,1^{\prime}, 3$ & $1,1^{\prime}, 3,4$ \\
3 & $2.76, \mathrm{~d}, 7.0 \mathrm{~Hz}$ & 44.9 & 2 & $1,1^{\prime}, 2,4,5$ \\
4 & & 197.4 & \\
5 & & 147.1 & \\
6 & $7.04, \mathrm{~s}$ & 109.0 & $4,5,7,8,14$ \\
7 & & 111.5 & \\
8 & $8.07, \mathrm{~s}$ & 130.1 & $5,6,9,14$ \\
9 & & 137.6 & \\
10 & $7.41, \mathrm{dd}, 7.0,1.7$ & 112.5 & 11 & 12 \\
11 & $7.18, \mathrm{~m}$ & 123.2 & 10,12 & $9,10,13$ \\
12 & $7.16, \mathrm{~m}$ & 121.0 & 11,13 & 10,14 \\
13 & $7.82, \mathrm{dd}, 6.5,1.7 \mathrm{~Hz}$ & 119.1 & 12 & $7,9,11$ \\
\hline & & 128.4 & \\
\hline
\end{tabular}

Chemical shifts recorded in $\mathrm{CD}_{3} \mathrm{OD}$. 


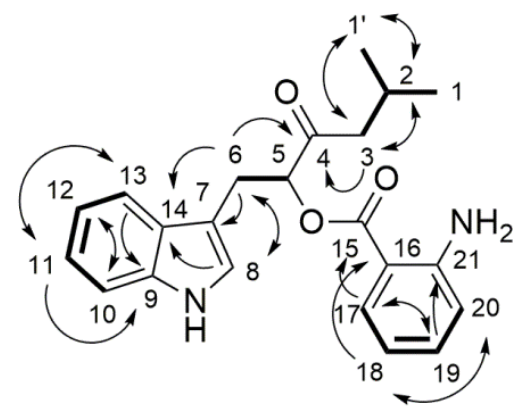

Figure S4. COSY (bold lines) and HMBC correlations (arrows) of compound 4. 
Table S7. ${ }^{1} \mathrm{H}(500 \mathrm{MHz})$ and ${ }^{13} \mathrm{C}$ NMR $(125 \mathrm{MHz})$ data of 4.

\begin{tabular}{|c|c|c|c|c|}
\hline & $\delta_{\mathrm{H}}$ mult $(\mathrm{J}$ in $\mathrm{Hz})$ & $\delta_{c}$ & COSY & HMBC \\
\hline 1 & $0.71, \mathrm{~d}, 6.9 \mathrm{~Hz}$ & 22.8 & 2 & $1 ;, 2,3$ \\
\hline $1^{\prime}$ & $0.75, \mathrm{~d}, 6.8 \mathrm{~Hz}$ & 22.9 & 2 & $1,2,3$ \\
\hline 2 & $1.96, \mathrm{~m}$ & 24.9 & $1,1^{\prime}, 3$ & $1,1^{\prime}, 4$ \\
\hline \multirow[t]{2}{*}{3} & a) 2.33 , dd, $17.6,6.5 \mathrm{~Hz}$ & 48.5 & 2 & $1,1^{\prime}, 2,4$ \\
\hline & b) 2.25 , dd, $17.6,6.7 \mathrm{~Hz}$ & & 2 & $1,1^{\prime}, 2,4$ \\
\hline 4 & & 214.1 & & \\
\hline 5 & $4.44, t, 6.5$ & 64.0 & 6 & $4,6,7$ \\
\hline 6 & $3.26, \mathrm{~m}$ & 29.0 & 5 & $4,5,7,8,14$ \\
\hline 7 & & 110.5 & & \\
\hline 8 & $7.14, \mathrm{~s}$ & 124.8 & & 6,14 \\
\hline 9 & & 138.0 & & \\
\hline 10 & 7.31, m & 112.3 & 11 & 12,14 \\
\hline 11 & 7.07, dd, 7.6, 7.9 Hz & 122.4 & 10,12 & 9,13 \\
\hline 12 & $6.99, \mathrm{dd}, 7.6,7.9 \mathrm{~Hz}$ & 119.8 & 11,13 & 10,14 \\
\hline 13 & $7.51, \mathrm{~d}, 8.1 \mathrm{~Hz}$ & 119.2 & 12 & 9,11 \\
\hline 14 & & 128.6 & & \\
\hline 15 & & 171.8 & & \\
\hline 16 & & 112.0 & & \\
\hline 17 & $7.89, \mathrm{~d}, 7.8 \mathrm{~Hz}$ & 133.5 & 18 & $15,19,21$ \\
\hline 18 & $6.58, \mathrm{~m}$ & 116.3 & 17,19 & 20 \\
\hline 19 & $7.28, \mathrm{~m}$ & 135.6 & 18,20 & 17,21 \\
\hline 20 & $6.55, \mathrm{~m}$ & 112.6 & 19 & 16,18 \\
\hline 21 & & 151.3 & & \\
\hline
\end{tabular}

Chemical shifts recorded in $\mathrm{CD}_{3} \mathrm{OD}$. 


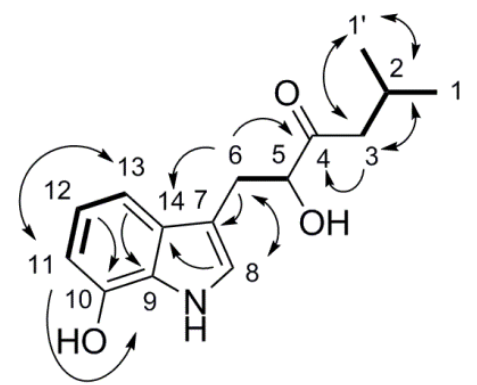

Figure S5. COSY (bold lines) and HMBC correlations (arrows) of compound 5.

Table S8. ${ }^{1} \mathrm{H}(500 \mathrm{MHz})$ and ${ }^{13} \mathrm{C}$ NMR $(125 \mathrm{MHz})$ data of 5.

\begin{tabular}{|c|c|c|c|c|}
\hline & $\delta_{\mathrm{H}}$ mult $(\mathrm{J}$ in $\mathrm{Hz})$ & $\delta_{C}$ & COSY & HMBC \\
\hline 1 & $0.85 \mathrm{~d}(6.7)$ & 22.9 & 2 & 1.2 .3 .4 \\
\hline 1' & $0.85 \mathrm{~d}(6.7)$ & 22.9 & 2 & $1,2,3,4$ \\
\hline 2 & $2.05 \mathrm{~m}$ & 25.1 & $1,1^{\prime}, 3$ & $1,1,3,4$ \\
\hline 3 & $2.36 \mathrm{~d}(6.7)$ & 48.9 & 2 & $1,1^{\prime}, 2,4$ \\
\hline 4 & & 214.8 & & \\
\hline 5 & $4.41 \mathrm{dd}(7.1,5.5)$ & 78.3 & 6 & $4,6,7$ \\
\hline 6 & a) $3.01 \mathrm{dd}(14.8,7.1)$ & 31.1 & 5 & $4,5,7,8,14$ \\
\hline & b) $3.15 \mathrm{dd}(14.8,5.5)$ & & 5 & $4,5,7,8,14$ \\
\hline 7 & & 111.4 & & \\
\hline 8 & $7.07 \mathrm{~s}$ & 124.2 & & $6,7,14$ \\
\hline 9 & & 128.0 & & \\
\hline 10 & & 144.6 & & \\
\hline 11 & $6.53 \mathrm{dd}(7.7,1.0)$ & 106.6 & 12 & $9,10,13$ \\
\hline 12 & 6.85 dd $(7.8,7.7)$ & 120.4 & 11,13 & $10,11,14$ \\
\hline 13 & 7.08 dd $(7.8,1.0)$ & 111.1 & 12 & $9,10,11$ \\
\hline 14 & & 130.8 & & \\
\hline
\end{tabular}




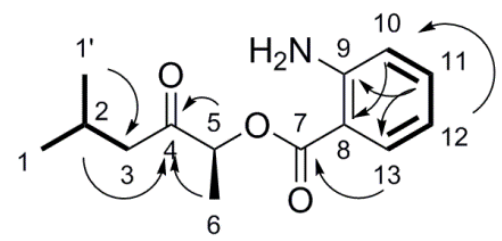

Figure S6. COSY (bold lines) and HMBC correlations (arrows) of compound 6.

Table S9. ${ }^{1} \mathrm{H}(600 \mathrm{MHz})$ and ${ }^{13} \mathrm{C}$ NMR $(150 \mathrm{MHz})$ data of 6.

\begin{tabular}{lllll}
\hline & $\delta_{H}$ mult $(J$ in Hz) & $\delta_{C}$ & COSY & HMBC \\
\hline 1 & 0.85 d $(6.7)$ & 22.7 & 2 & $1^{\prime}, 2,3$ \\
$1^{\prime}$ & $0.90 \mathrm{~d}(6.7)$ & 22.7 & 2 & $1,2,3$ \\
2 & 2.12 qui $(6.7)$ & 25.0 & $1,1^{\prime}$ & $1,1^{\prime}, 3,4$ \\
3 & a: 2.49 dd $(17.2,7)$ & 47.4 & 2 & $1,1^{\prime}, 2,4$ \\
& b: 2.38 dd $(17.2,6.8)$ & & 2 & \\
4 & & 213.7 & & \\
5 & 4.20 q $(7.0)$ & 58.8 & 6 & $3,4,6$ \\
6 & $1.40 \mathrm{~d}(7.0)$ & 17.8 & 5 & 4,5 \\
7 & & 172.0 & & \\
8 & & 112.6 & & \\
9 & & 150.9 & & \\
10 & $6.54 \mathrm{dd}(8.0,1.1)$ & 112.4 & 11 & $7.8,12,13$ \\
11 & $7.32 \mathrm{td}(7.2,1.8)$ & 135.3 & 10,12 & 9,13 \\
12 & $6.61 \mathrm{td}(7.2,1.1)$ & 116.2 & 11,13 & $8,9,10,11,13$ \\
13 & $7.92 \mathrm{dd}(8.0,1.8)$ & 133.3 & 12 & $7,9,11$ \\
\hline & & & & \\
\hline
\end{tabular}

Chemical shifts recorded in $\mathrm{CD}_{3} \mathrm{OD}$. 
Table S10. ThDP-dependent enzymes used in the phylogenetic tree. Abbreviations: ACS, acyloin synthase; ALS, acetolactate synthase; BAL, benzaldehyde lyase; BFD, benzoylformate decarboxylase; CeaS, $N^{2}$-(2-carboxyethyl)arginine synthase; GCL, glycoxylate carboligase; loID, 3D-(3,5/4)-trihydroxycyclohexane-1,2-dione hydrolase; IpdC, indole-3-pyruvate decarboxylase; MenD, 2-succinyl-5-enolpyruvyl-6-hydroxy-3-cyclohexene-1-carboxylate synthase; OcaDC, oxalyl-CoA decarboxylase; PDC, pyruvate decarboxylase; PO: pyruvate oxidase; PpdC: phenylpyruvate decarboxylase, PPDC: phosphonopyruvate decarboxylase.

\begin{tabular}{|c|c|c|c|}
\hline Proteins & Function & Source & Accession number \\
\hline IIvB & ALS & Escherichia coli K-12 & AAC76694.1 \\
\hline IlvG & ALS & Escherichia coli K-12 & P0DP90.1 \\
\hline ALS_Pp & ALS & Pseudomonas protegens Pf5 & $5 \mathrm{AHK}$ \\
\hline YerE & ALS & Yersinia pseudotuberculosis & AEP25490.1 \\
\hline BudB & ALS & Klebsiella pneumoniae & $5 \mathrm{D} \times 6$ \\
\hline ALS_Gs & ALS & Geobacillus stearothermophilus & AAL99356.1 \\
\hline ALS_Bs1 & ALS & Bacillus subtilis PY79 & 4RJI \\
\hline ALS_Bs2 & ALS & Bacillus subtilis & AAA22222.1 \\
\hline PPDC_Sw & PPDC & Streptomyces wedmorensis & BAA32496.1 \\
\hline PPDC_Sh & PPDC & Streptomyces hygroscopicus & BAA07055.2 \\
\hline PPDC_Sv & PPDC & Streptomyces viridochromogenes & O86938.1 \\
\hline PPDC_Bf & PPDC & Bacteroides fragilis & AAG26466.1 \\
\hline GCL & GCL & Escherichia coli K-12 & P0AEP7.2 \\
\hline GCL_Pp & GCL & Pseudomonas putida KT2440 & AAN69877.1 \\
\hline CeaS & Ceas & Streptomyces clavuligerus & 2IHT \\
\hline MenD_Ec & MenD & Escherichia coli K-12 & 2JLC \\
\hline MenD_Bs & MenD & Bacillus subtilis & $2 \times 7 \mathrm{~J}$ \\
\hline MenD_MW & MenD & Mycobacterium tuberculosis H37Rv & 5ESU \\
\hline IolD_Lc & IolD & Lactobacillus casei & A5YBJ6.2 \\
\hline IolD_Bs & IolD & Bacillus subtilis & P42415.2 \\
\hline OcaDC_Ec & OcaDC & Escherichia coli & $2 Q 27$ \\
\hline OcaDC_Of & OcaDC & Oxalobacter formigenes & 2JI6 \\
\hline
\end{tabular}




\begin{tabular}{|c|c|c|c|}
\hline Bal & BAL & Pseudomonas fluorescens & $2 A G 0$ \\
\hline Bal_Pf & BAL & Pseudomonas fluorescens & AAA50176.1 \\
\hline BFD_Pn & BFD & Polynucleobacter necessarius & $4 \mathrm{~K} 9 \mathrm{Q}$ \\
\hline BFD_Ms & BFD & Mycobacterium smegmatis & 4Q9D \\
\hline MdIC & BFD & Pseudomonas putida & 1BFD \\
\hline PO_Lp & $\mathrm{PO}$ & Lactobacillus plantarum WCFS1 & P37063.3 \\
\hline PO_Ec & PO & Escherichia coli & $3 E Y 9$ \\
\hline PO_Av & $\mathrm{PO}$ & Aerococcus viridans & $1 \mathrm{~V} 5 \mathrm{~F}$ \\
\hline ZmoPDC & PDC & Zymomonas mobilis & 2WVA \\
\hline PDC_Gd & PDC & Gluconoacetobacter diazotrophicus & $4 \mathrm{COK}$ \\
\hline PDC_KI & PDC & Kluyveromyces lactis & 2VJY \\
\hline PDC_Ap & PDC & Acetobacter pasteurianus & 2VBI \\
\hline $\mathrm{KdcA}$ & PDC & Lactococcus lactis & AAS49166.1 \\
\hline ScPDC & PDC & Saccharomyces cerevisiae & P06169.7 \\
\hline PpdC & PpdC & Azospirillum brasilense & 2Q5J \\
\hline IpdC_Ec & IpdC & Enterobacter cloacae & $10 \mathrm{VM}$ \\
\hline IpdC_Pp & IpdC & Paenibacillus polymyxa & ABV24338.1 \\
\hline IpdC_Pa & IpdC & Pantoea agglomerans & P71323 \\
\hline IpdC_Ab & IpdC & Azospirillum brasilense & P51852.1 \\
\hline IpdC_Al & IpdC & Azospirillum lipoferum & Q93RB7 \\
\hline $\mathrm{NzsH}$ & ACS & Streptomyces sp. MA37 & ALL53321.1 \\
\hline ScyA & ACS & Nostoc punctiforme PCC 73102 & ACC79997.1 \\
\hline XclA & ACS & Xenorhabdus bovienii SS-2004 & CBJ83019.1 \\
\hline Thzk0150 & ACS & Thermosporothrix hazakensis & BAO66169.1 \\
\hline Cbei_2646 & & Clostridium beijerinckii NCIMB 8052 & ABR34800 \\
\hline Cbei_4548 & & Clostridium beijerinckii NCIMB 8052 & ABR36657 \\
\hline Cbei_2730 & ACS & Clostridium beijerinckii NCIMB 8052 & ABR34881 \\
\hline Cbei_4337 & & Clostridium beijerinckii NCIMB 8052 & ABR36447 \\
\hline Cbei_0217 & & Clostridium beijerinckii NCIMB 8052 & ABR32407 \\
\hline
\end{tabular}




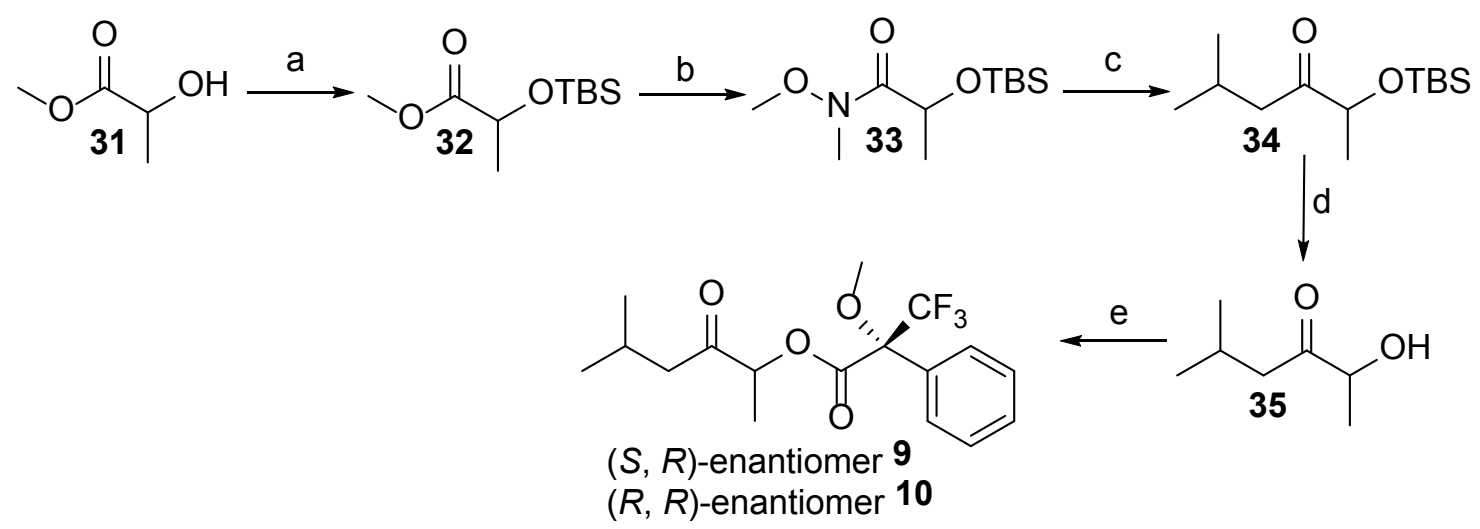

Figure S7. Preparation of synthetic standards and MTPA diastereomers 7 and 8. a: imidazole, $\mathrm{TBSCl}, \mathrm{DCM}, 0{ }^{\circ} \mathrm{C} \rightarrow \mathrm{RT} 16 \mathrm{~h}, \mathrm{~b}: \mathrm{Me}_{3} \mathrm{Al}, \mathrm{NMe}(\mathrm{OMe}) \cdot \mathrm{HCl}, \mathrm{DCM}, 0{ }^{\circ} \mathrm{C} \rightarrow \mathrm{RT} 4 \mathrm{~h}, \mathrm{c}:{ }^{\mathrm{i}} \mathrm{BuMgBr}$, $\mathrm{Et}_{2} \mathrm{O}, \mathrm{RT} 16 \mathrm{~h}, \mathrm{~d}$ : TBAF, THF, $0{ }^{\circ} \mathrm{C} 2 \mathrm{~h}$, e: pyridine, (R)-MTPA-Cl, DCM, RT $16 \mathrm{~h}$.

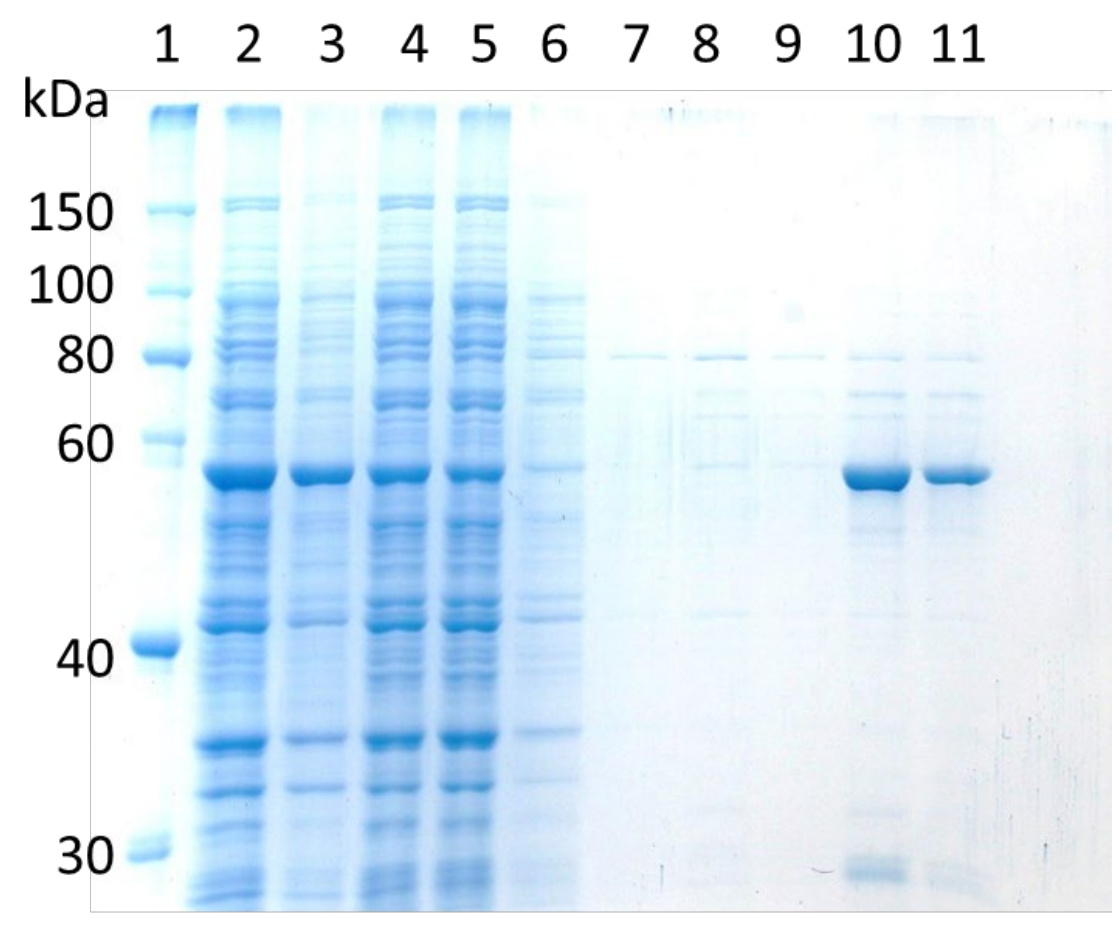

Figure S8. SDS-PAGE analysis of heterologously produced $\mathrm{His}_{6}-\mathrm{Cbei2730.} \mathrm{(1)} \mathrm{Marker} \mathrm{proteins,}$ (2) whole cells, (3) insoluble fraction, (4) soluble fraction, (5) flow though, $(6,7)$ buffer with 10 $\mathrm{mM}$ imidazole, $(8,9)$ buffer with $30 \mathrm{mM}$ imidazole, and $(10,11)$ buffer with $500 \mathrm{mM}$ imidazole. 


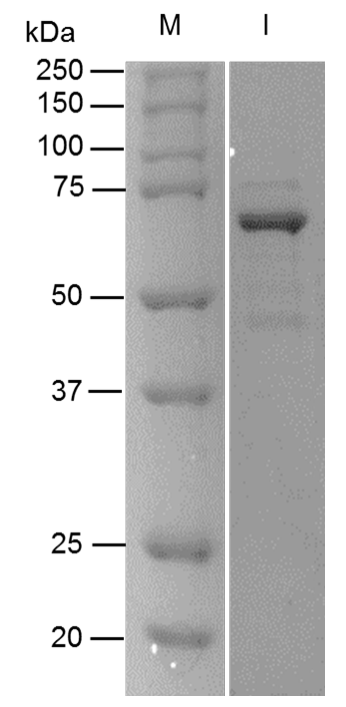

Figure S9. SDS-PAGE gel of CbeiHKI805_0381.

M: protein marker; I: CbeiHKI805_0381 (59.7 kDa). 


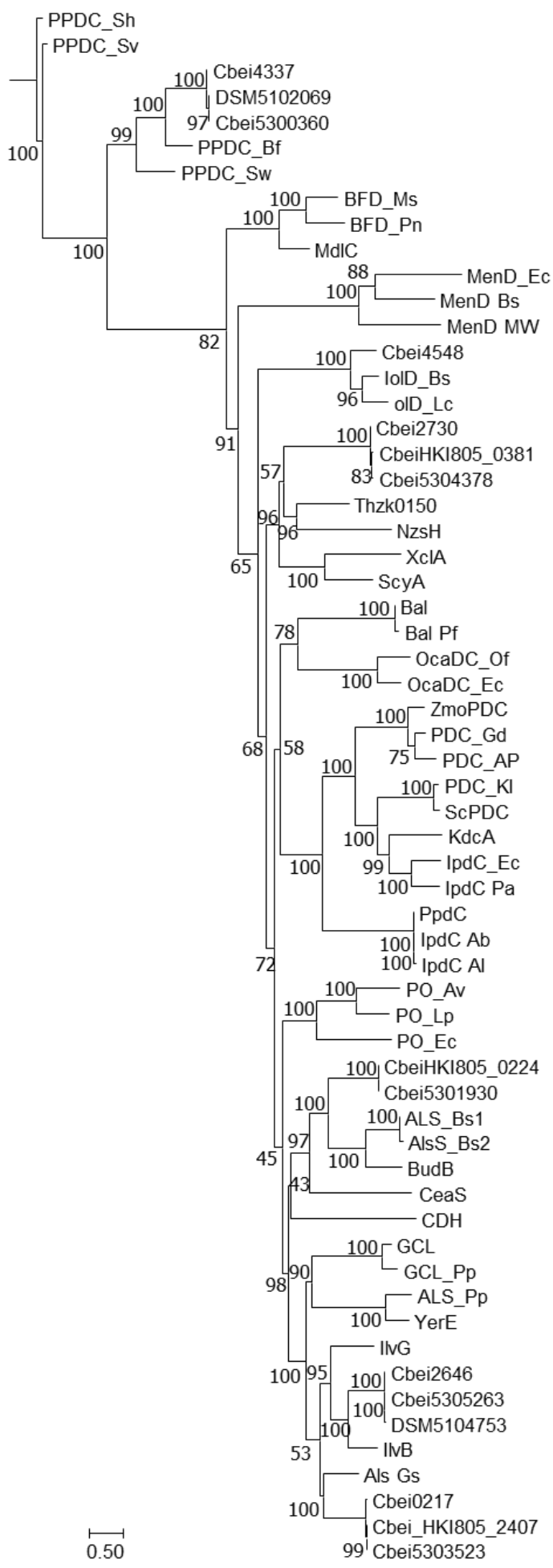

Figure S10. Maximum likelihood phylogenetic tree for acyloin synthases and related ThDPdependent enzymes. The scale bar indicates amino acid substitutions per site. The numbers at the nodes indicate the ultrafast bootstrap score (1,000 replicates, shown value: \%) for reliability of the different groups. 


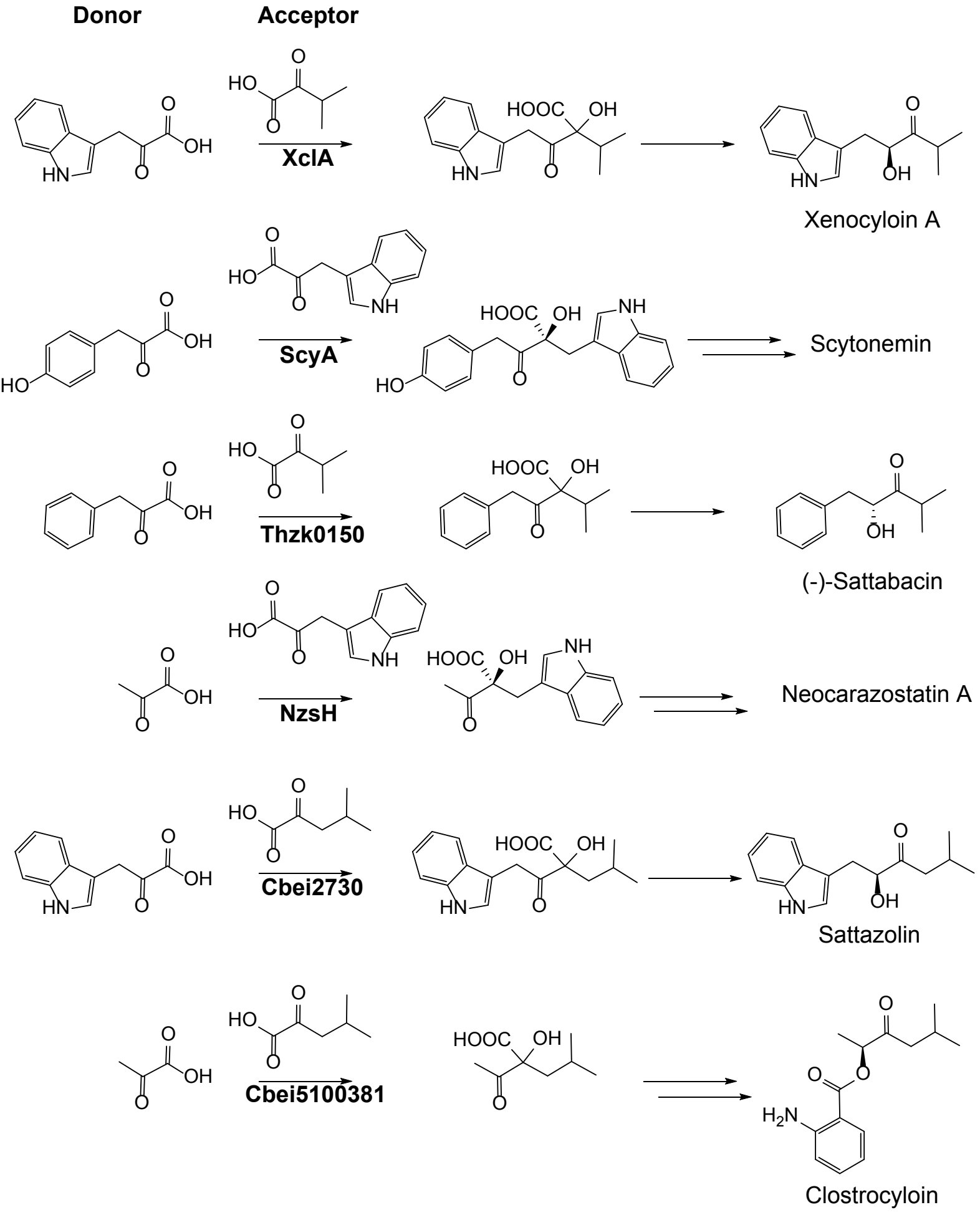

Figure S11. Acyloin synthases used in the phylogenetic tree, and the reactions that they catalyze. 

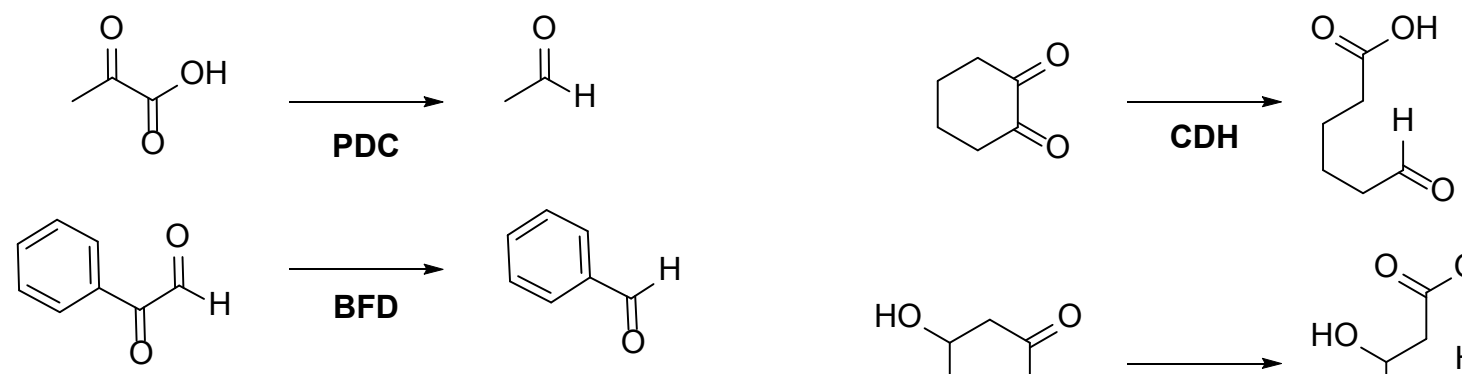<smiles>O=CCc1c[nH]c2ccccc12</smiles><smiles>CC(C)CC1C(=O)CC(O)C(O)C1O</smiles><smiles>O=CCc1ccccc1</smiles><smiles>O=C(O)COC(=O)COC(=O)SC(=O)O</smiles><smiles>CC(=O)C(=O)O</smiles><smiles>CC(=O)C(=O)O</smiles><smiles>CC(=O)[C@H](O)C(=O)O</smiles><smiles>O=CC(=O)O</smiles><smiles>O=CC(=O)C(O)C(=O)O</smiles><smiles>O=Cc1ccccc1</smiles><smiles>CC(C)(C)CC=O</smiles><smiles>O=C(c1ccccc1)C(O)c1ccccc1</smiles><smiles>C=C(O)C(=O)O[C@H]1C=CC=C(C(=O)O)[C@H]1O</smiles>

Isochorismic acid<smiles>CC(=O)CCC(=O)C(=O)O</smiles><smiles>CCCCCCCC(=O)OC(=O)CCC(=O)C1=CC=CC(O)C1C(=O)O</smiles><smiles>N=C(N)NCCC[C@H](N)C(=O)O</smiles><smiles>O=CC(O)COP(=O)(O)O</smiles>

$\mathrm{SHCHC}$<smiles></smiles>

Figure S12. ThDP-dependent enzymes used in the phylogenetic tree, and the reactions they catalyze. SHCHC, 2-succinyl-5-enolpyruvyl-6-hydroxy-3-cyclohexadiene-1-carboxylate. 


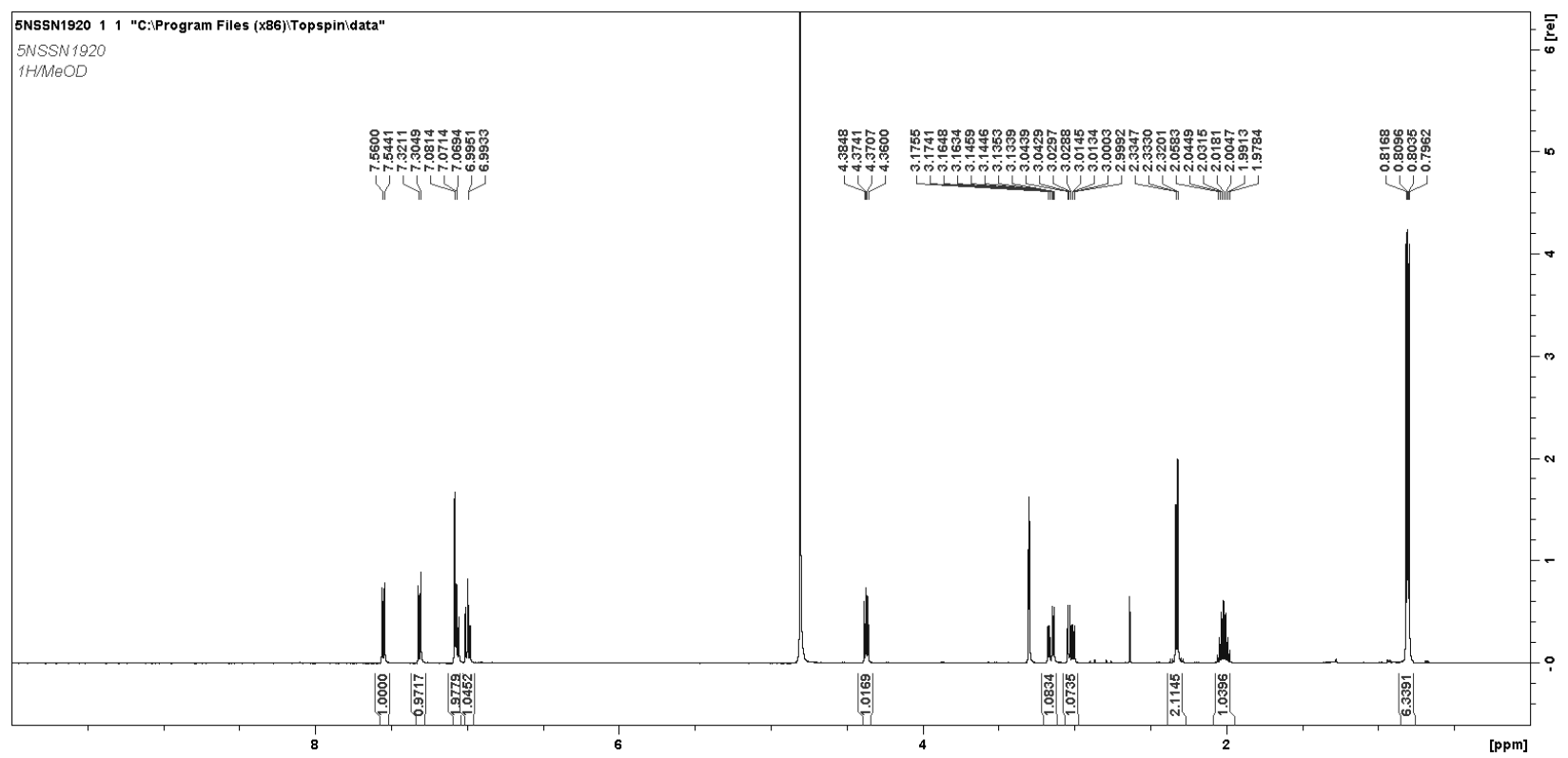

Figure S13. ${ }^{1} \mathrm{H}$ spectrum of compound 1.

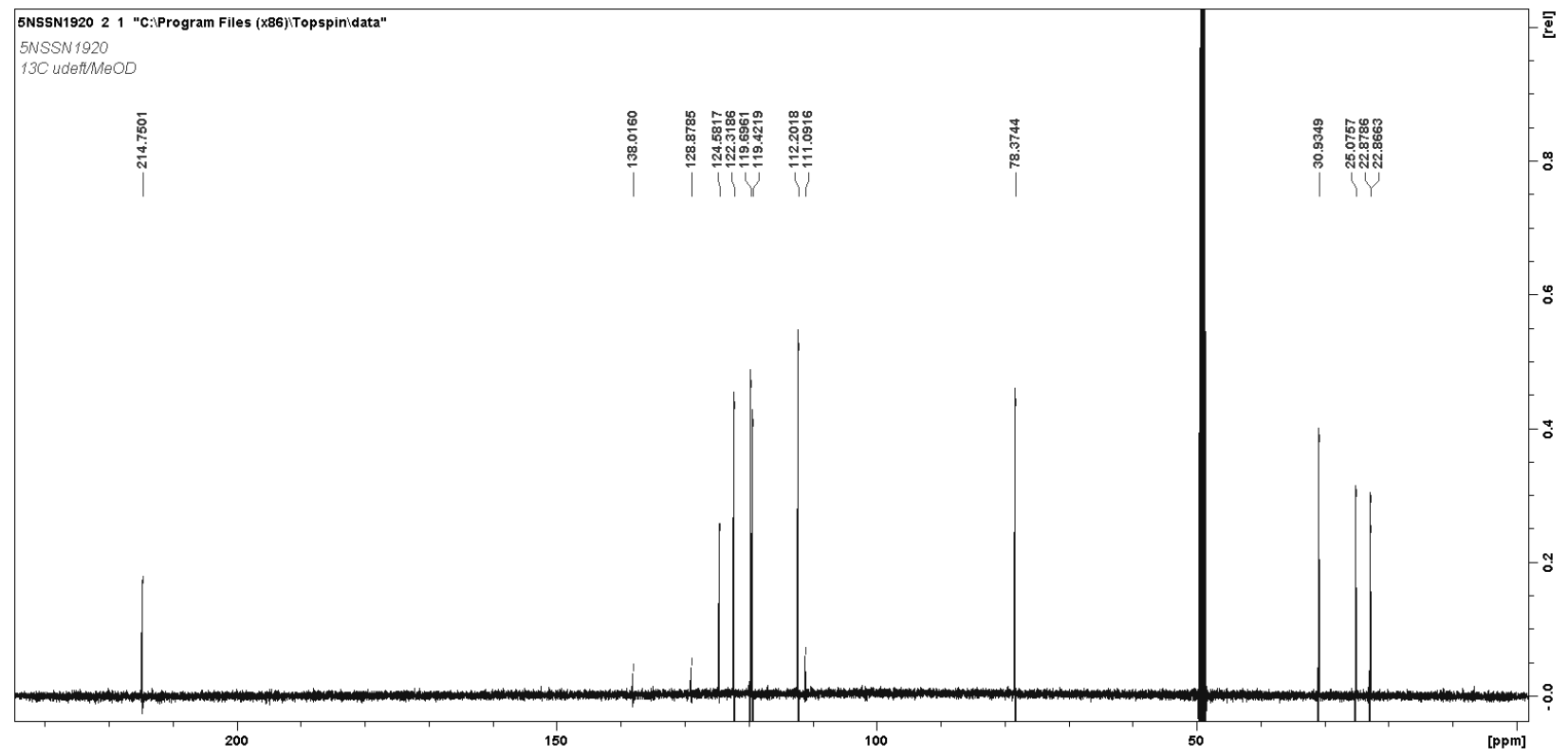

Figure S14. ${ }^{13} \mathrm{C}$ spectrum of compound 1. 


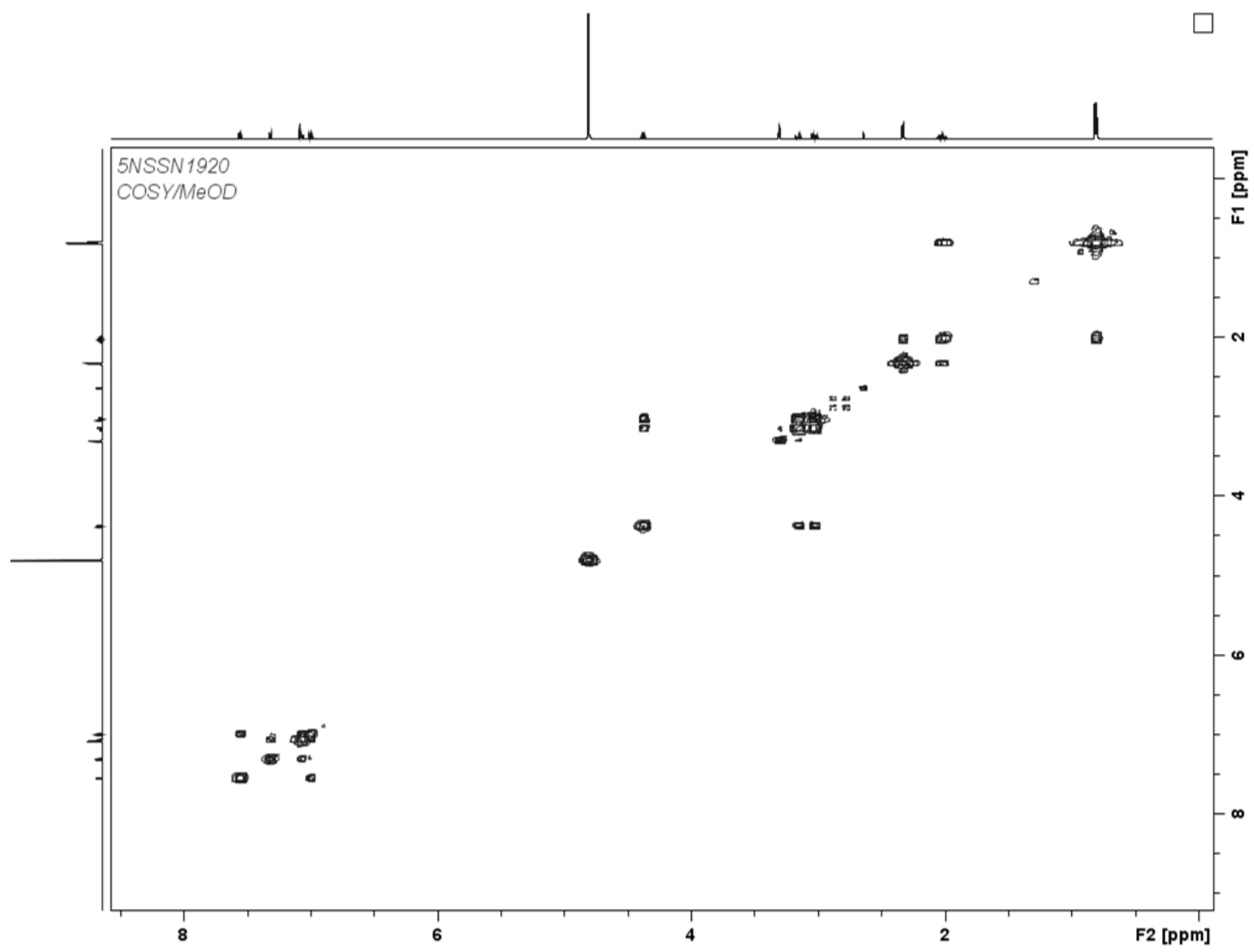

Figure S15. COSY spectrum of compound 1. 


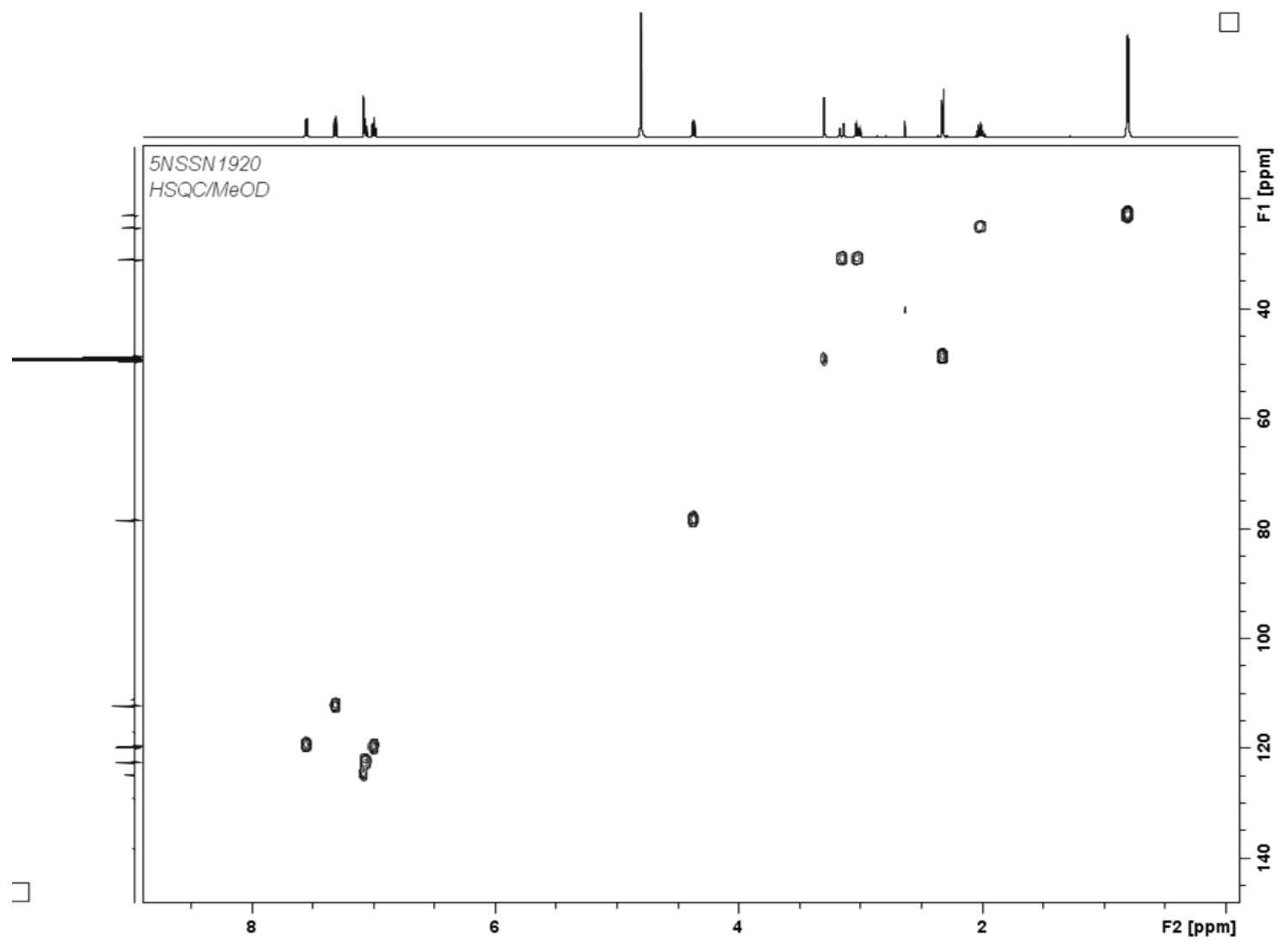

Figure S16. HSQC spectrum of compound 1. 


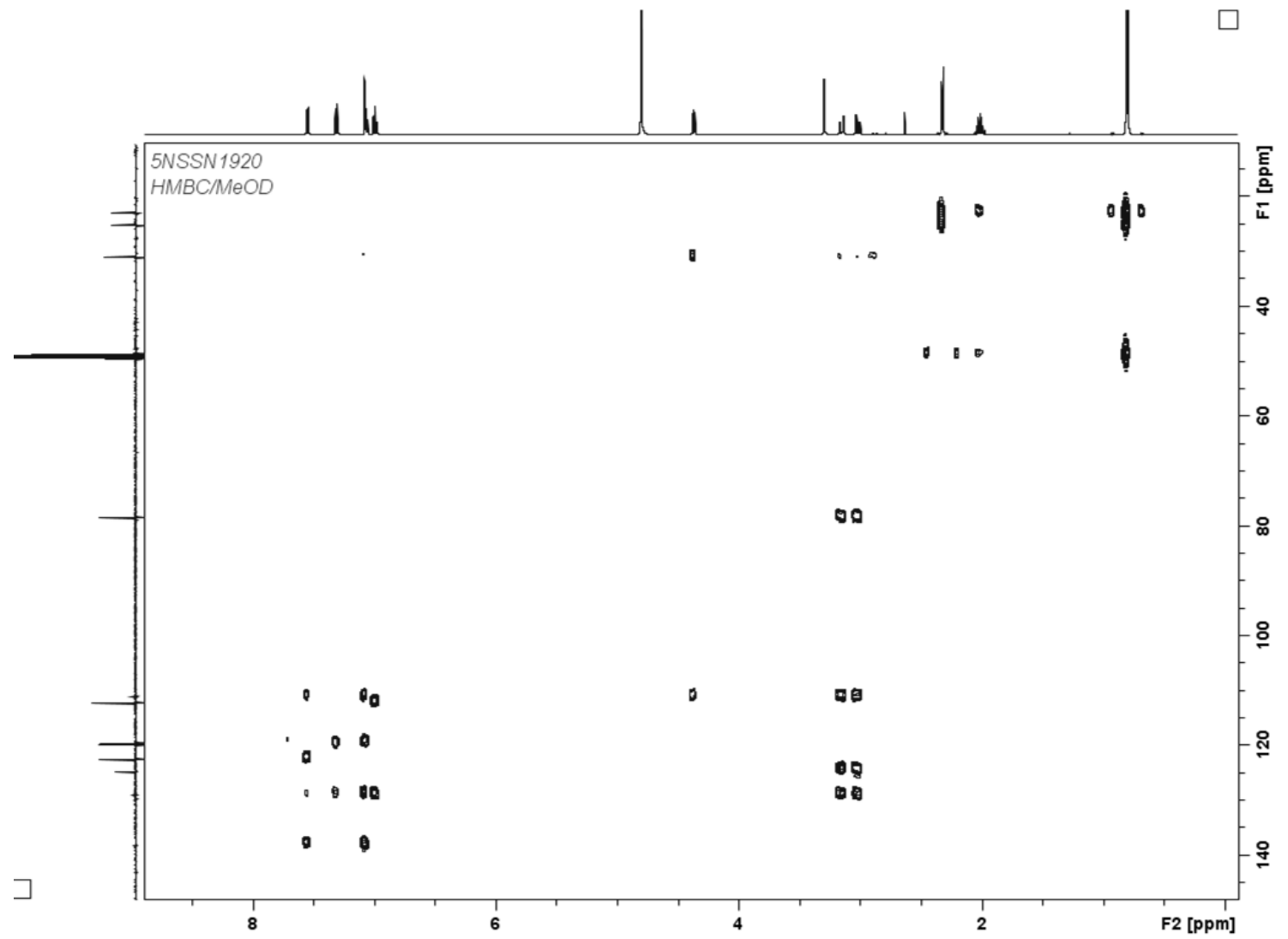

Figure S17. HMBC spectrum of compound 1.

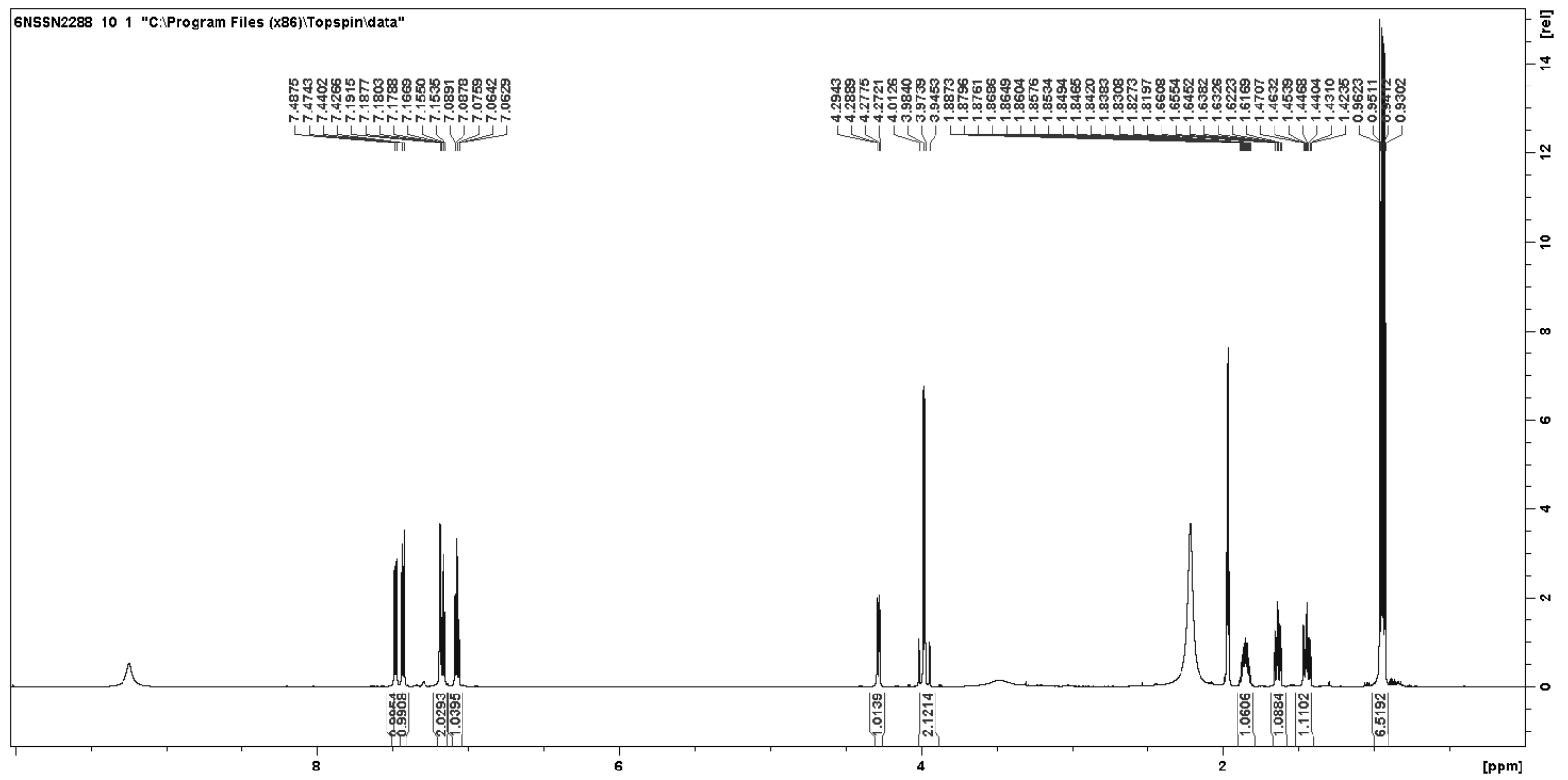

Figure S18. ${ }^{1} \mathrm{H}$ spectrum of compound 2. 


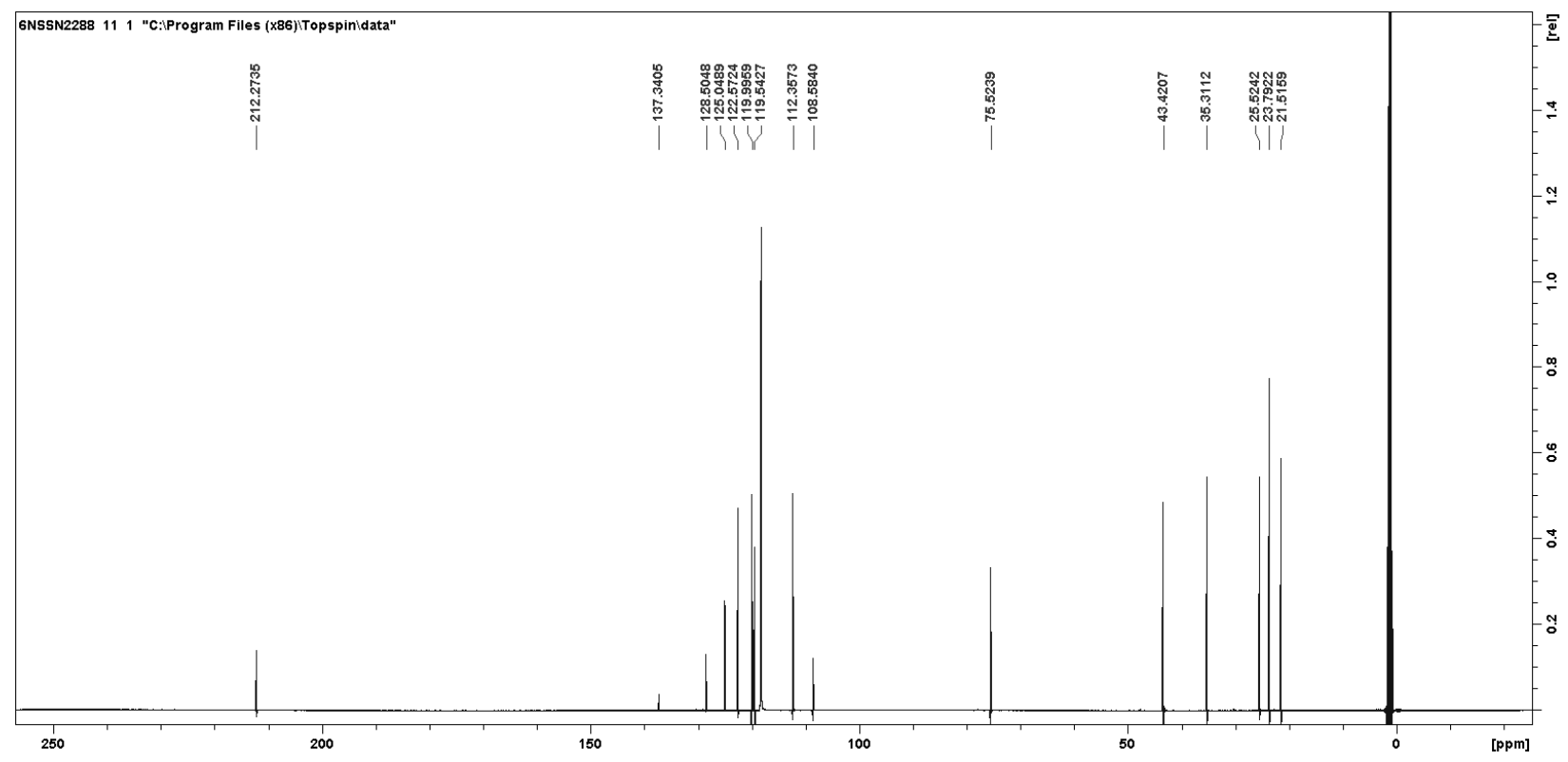

Figure S19. ${ }^{13} \mathrm{C}$ spectrum of compound 2.

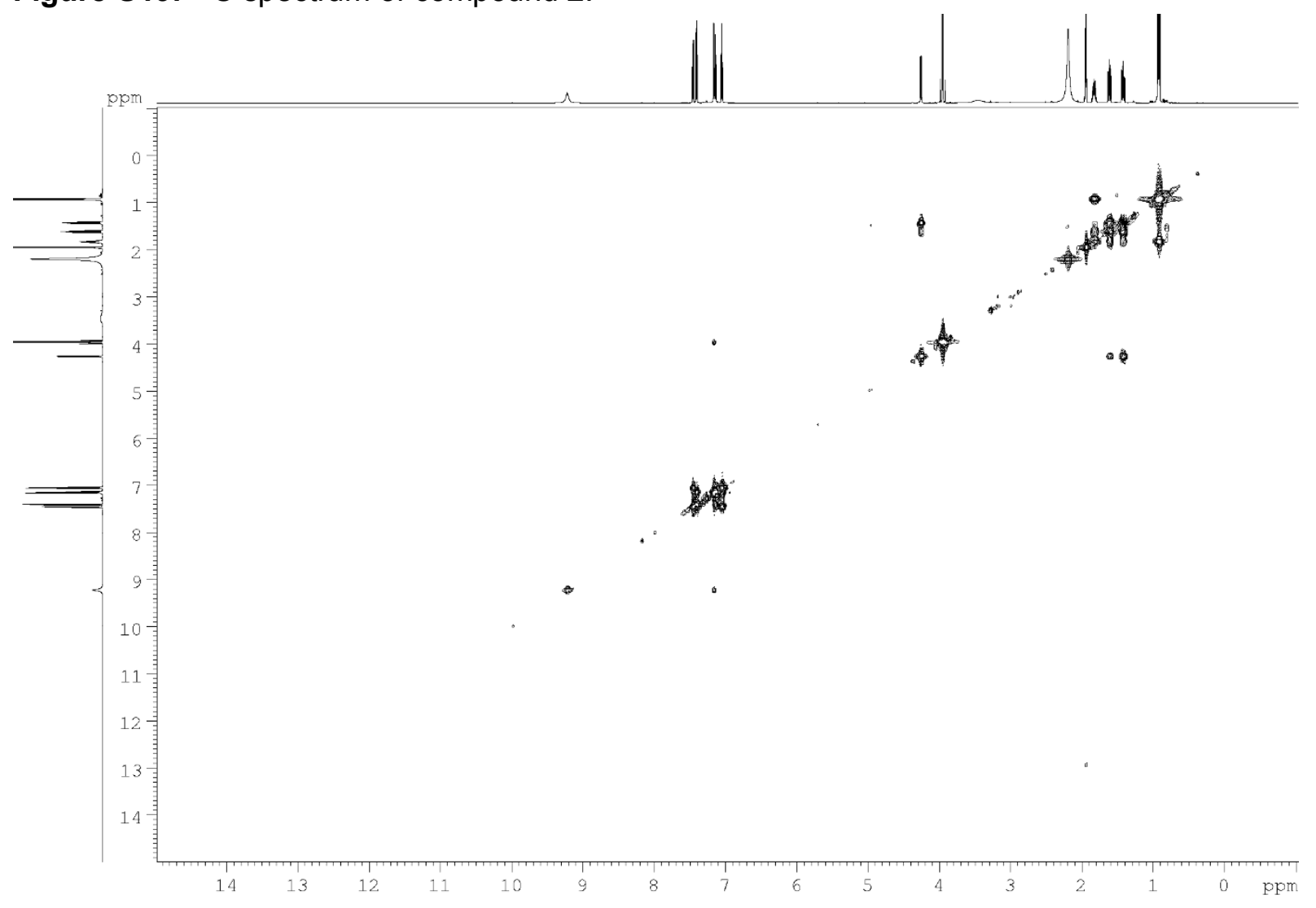

Figure S20. COSY spectrum of compound 2. 


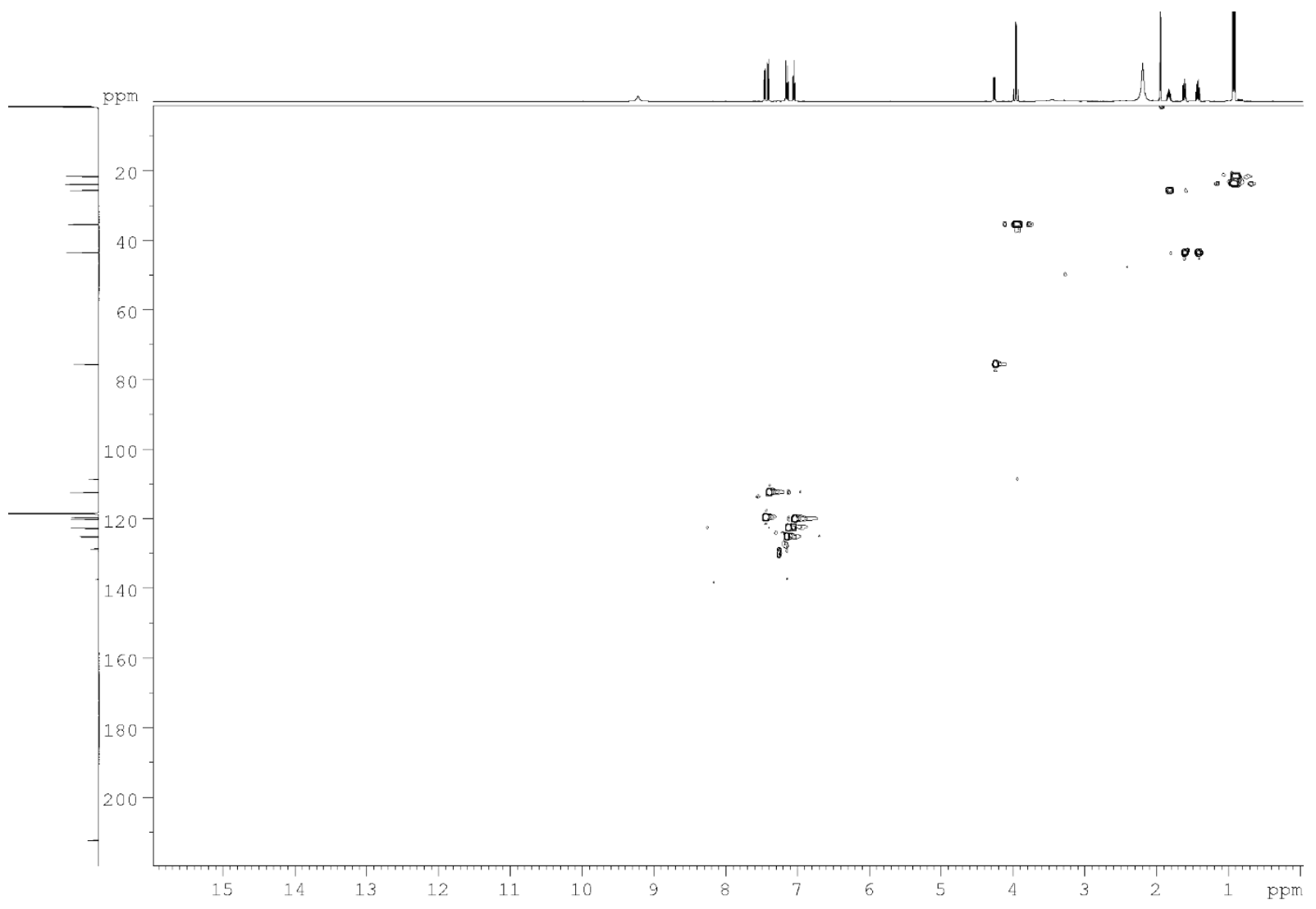

Figure S21. HSQC spectrum of compound 2. 


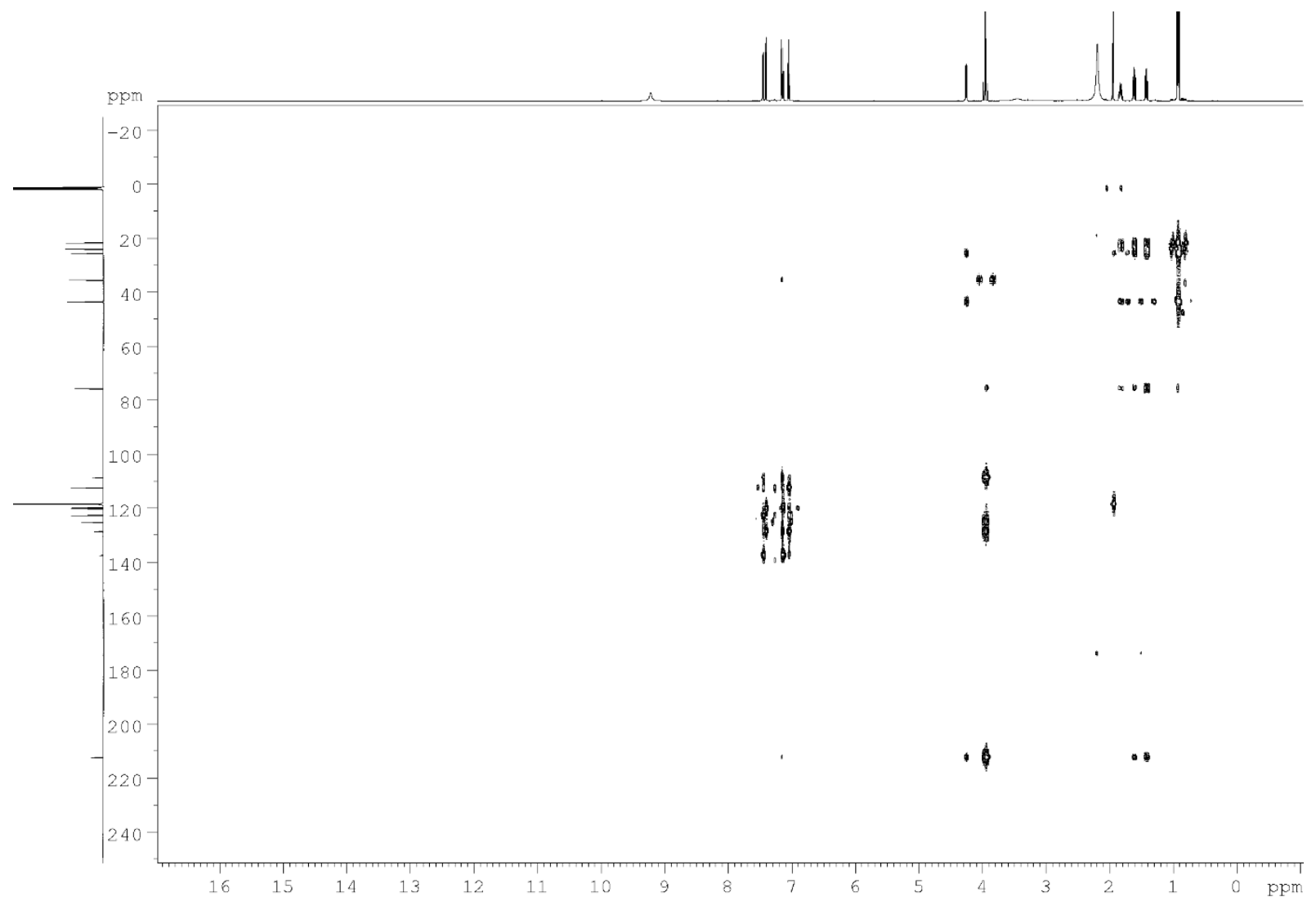

Figure S22. HMBC spectrum of compound 2.

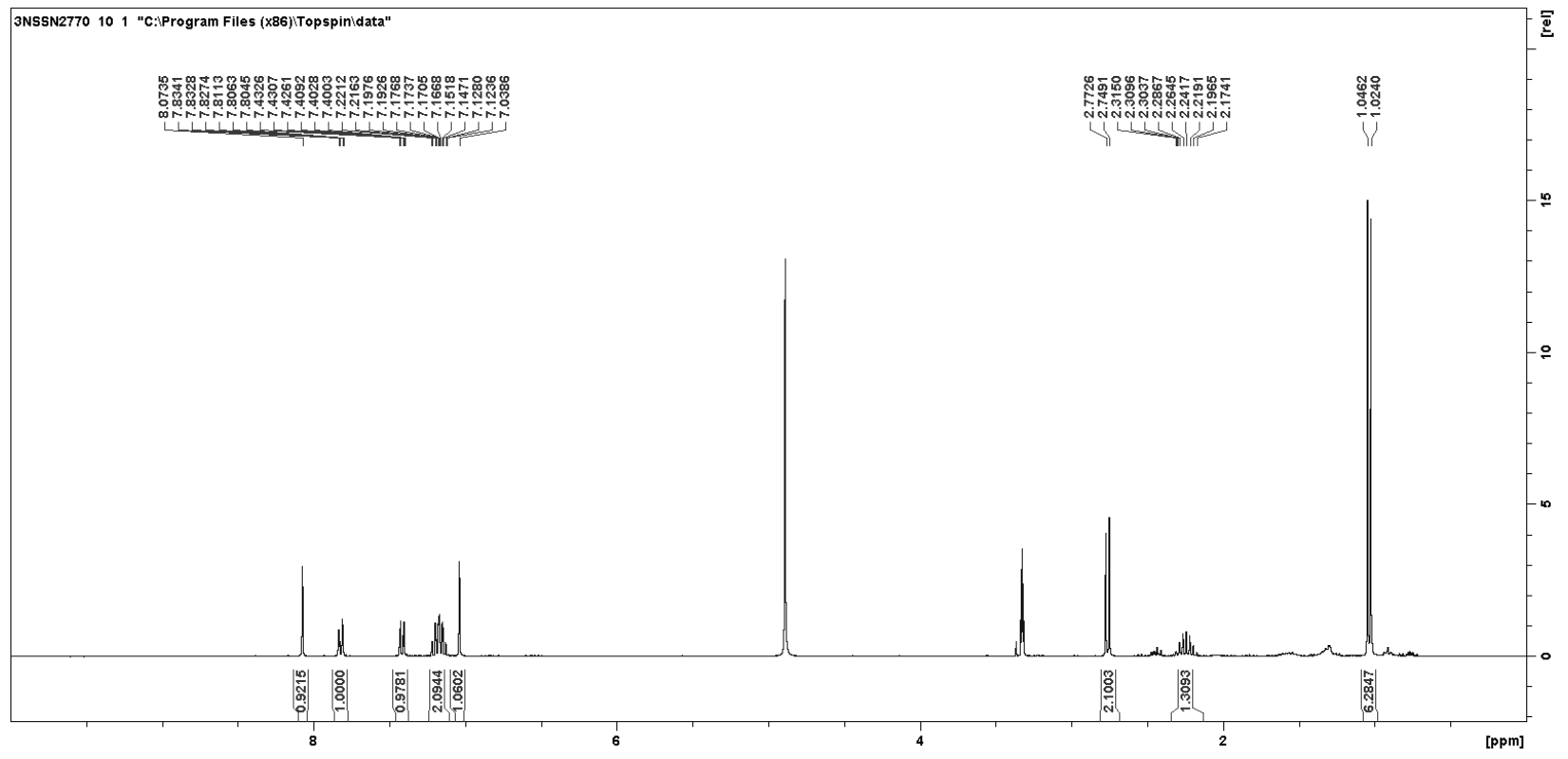

Figure S23. ${ }^{1} \mathrm{H}$ spectrum of compound 3. 


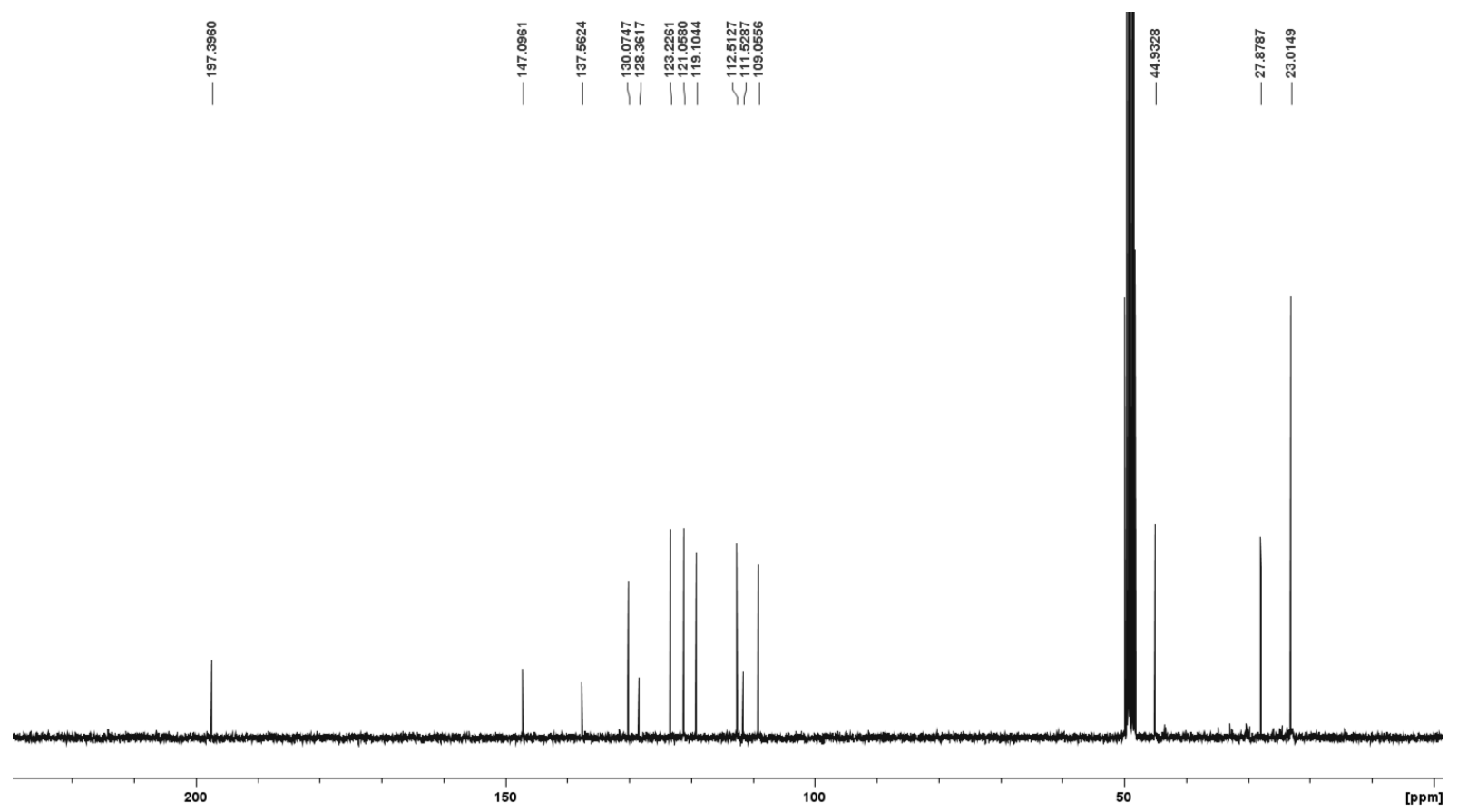

Figure S24. ${ }^{13} \mathrm{C}$ spectrum of compound 3.

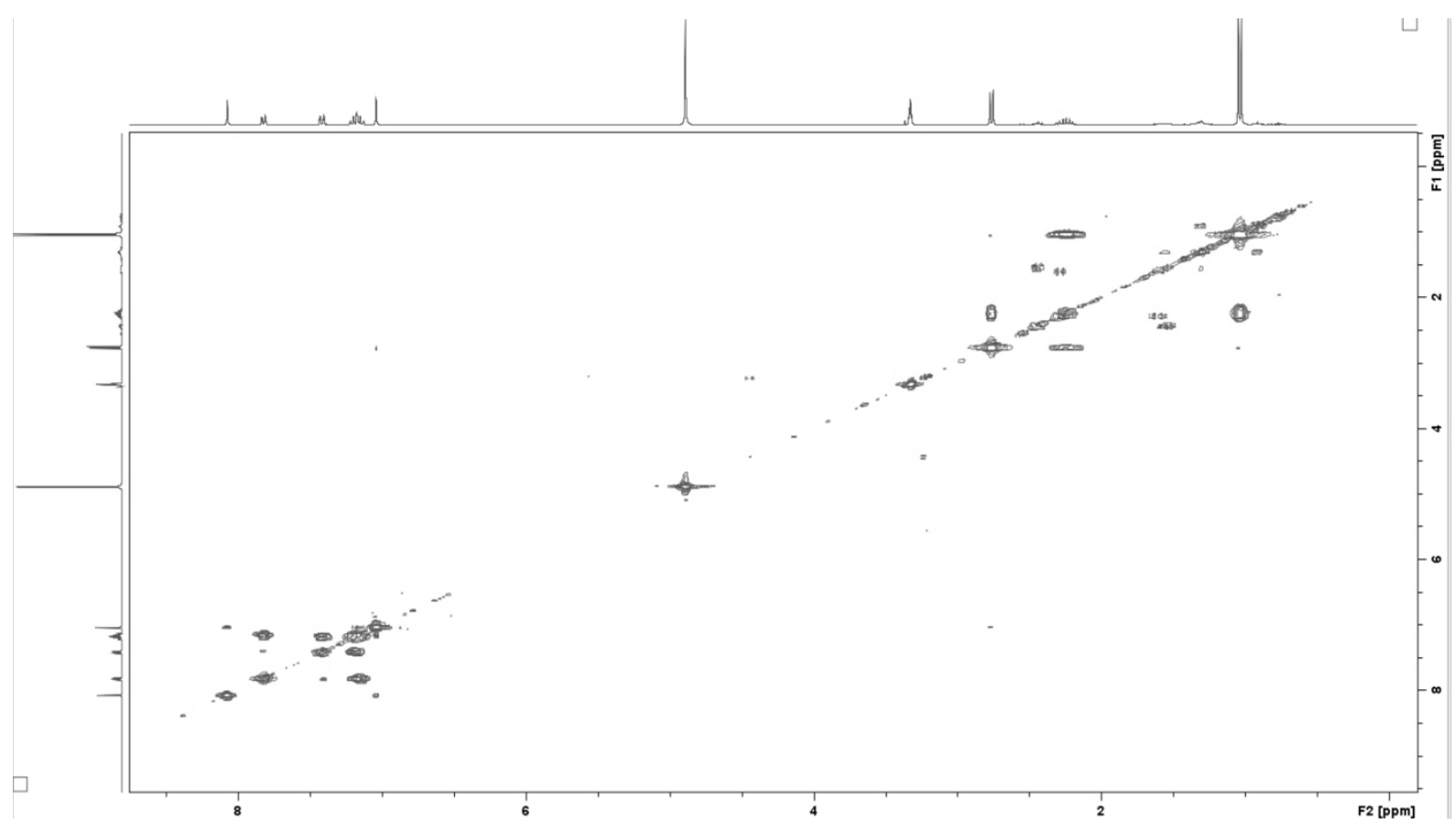

Figure S25. COSY spectrum of compound 3. 


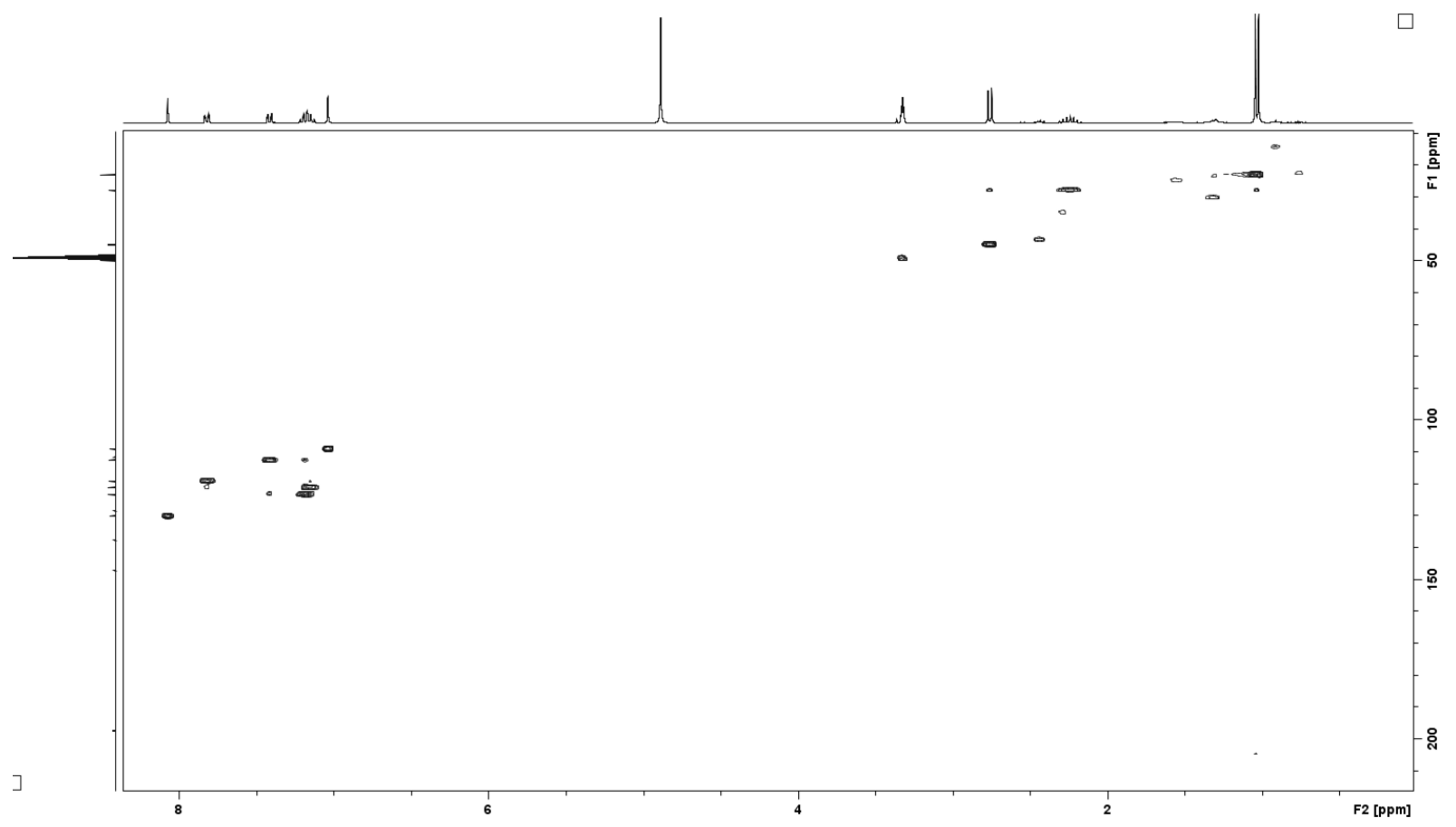

Figure S26. HSQC spectrum of compound 3. 


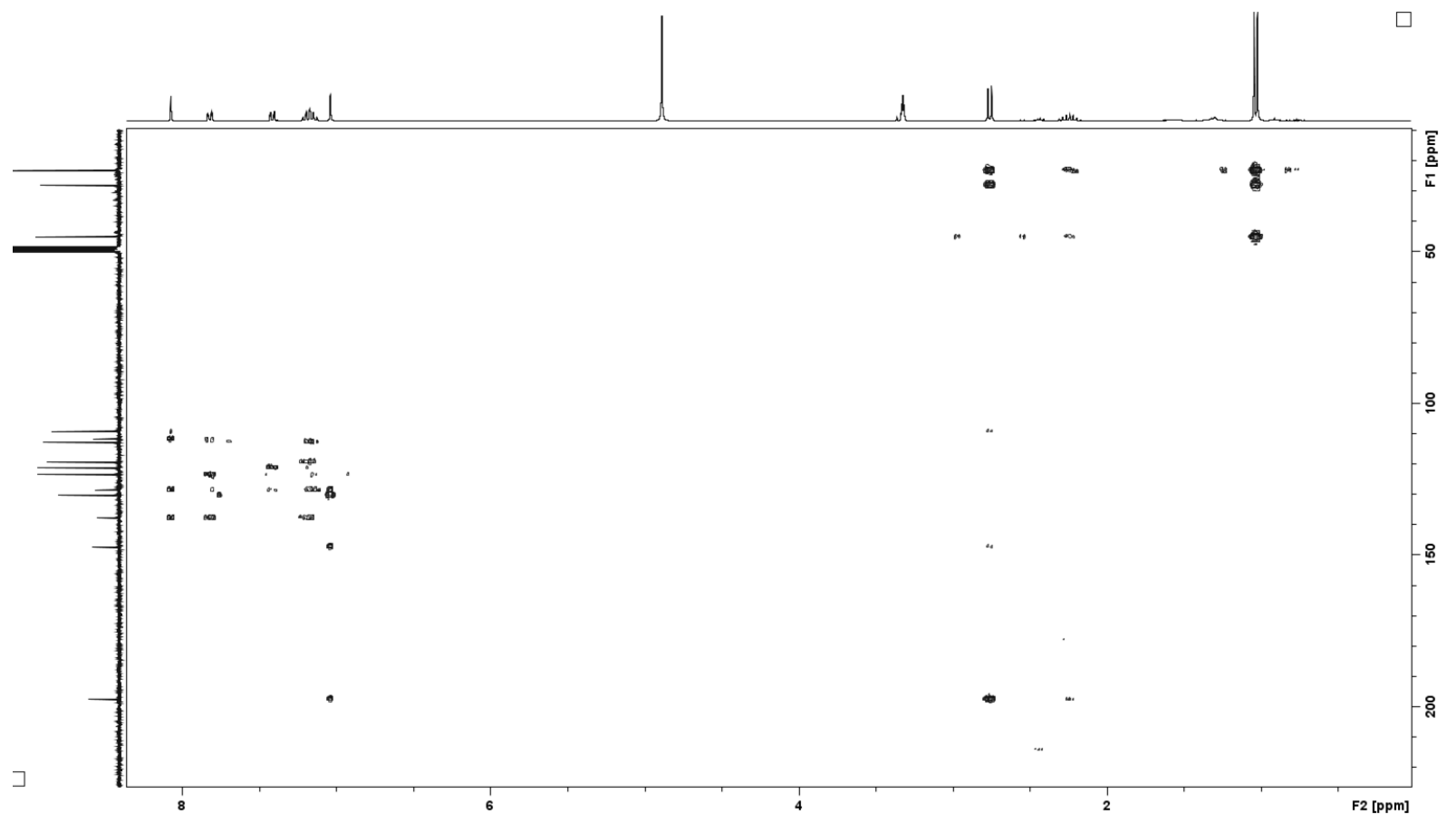

Figure S27. HMBC spectrum of compound 3.

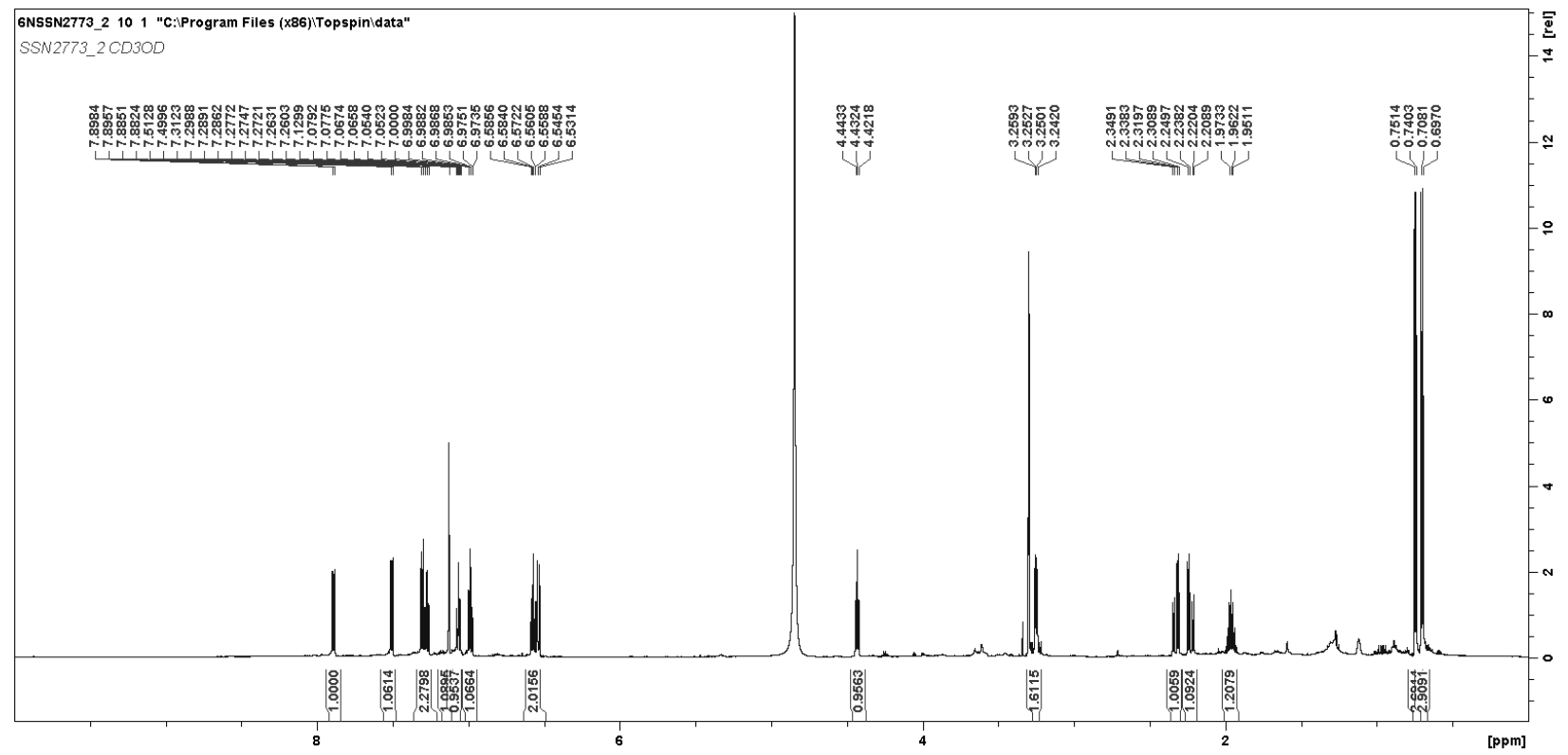

Figure S28. ${ }^{1} \mathrm{H}$ spectrum of compound 4. 


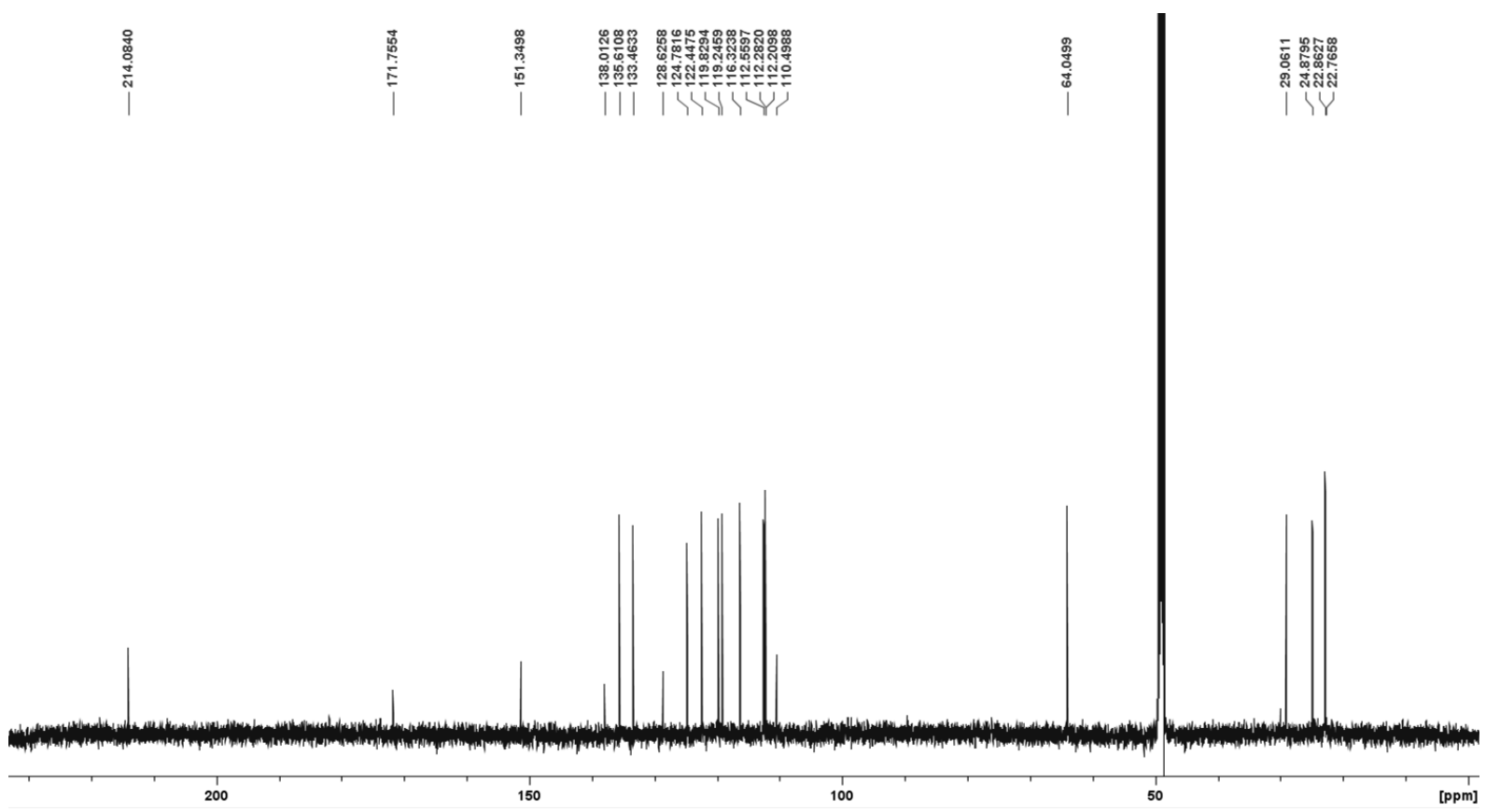

Figure S29. ${ }^{13} \mathrm{C}$ spectrum of compound 4 .

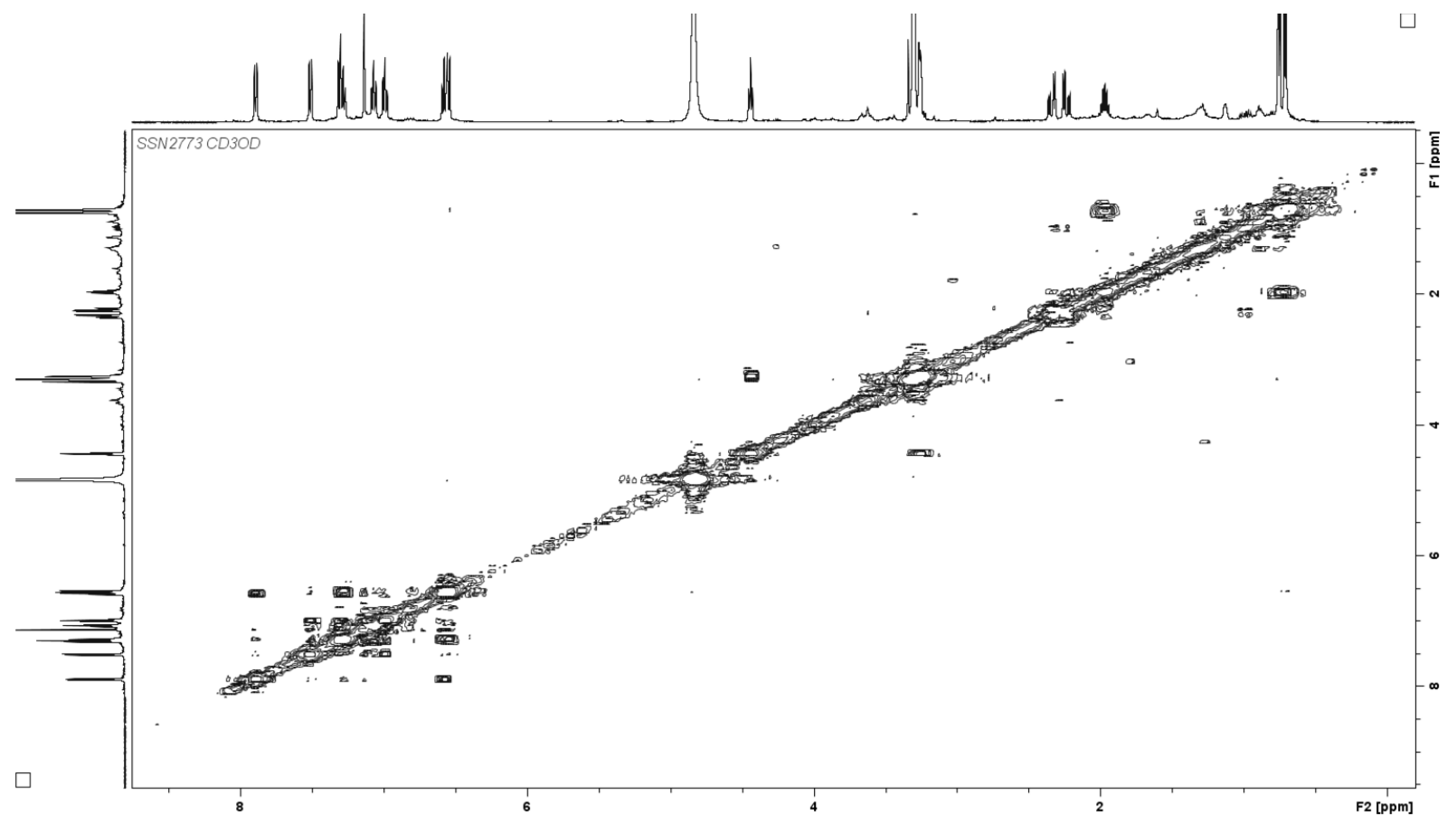

Figure S30. COSY spectrum of compound 4. 


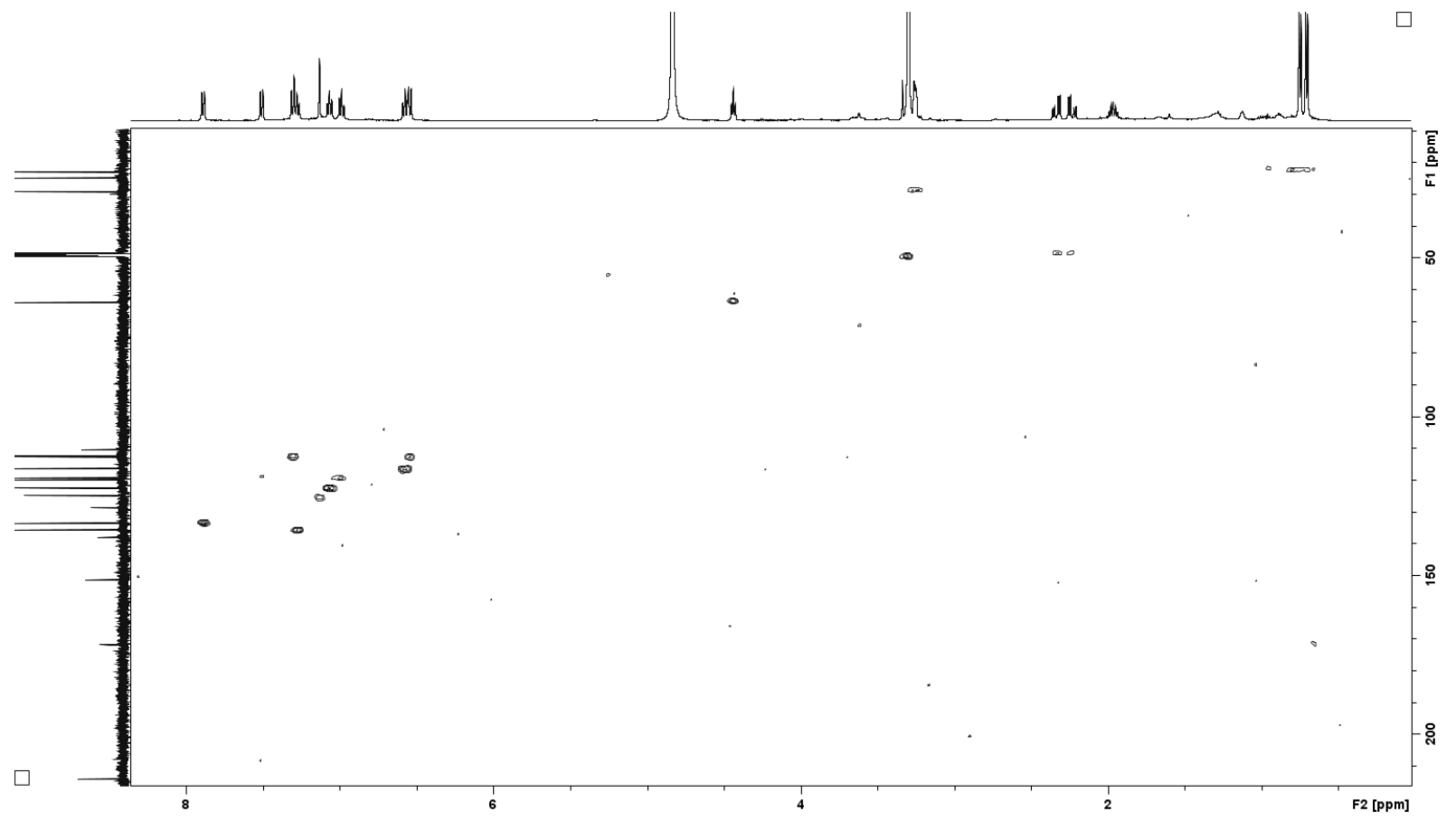

Figure S31. HSQC spectrum of compound 4.

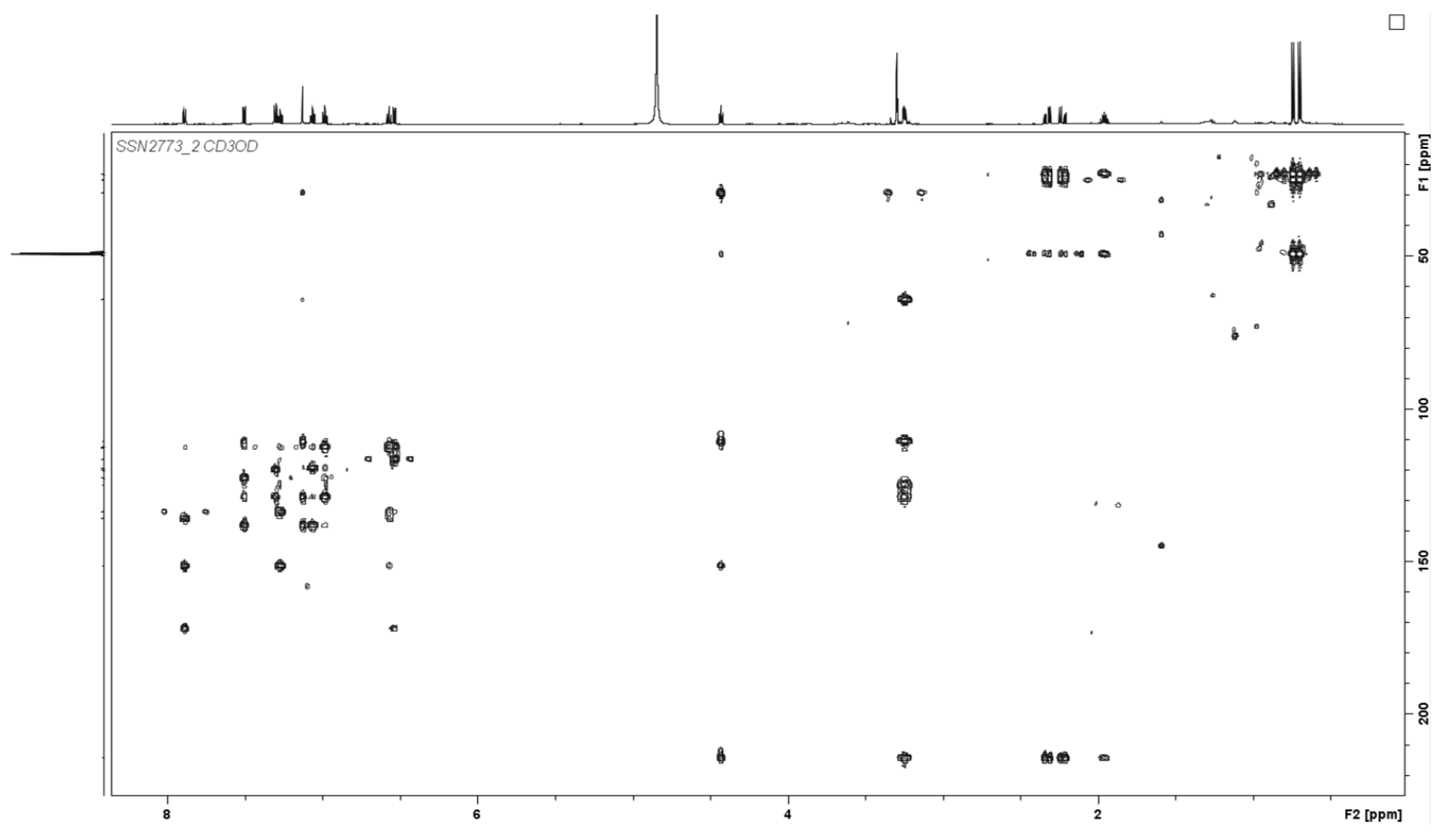

Figure S32. HMBC spectrum of compound 4. 


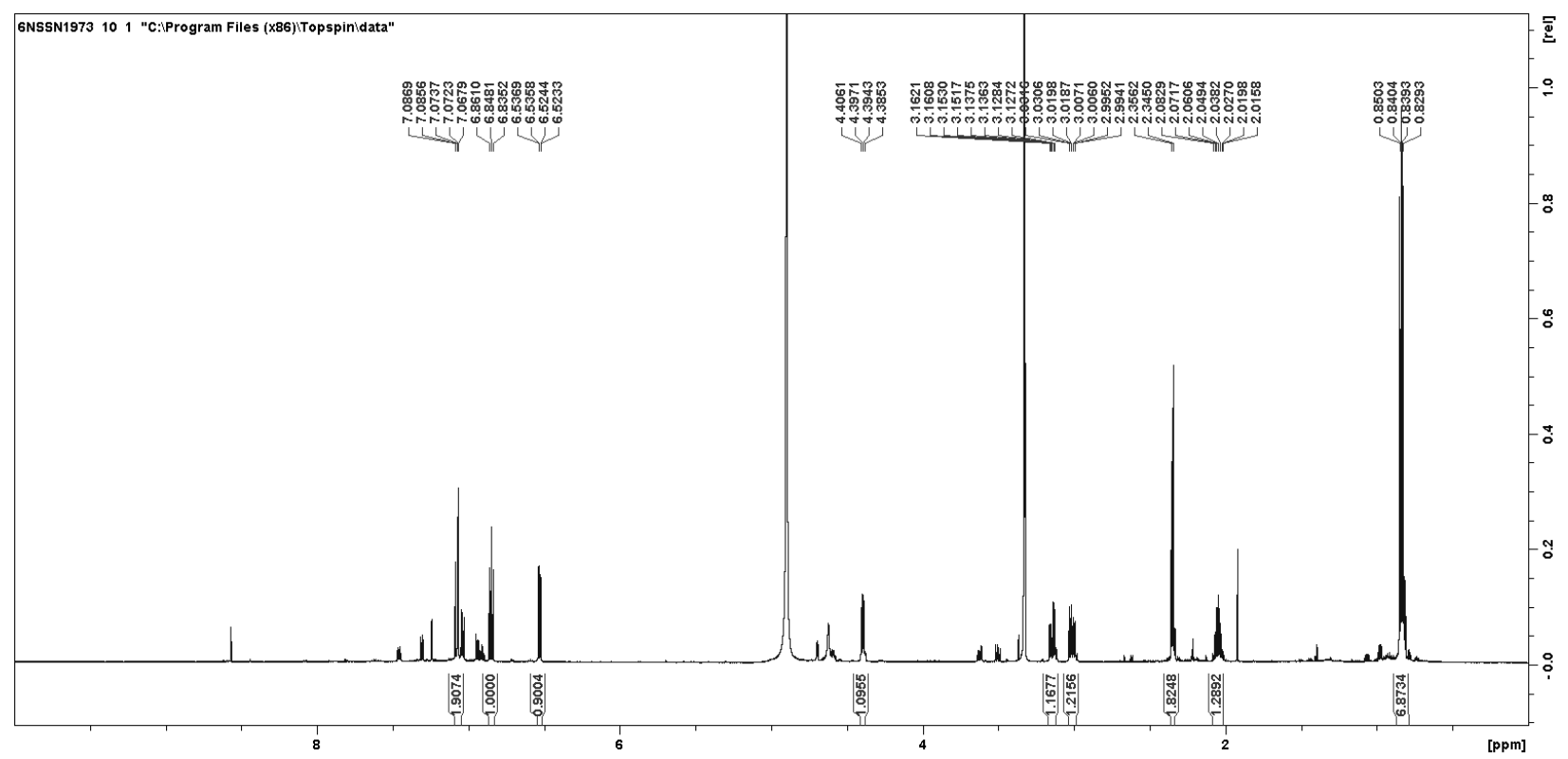

Figure S33. ${ }^{1} \mathrm{H}$ spectrum of compound 5.

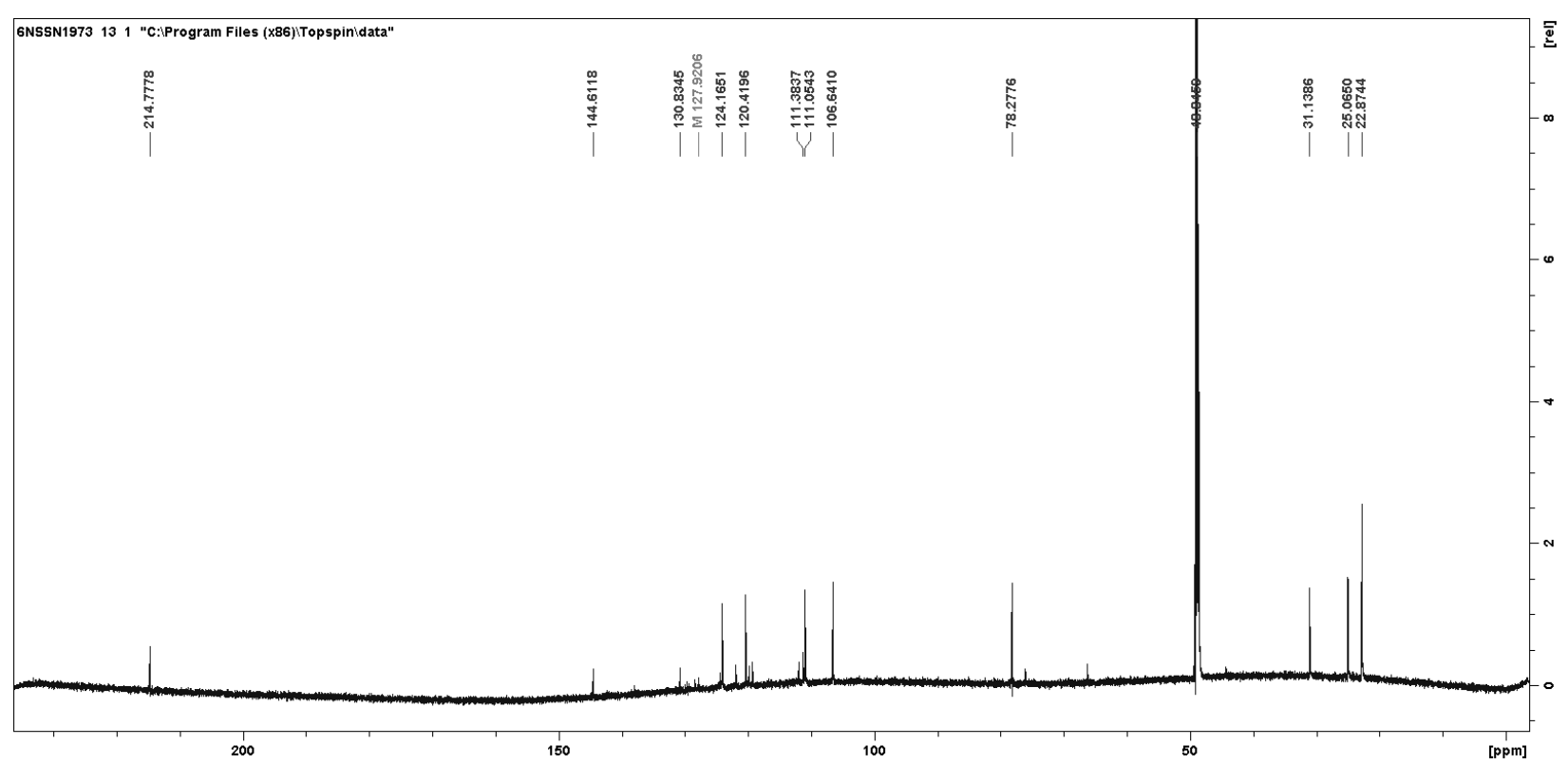

Figure S34. ${ }^{13} \mathrm{C}$ spectrum of compound 5 . 


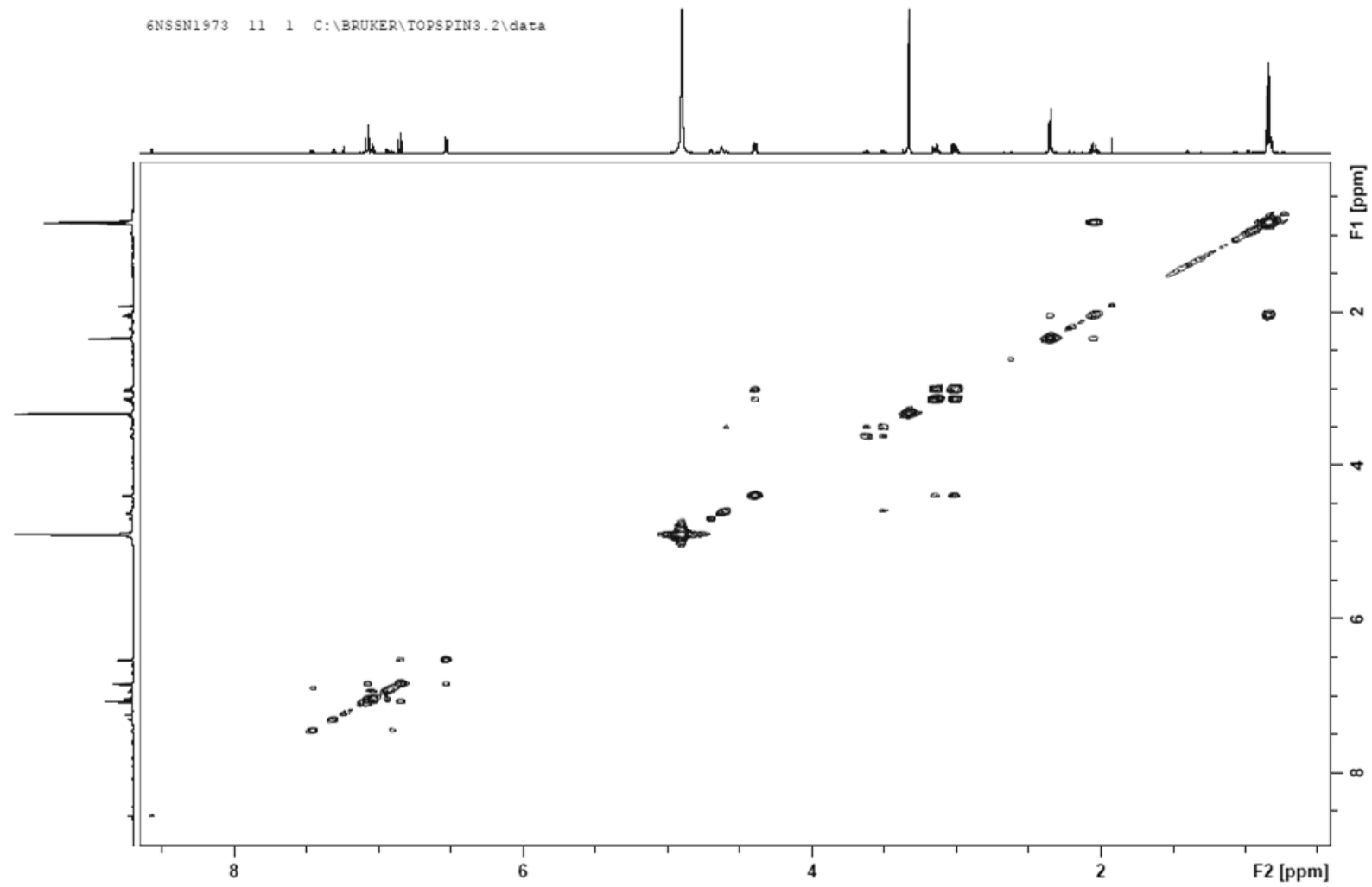

Figure S35. COSY spectrum of compound $\mathbf{5}$.

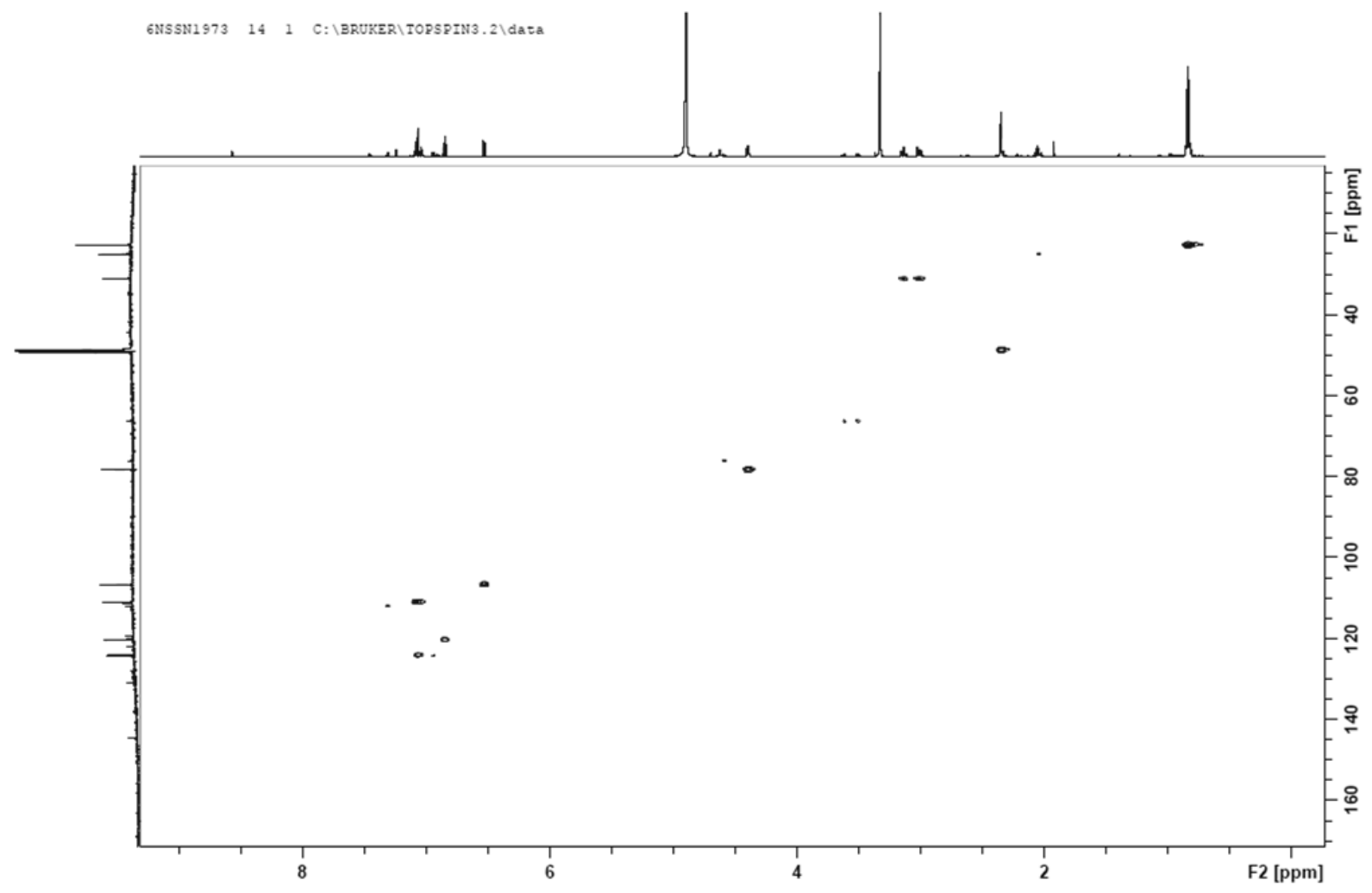

Figure S36. HSQC spectrum of compound 5. 


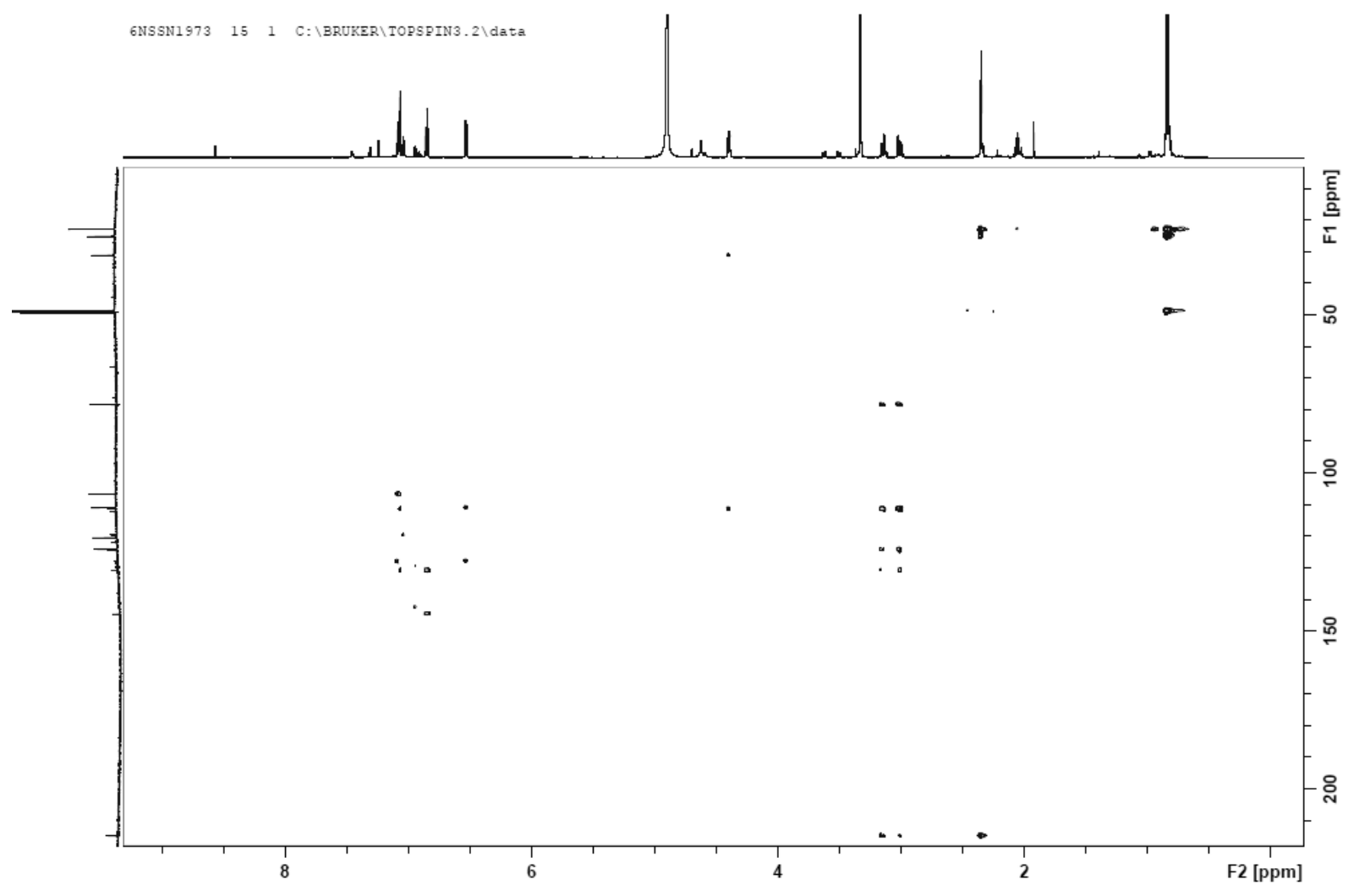

Figure S37. HMBC spectrum of compound 5.

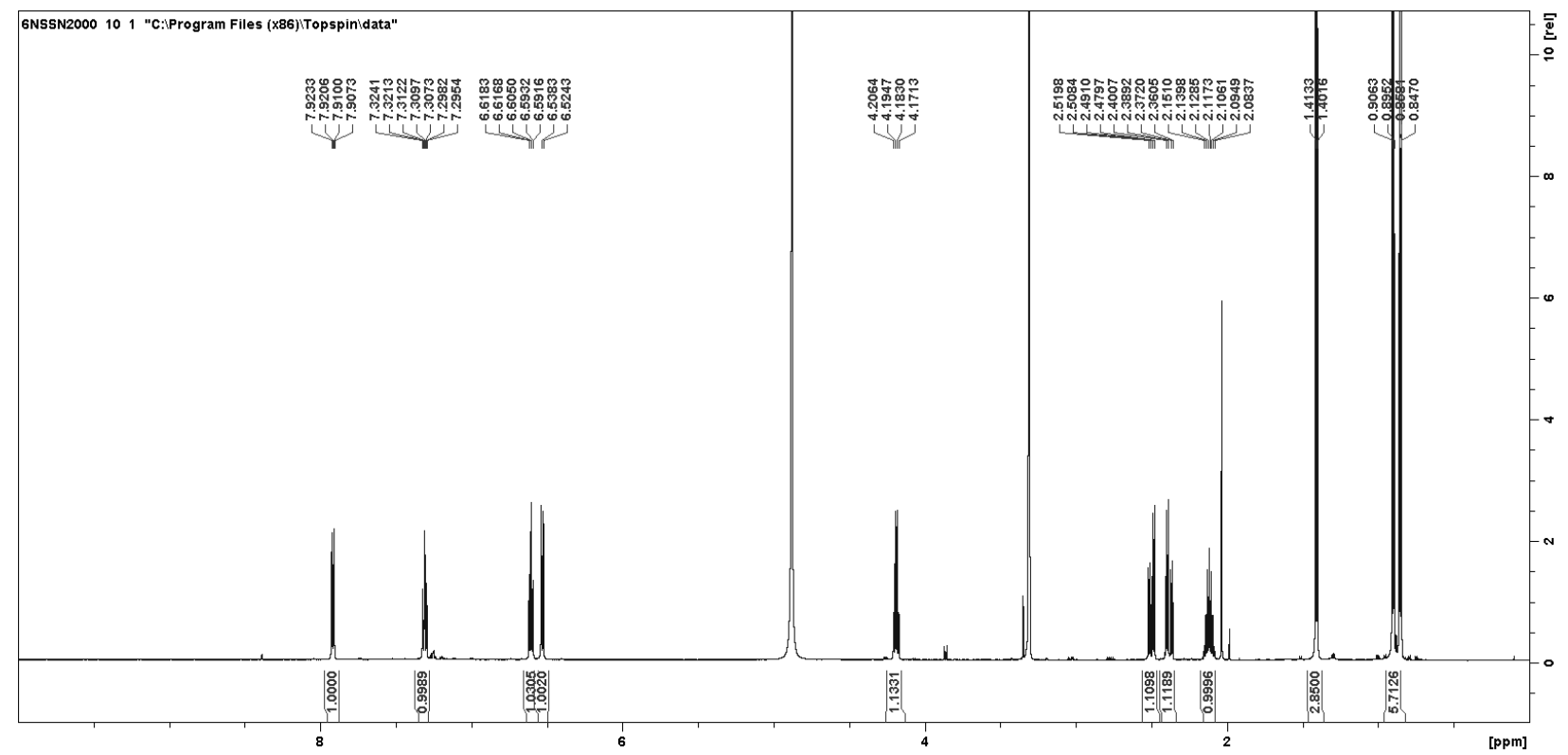

Figure S38. ${ }^{1} \mathrm{H}$ spectrum of compound 6. 


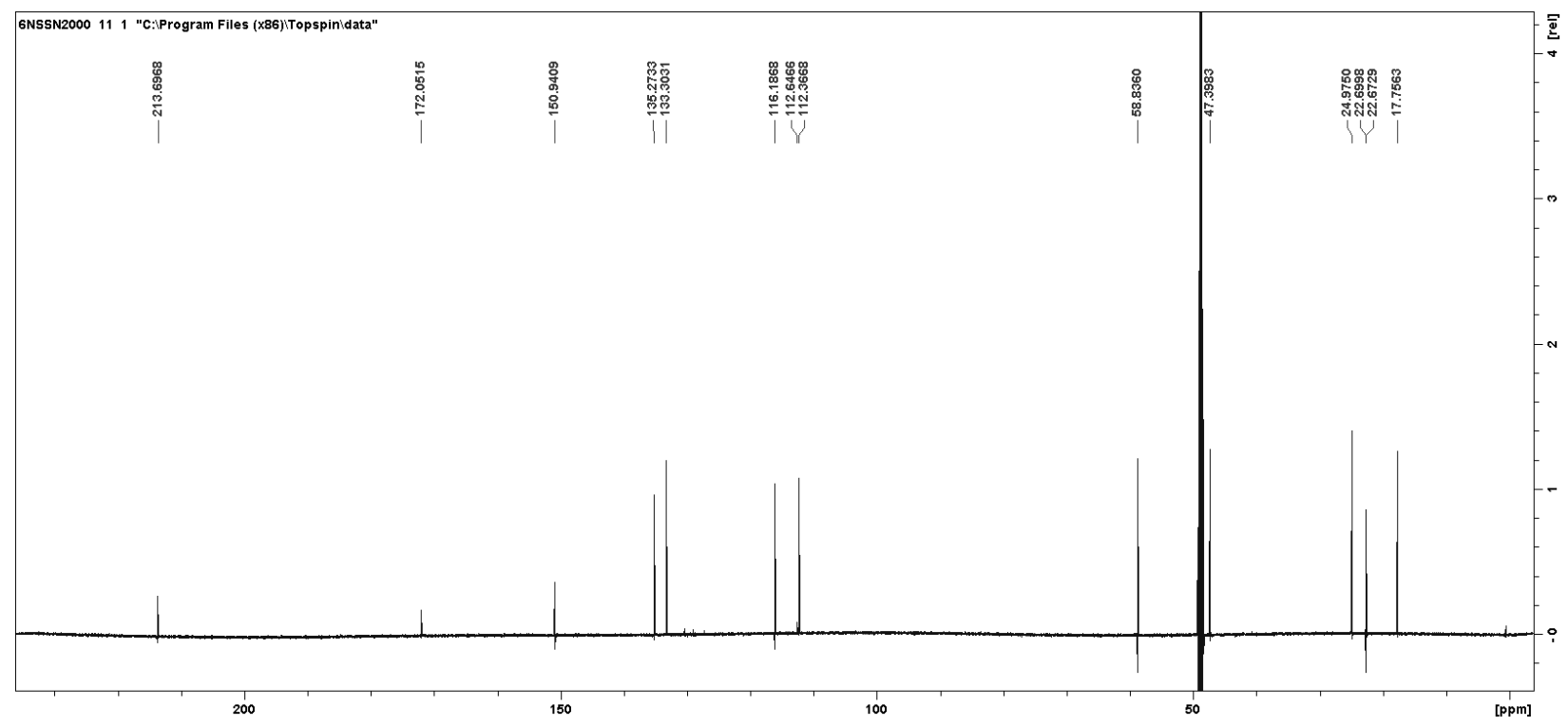

Figure S39. ${ }^{13} \mathrm{C}$ spectrum of compound 6 .

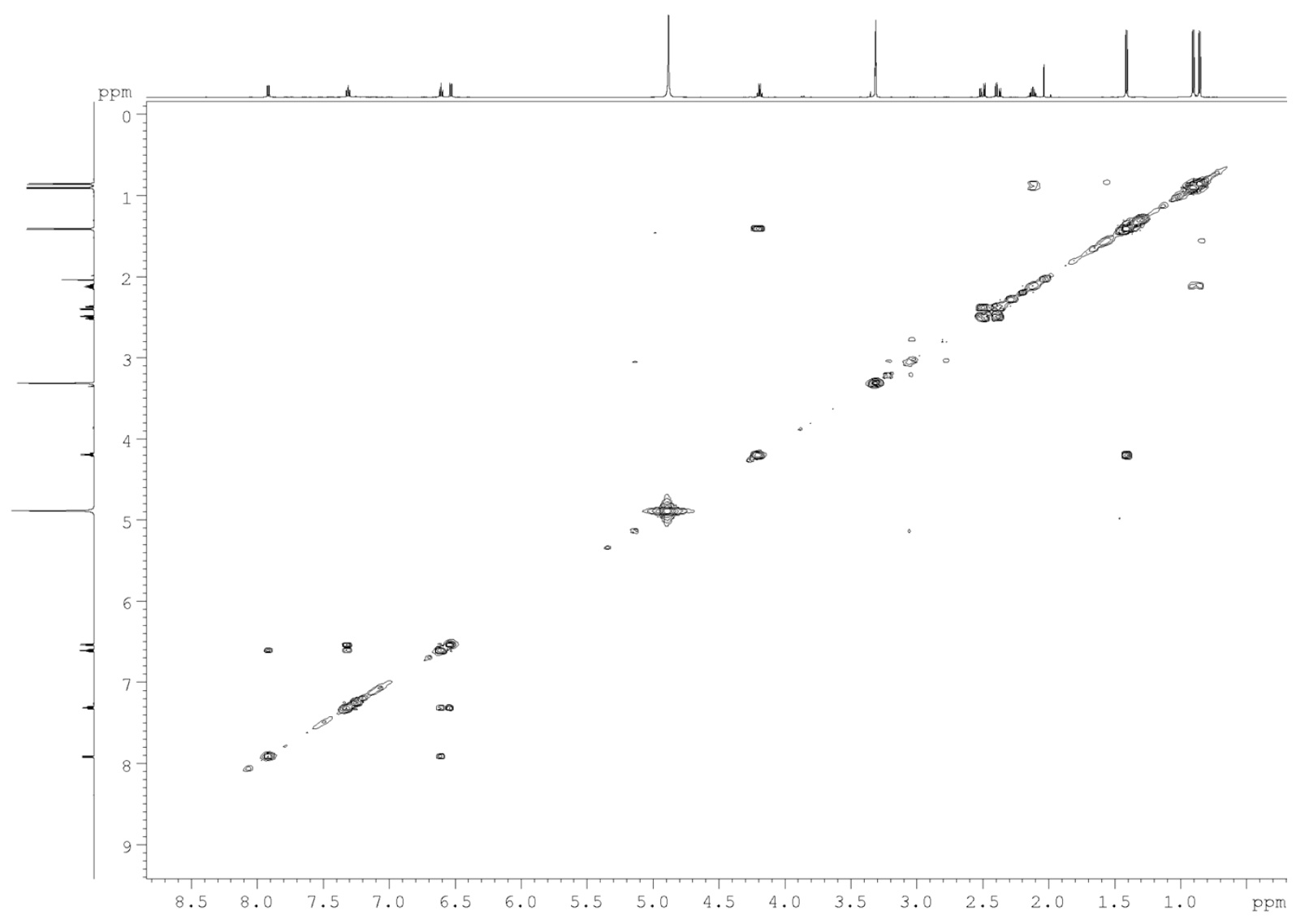

Figure S40. COSY spectrum of compound 6. 


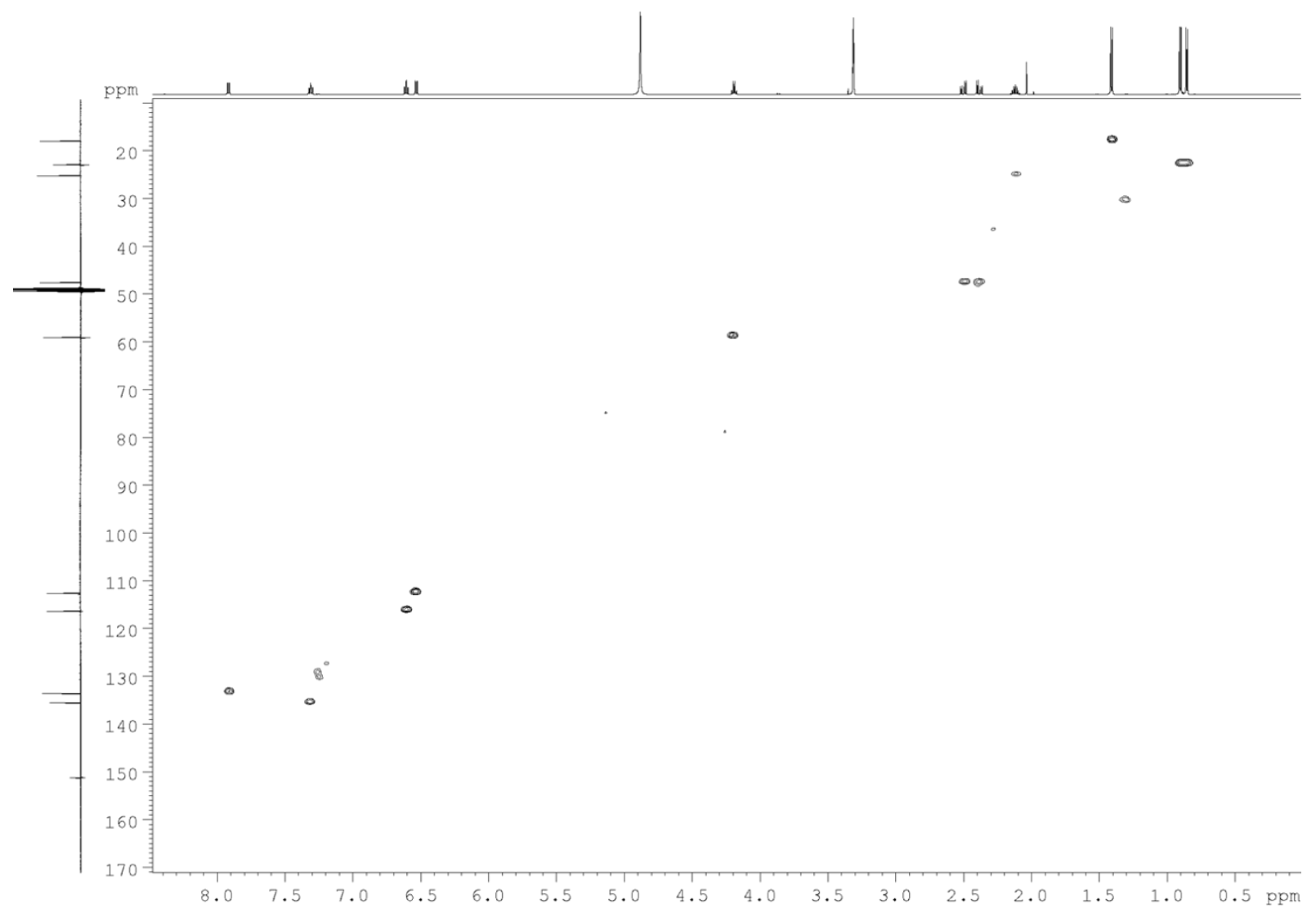

Figure S41. HSQC spectrum of compound 6. 


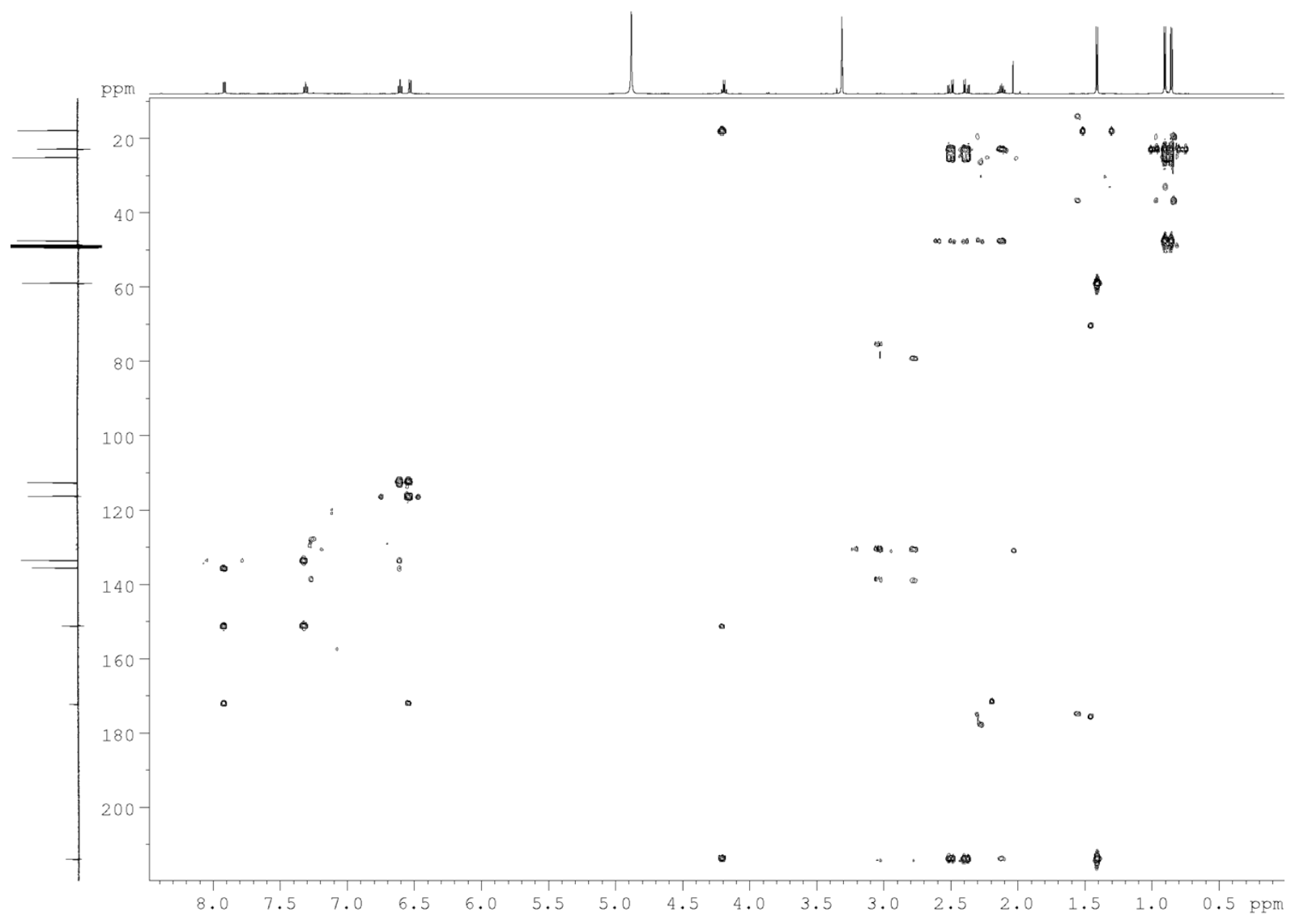

Figure S42. HMBC spectrum of compound 6.

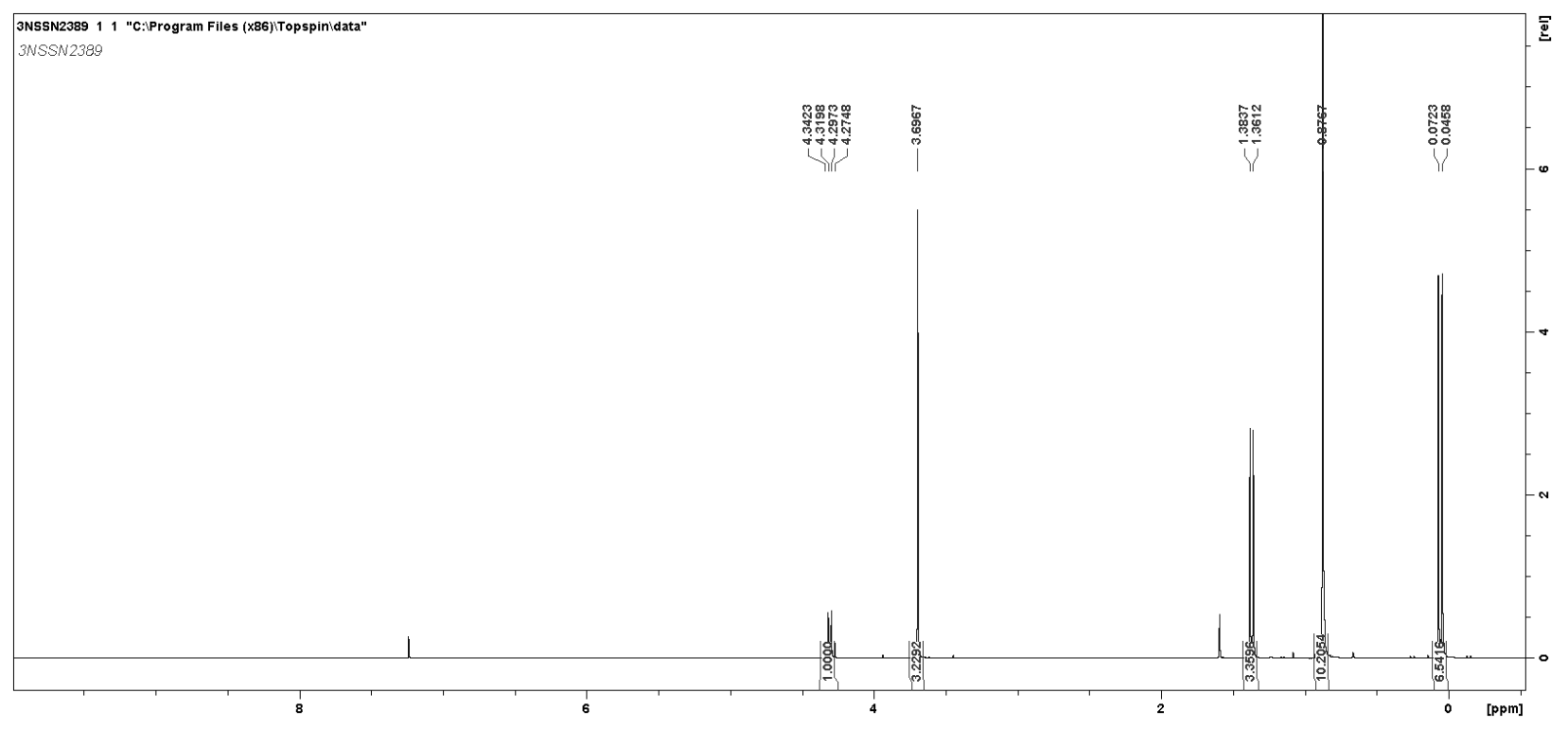

Figure S43. ${ }^{1} \mathrm{H}$ NMR spectrum of methyl 2-((tert-butyldimethylsilyl)oxy)propanoate (32). 


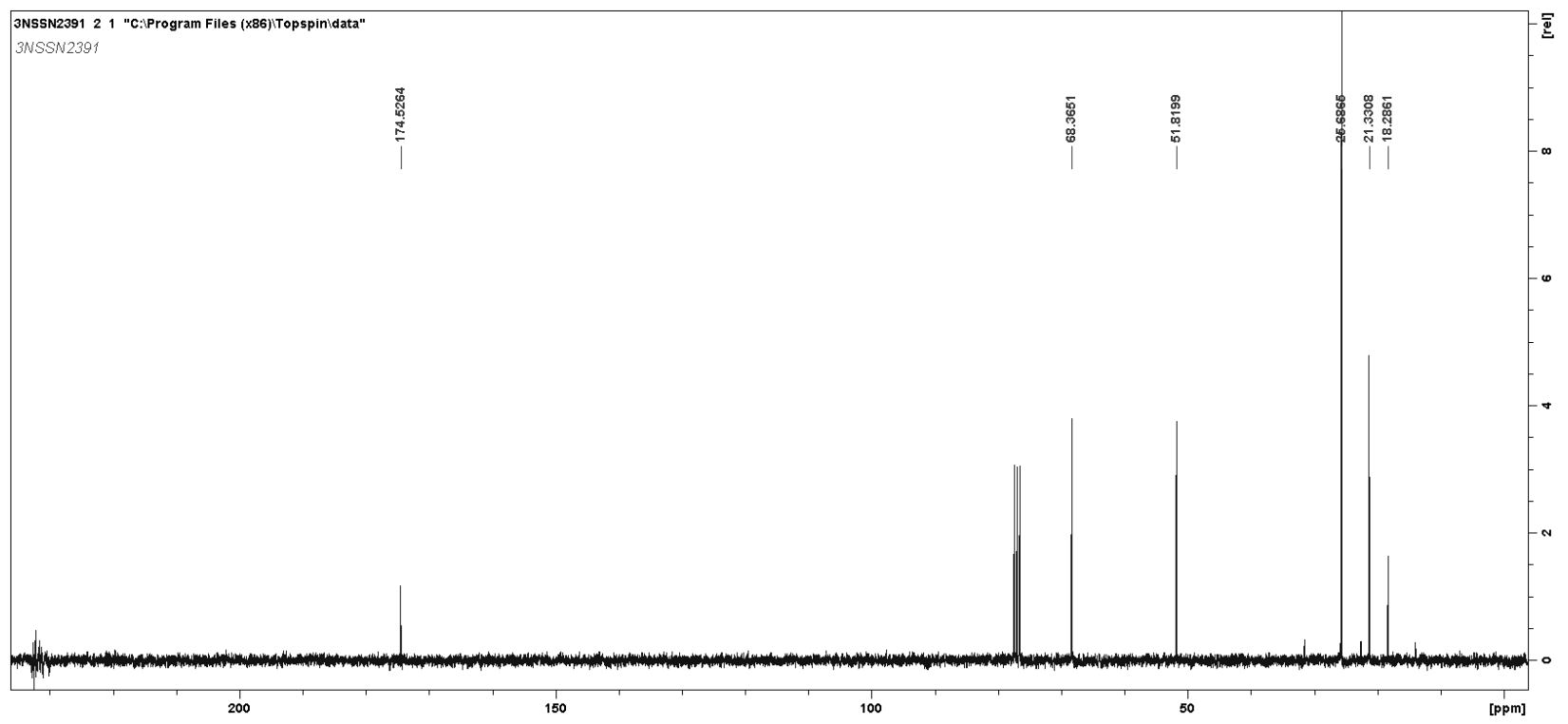

Figure S44. ${ }^{13} \mathrm{C}$ NMR spectrum of methyl 2-((tert-butyldimethylsilyl)oxy)propanoate (32).

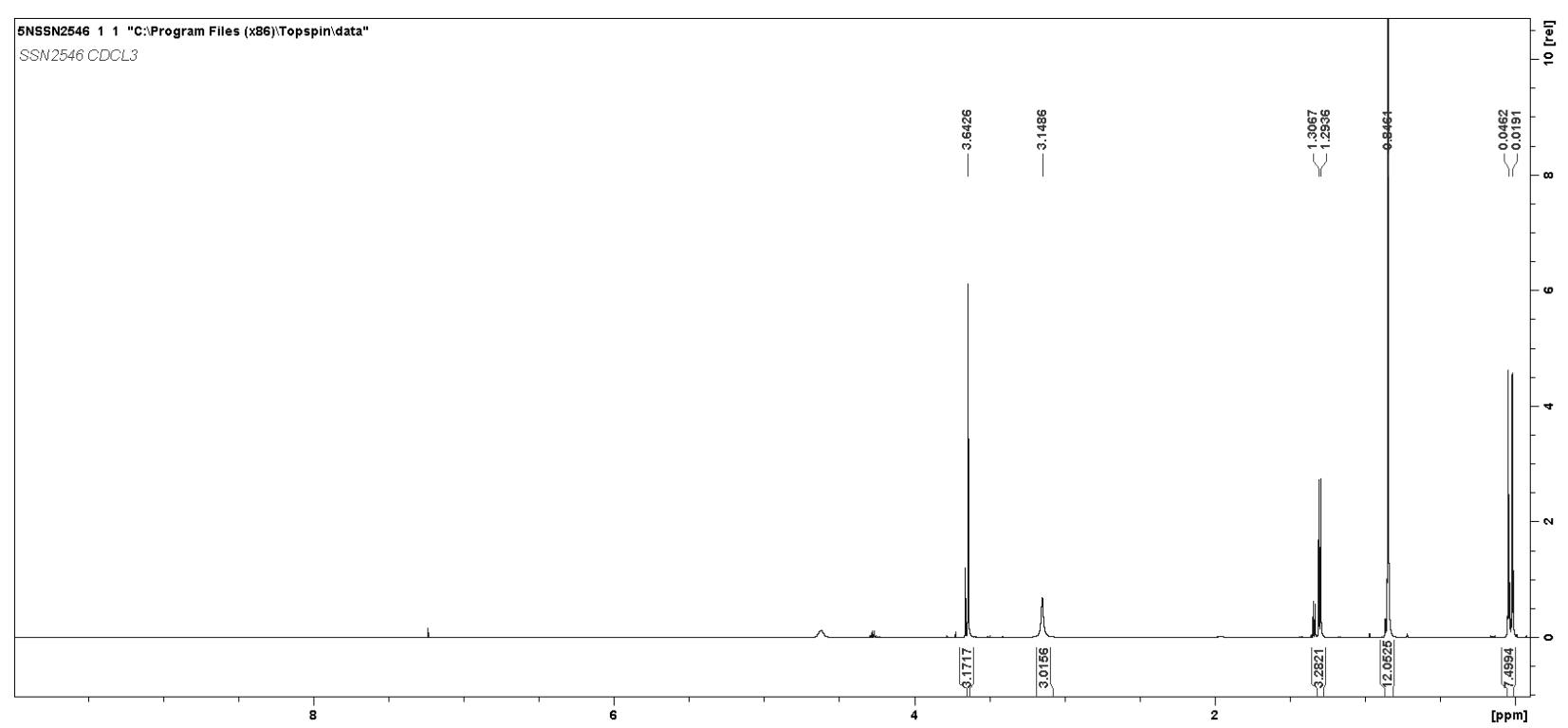

Figure S45. ${ }^{1} \mathrm{H}$ NMR spectrum of 2-((tert-butyldimethylsilyl)oxy)- $N$-methoxy- $N$ methylpropanamide (33). 


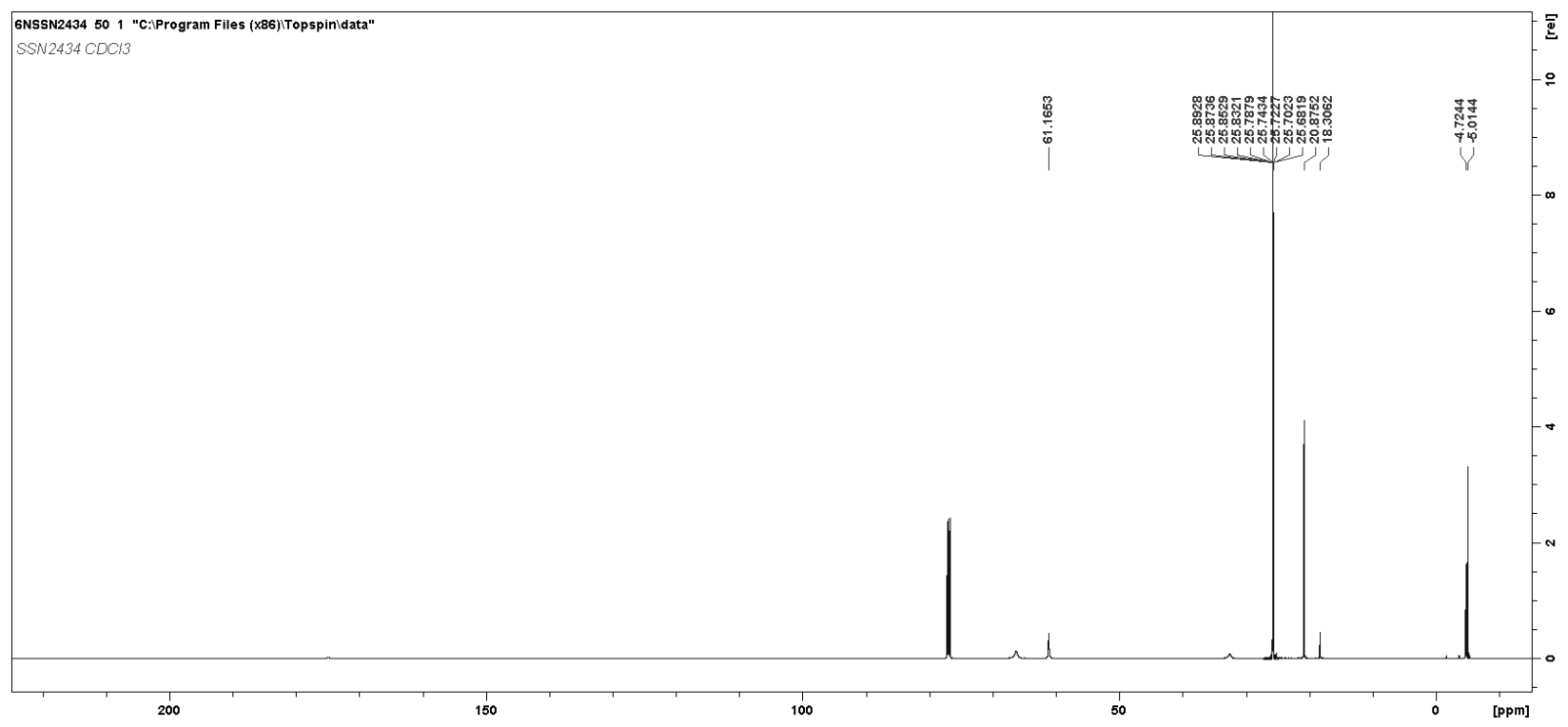

Figure S46. ${ }^{13} \mathrm{C}$ NMR spectrum of 2-((tert-butyldimethylsilyl)oxy)- $N$-methoxy- $N$ methylpropanamide (33).

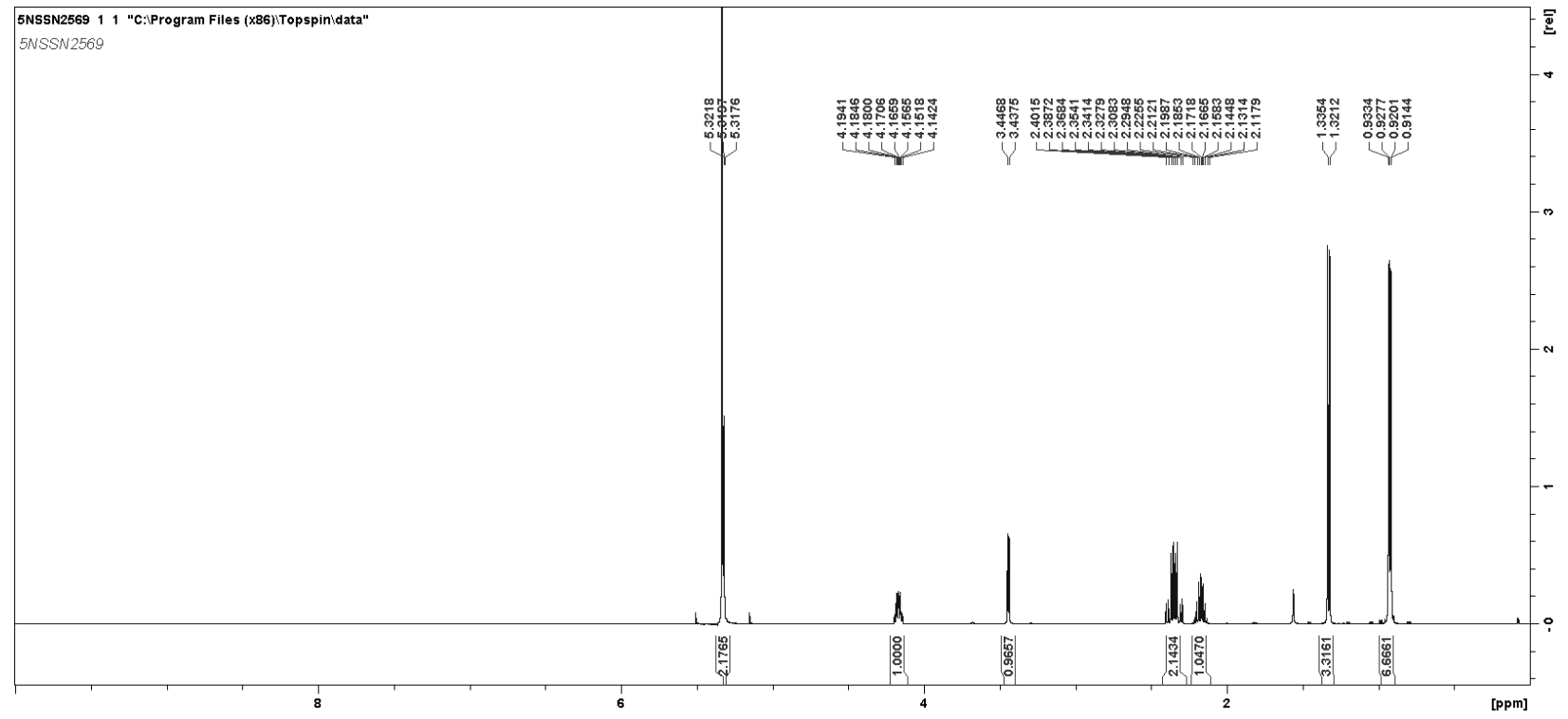

Figure S47. ${ }^{1} \mathrm{H}$ NMR spectrum of 2-hydroxy-5-methylhexan-3-one (35). 


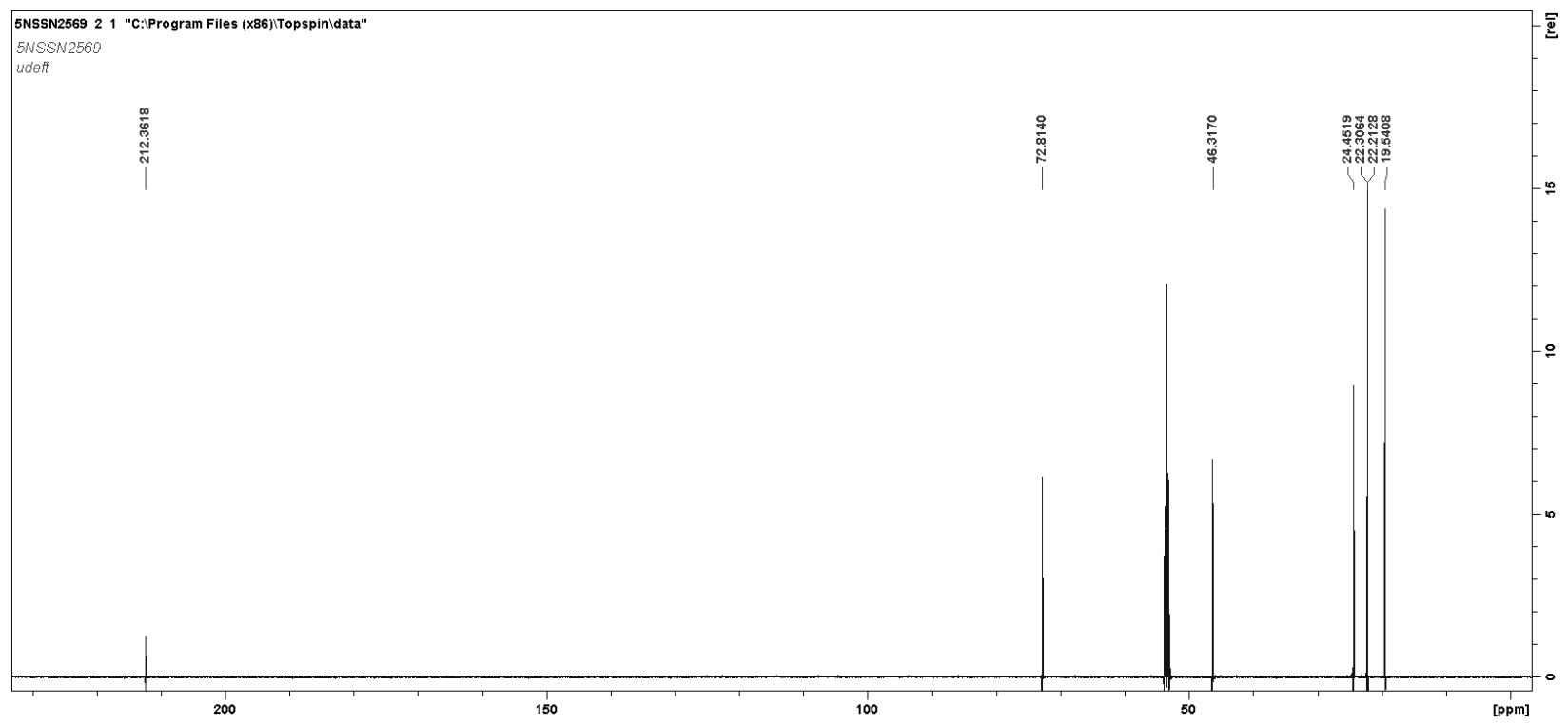

Figure S48. ${ }^{13} \mathrm{C}$ NMR spectrum of 2-hydroxy-5-methylhexan-3-one (35).

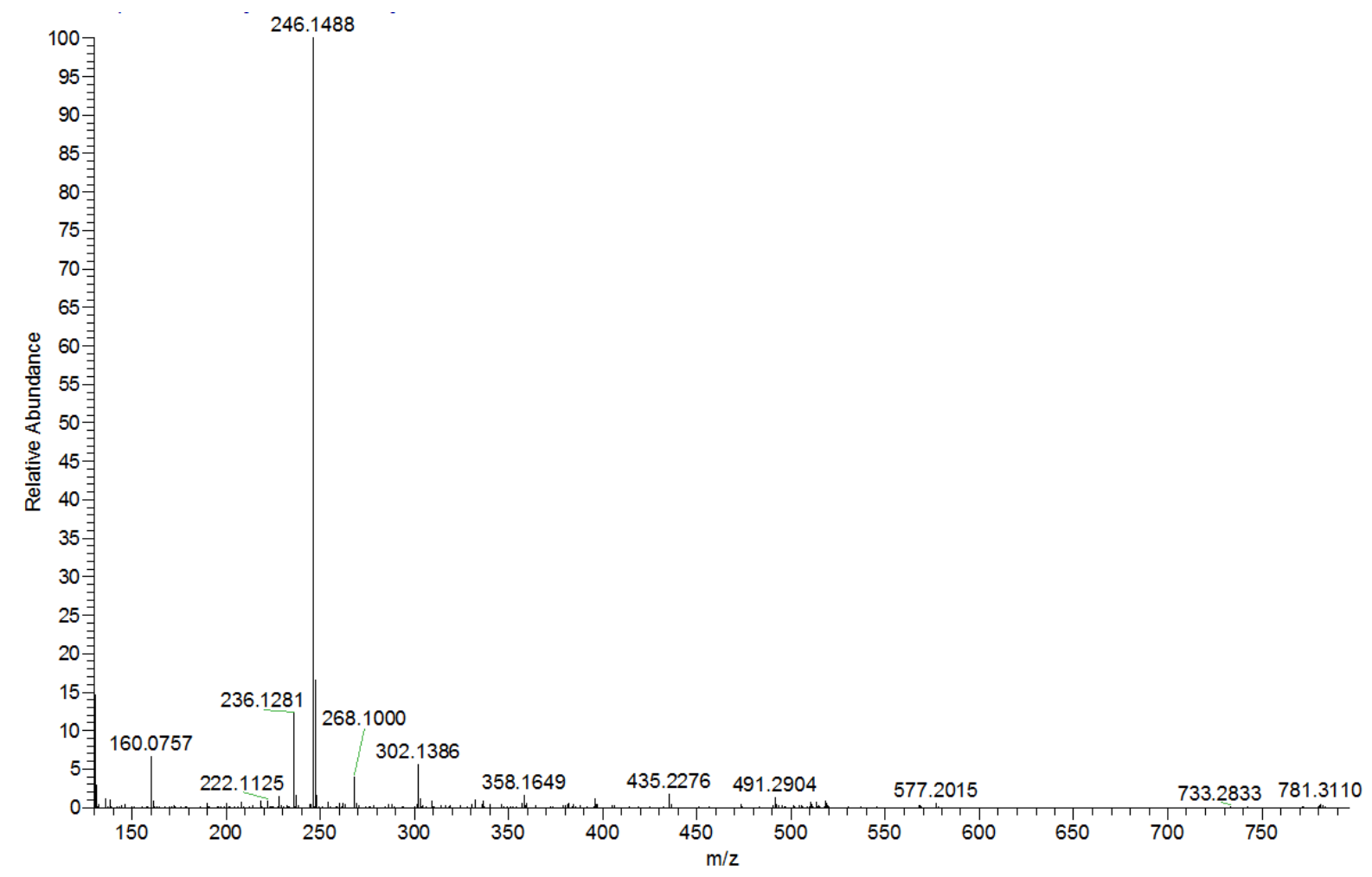

Figure S49. ESI-HR-MS spectrum of compound 1 measured in positive mode. 


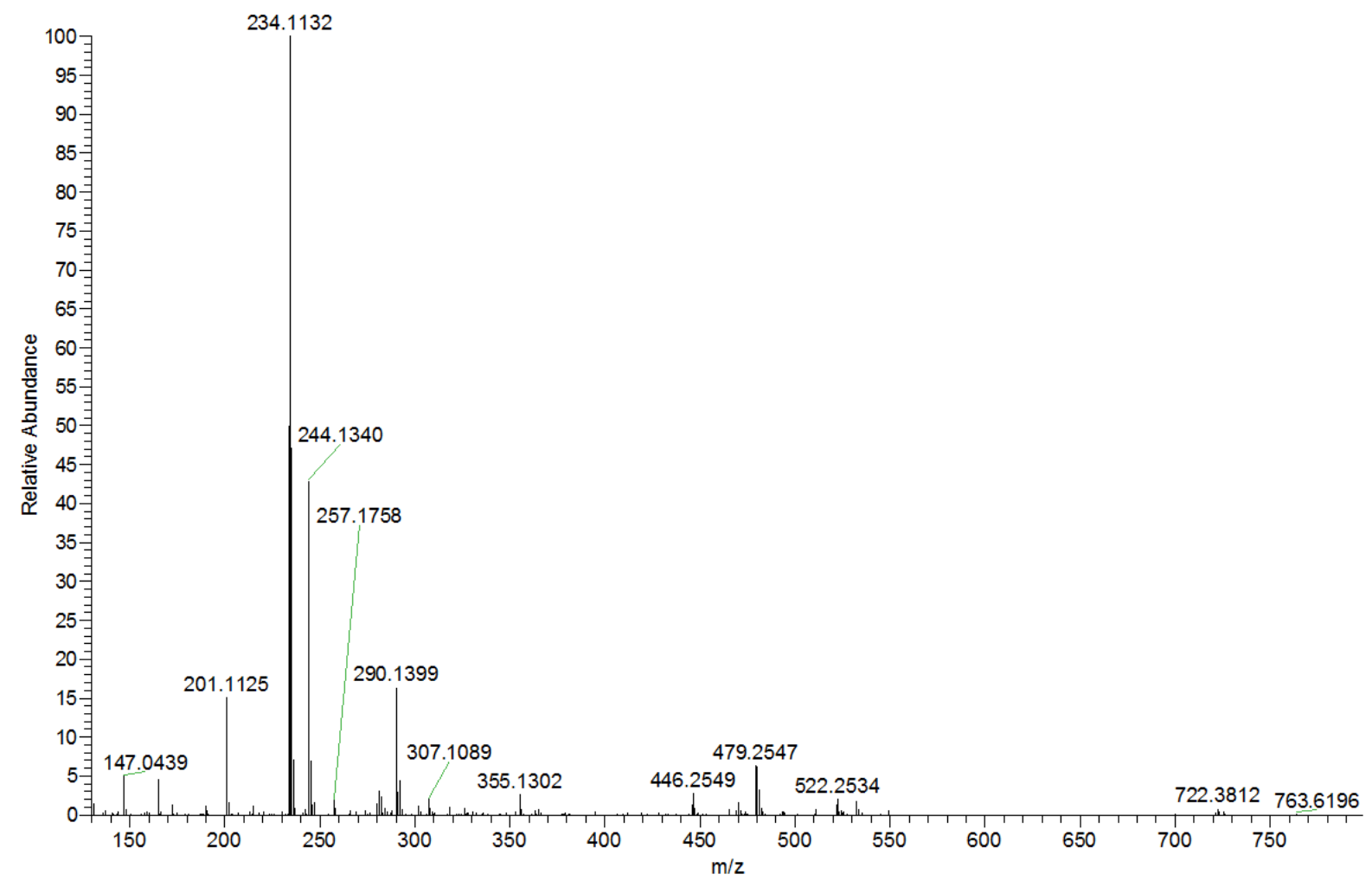

Figure S50. ESI-HR-MS spectrum of compound 1 measured in negative mode.

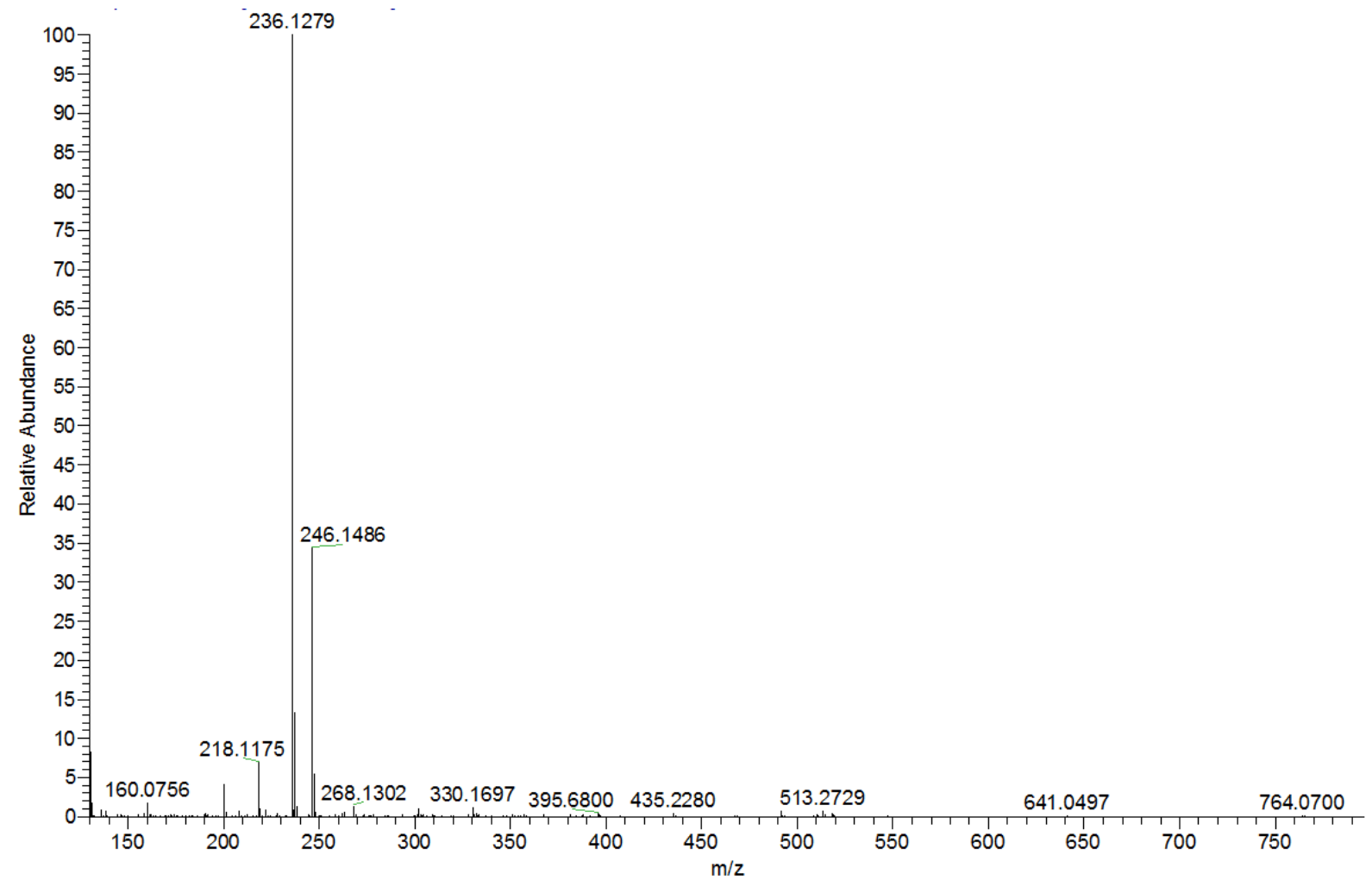


Figure S51. ESI-HR-MS spectrum of compound 2 measured in positive mode.

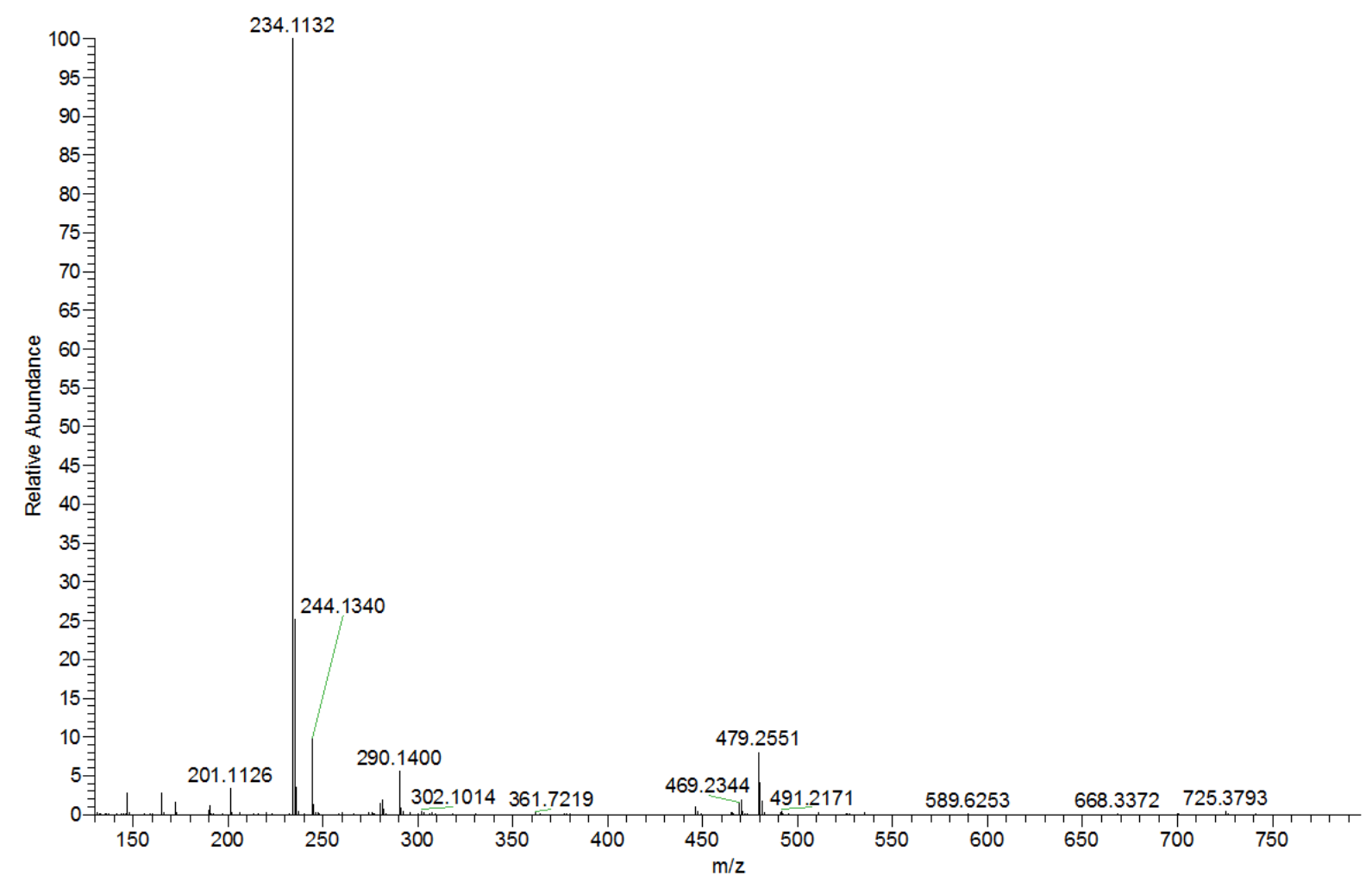

Figure S52. ESI-HR-MS spectrum of compound 2 measured in negative mode. 


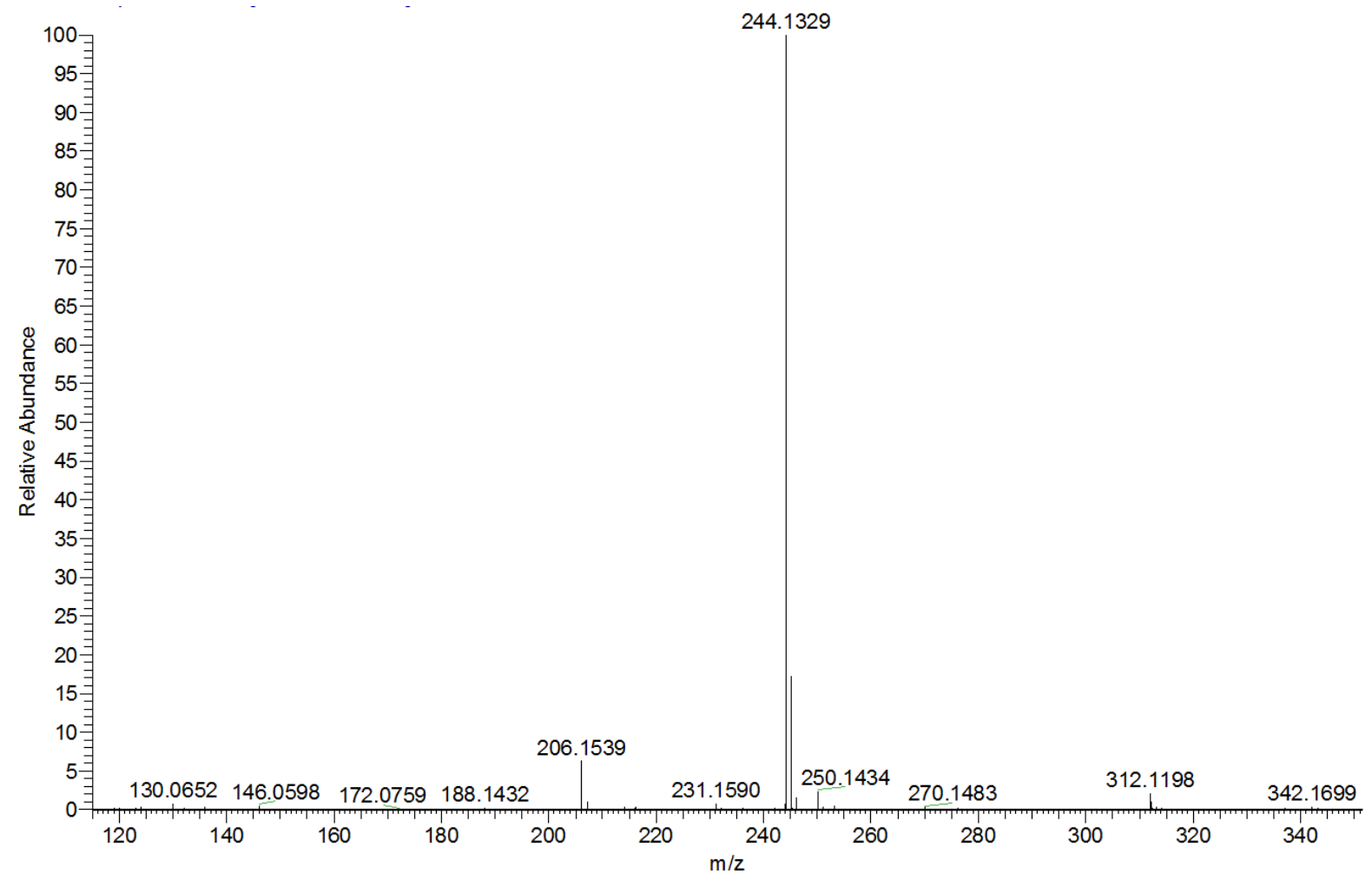

Figure S53. ESI-HR-MS spectrum of compound 3 measured in positive mode.

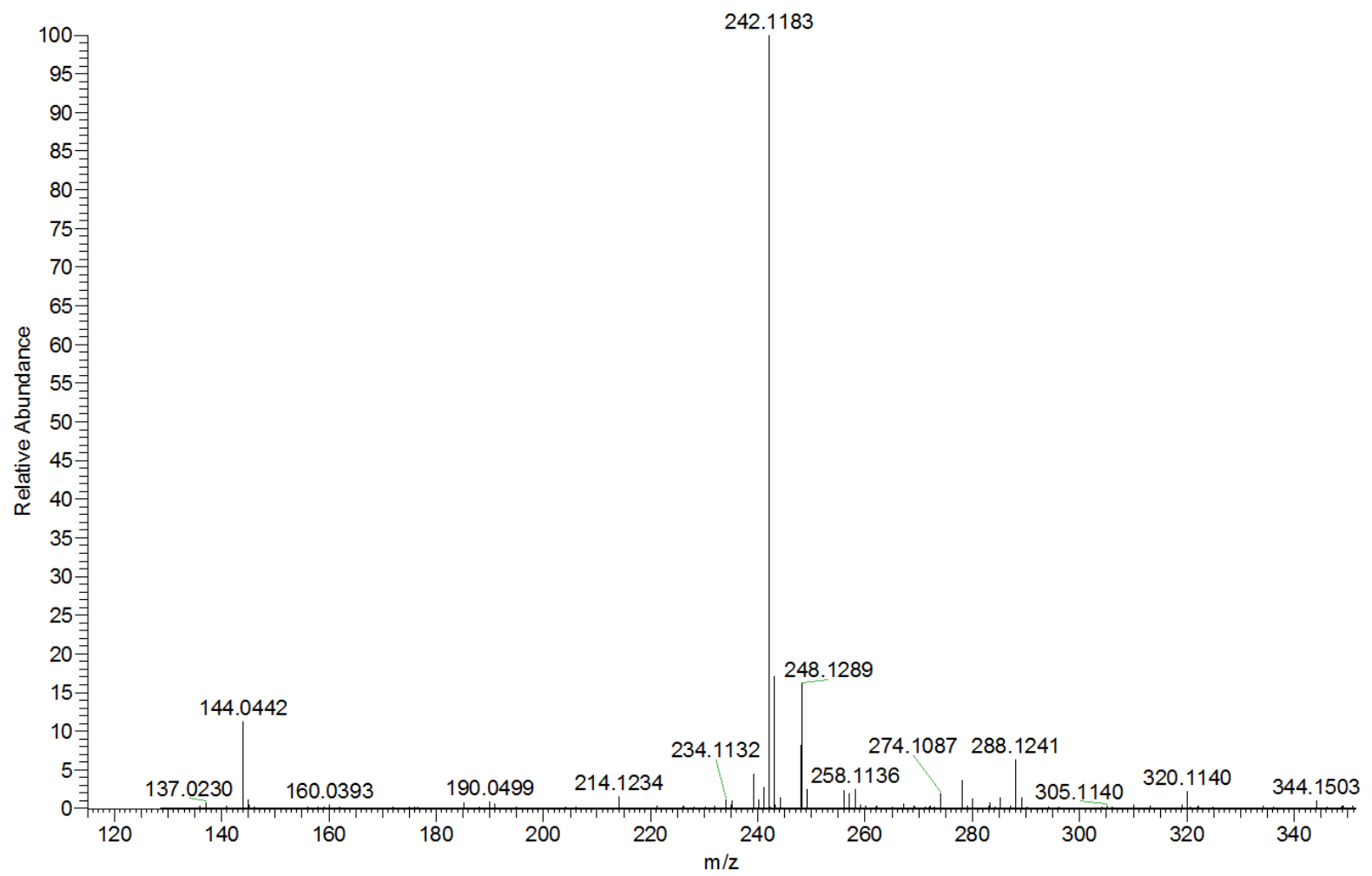


Figure S54. ESI-HR-MS spectrum of compound 3 measured in negative mode.

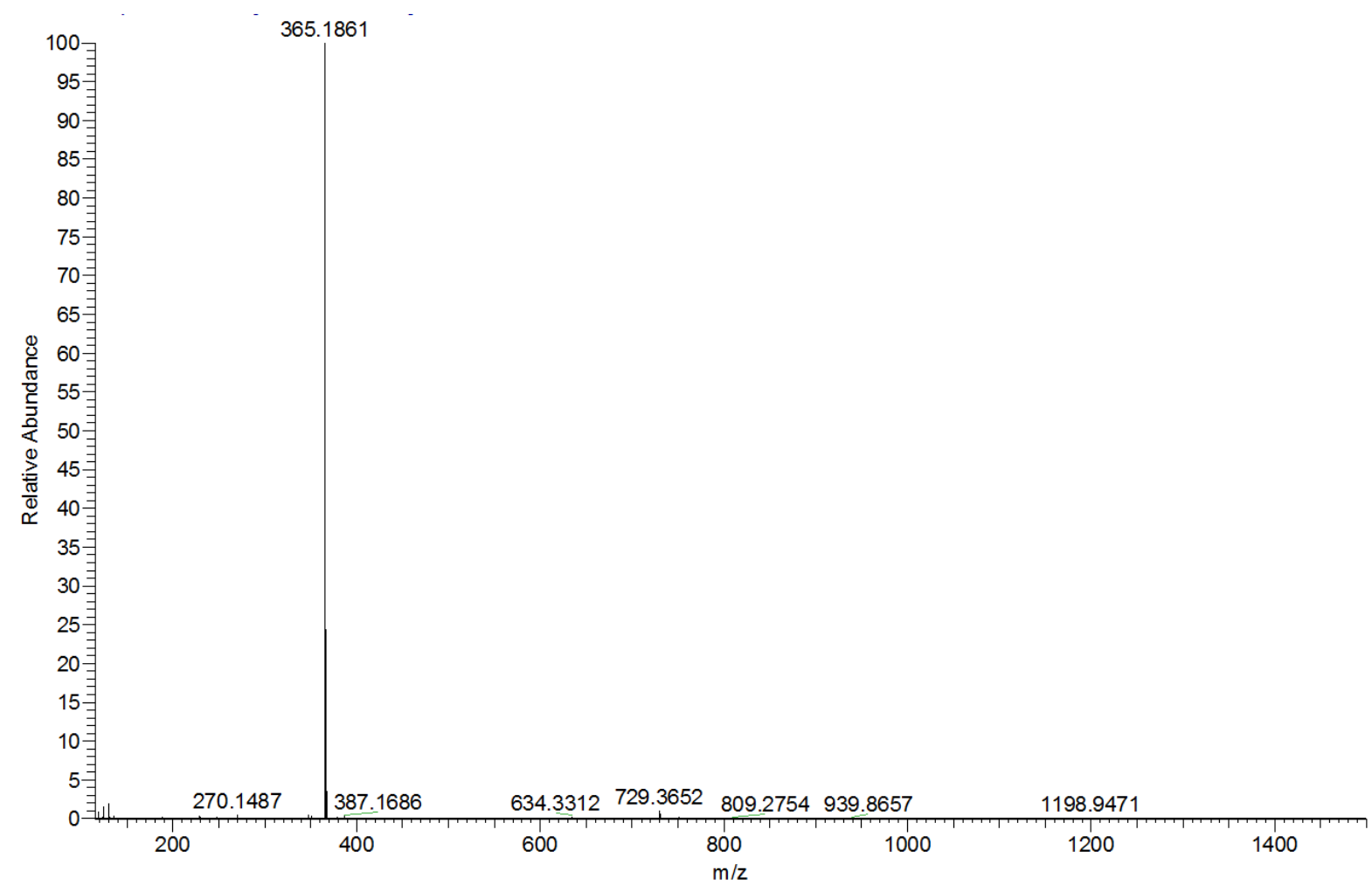

Figure S55. ESI-HR-MS spectrum of compound 4 measured in positive mode. 


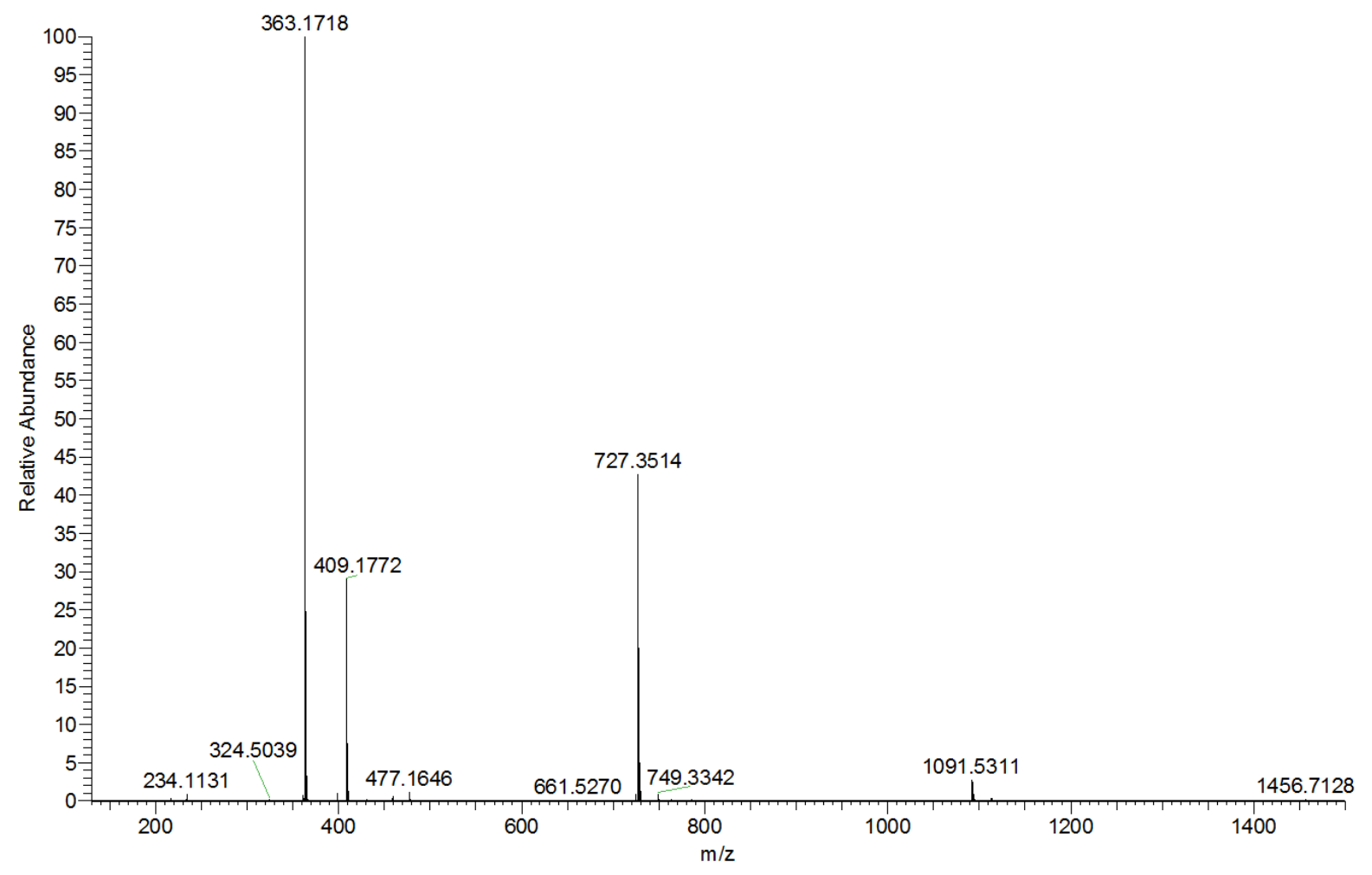

Figure S56. ESI-HR-MS spectrum of compound 4 measured in negative mode.

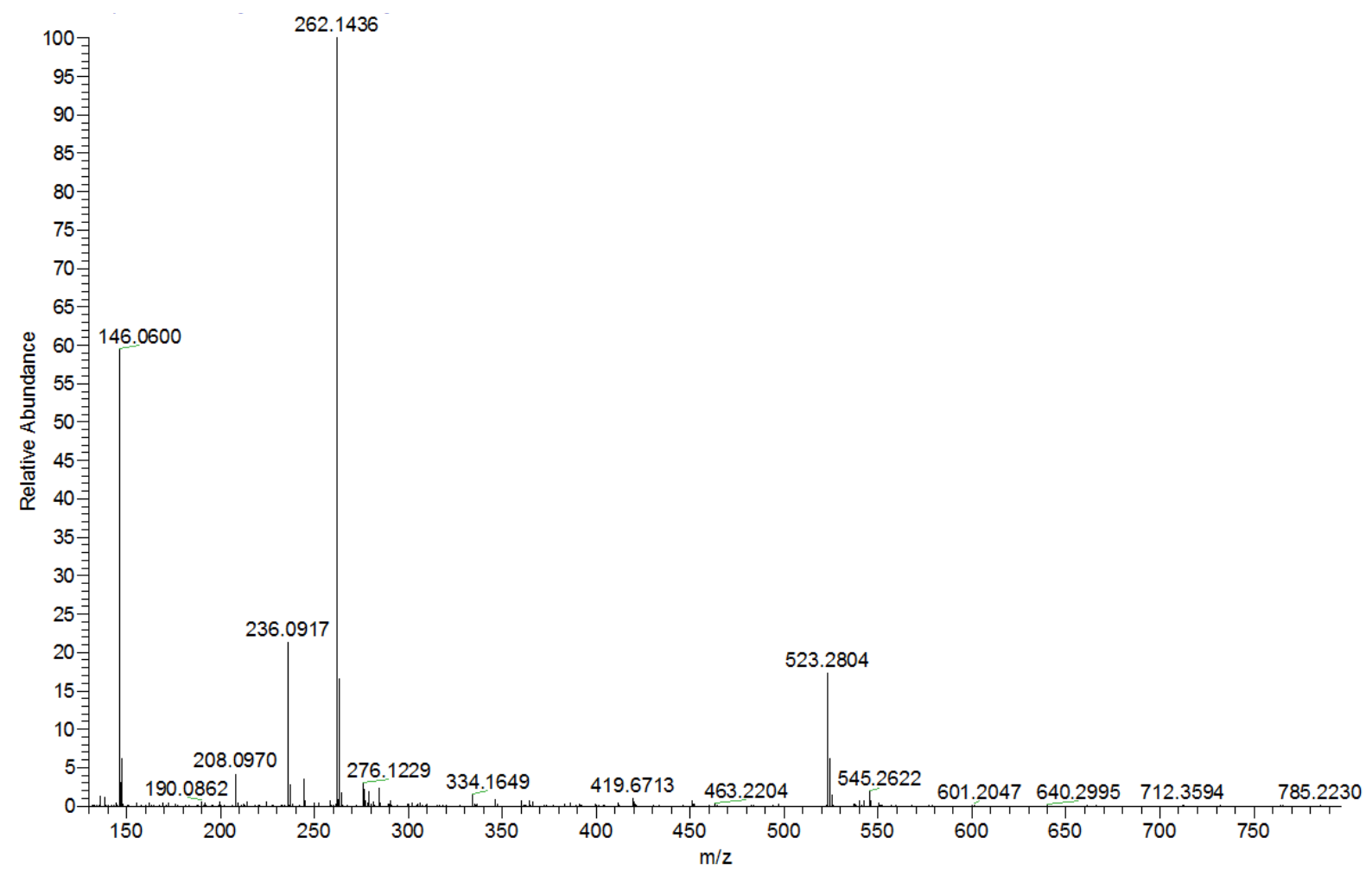


Figure S57. ESI-HR-MS spectrum of compound $\mathbf{5}$ measured in positive mode.

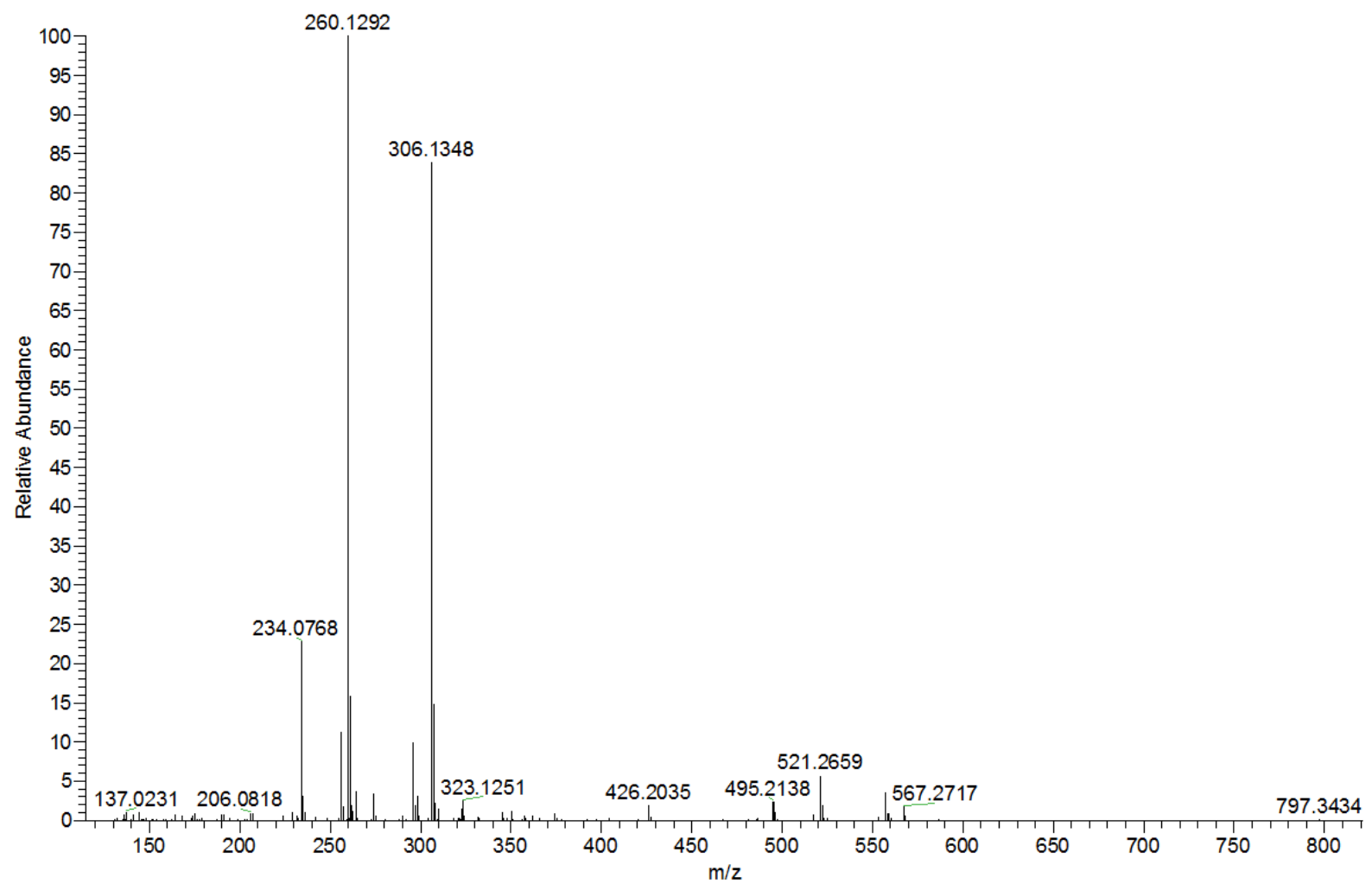

Figure S58. ESI-HR-MS spectrum of compound $\mathbf{5}$ measured in negative mode. 


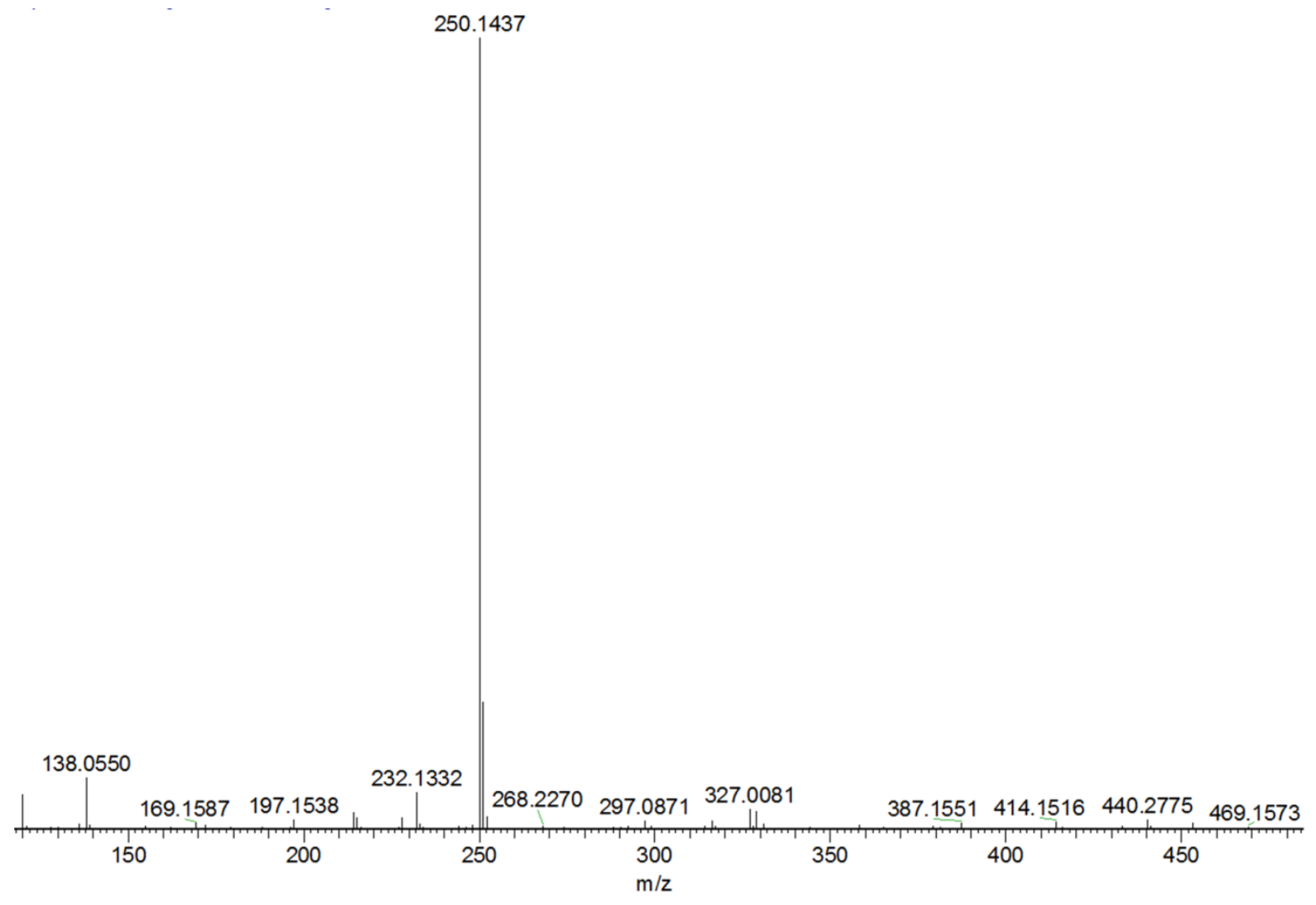

Figure S59. ESI-HR-MS spectrum of compound $\mathbf{6}$ measured in positive mode. 


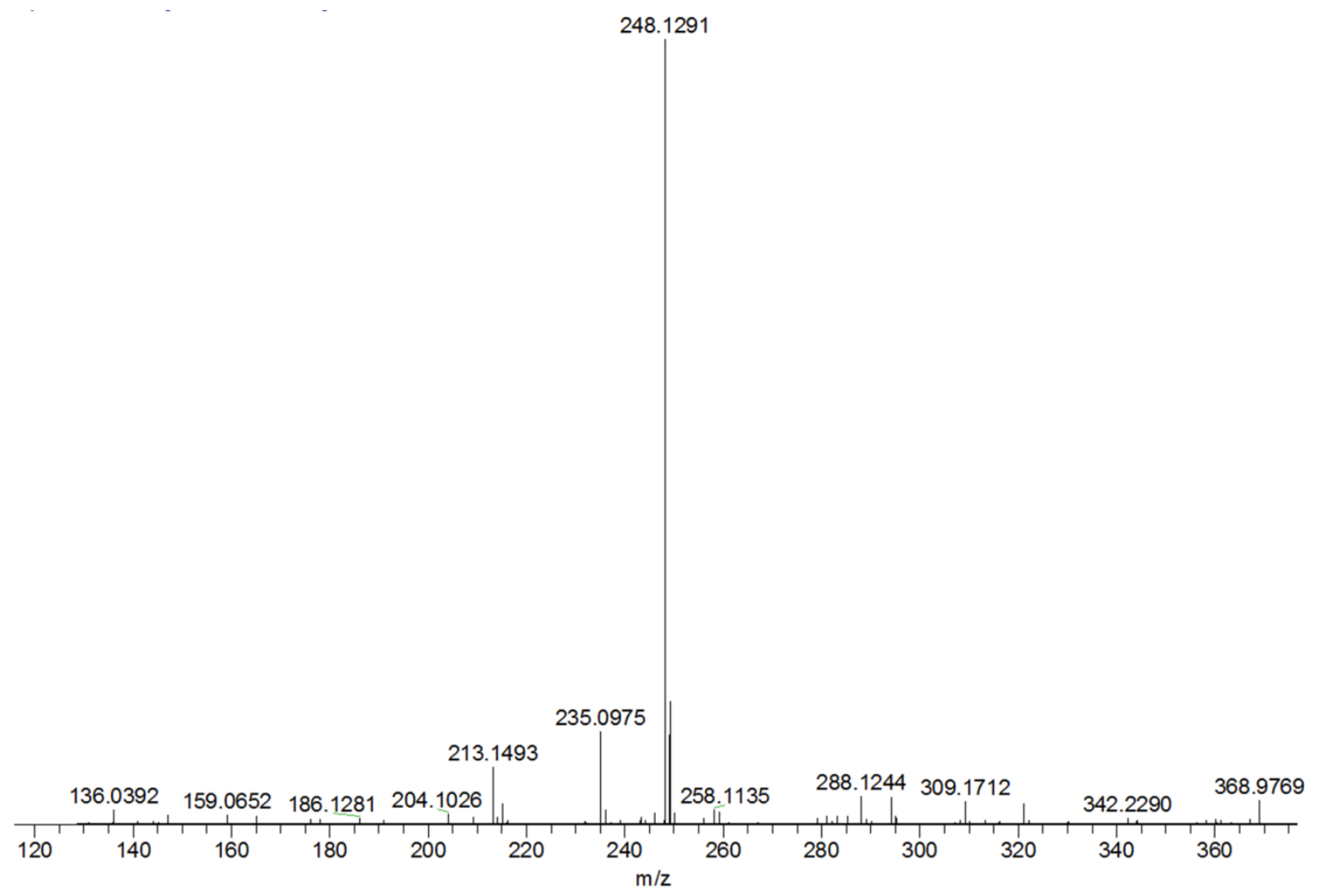

Figure S60. ESI-HR-MS spectrum of 6 measured in negative mode.

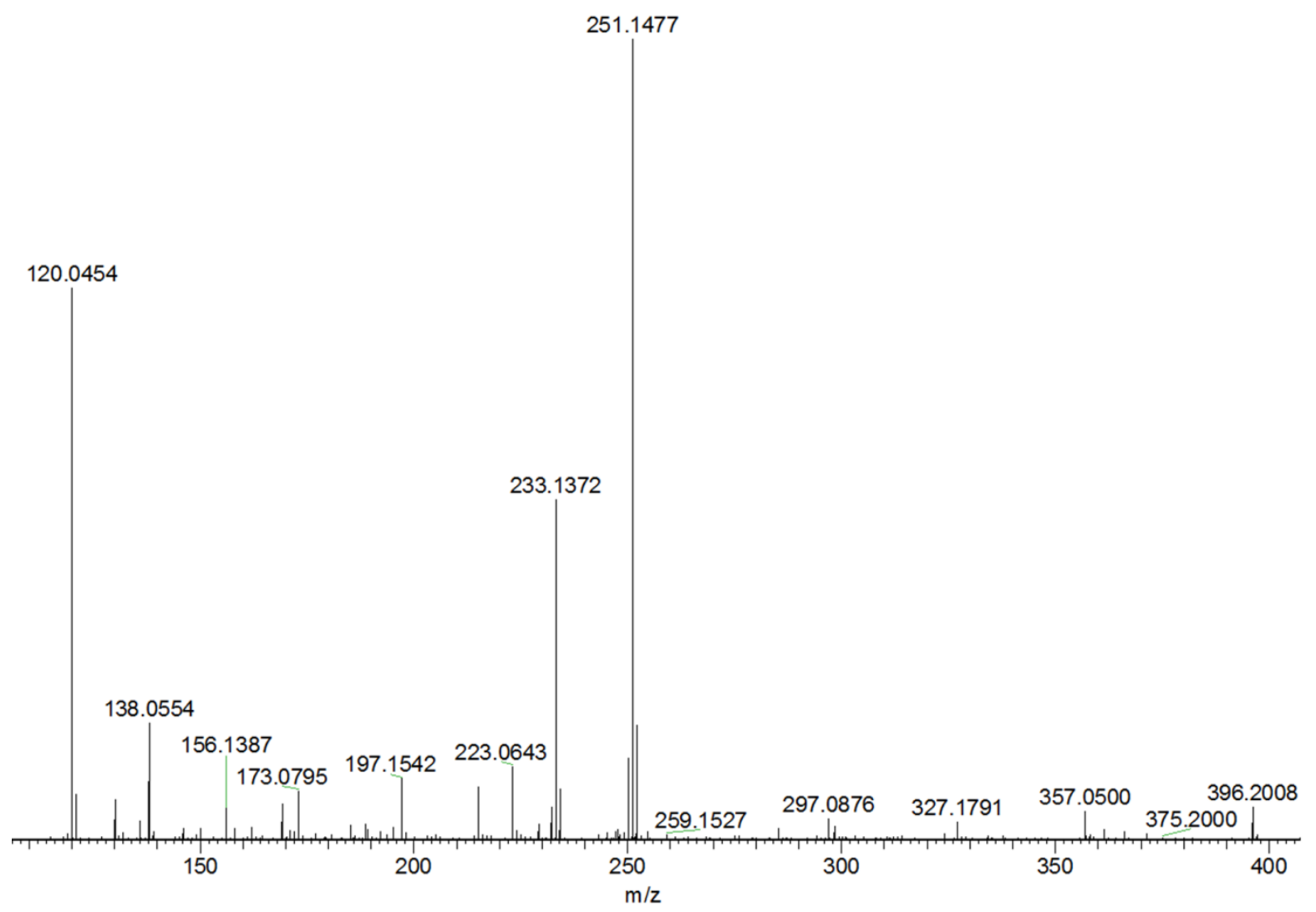


Figure S61. ESI-HR-MS spectrum of ${ }^{13} \mathrm{C}$-labeled 6 measured in positive mode.

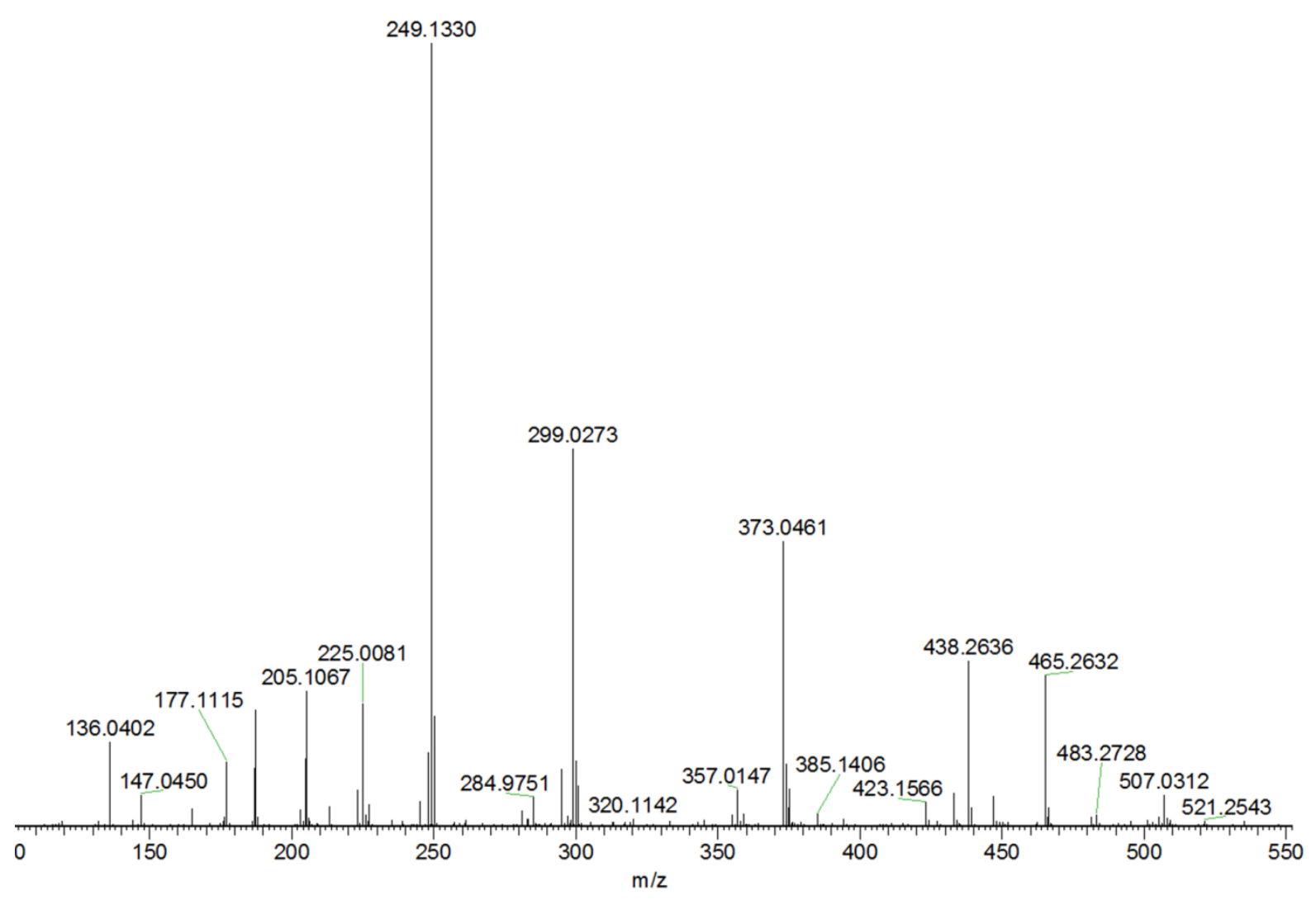

Figure S62. ESI-HR-MS spectrum of ${ }^{13} \mathrm{C}$-labeled 6 measured in negative mode. 


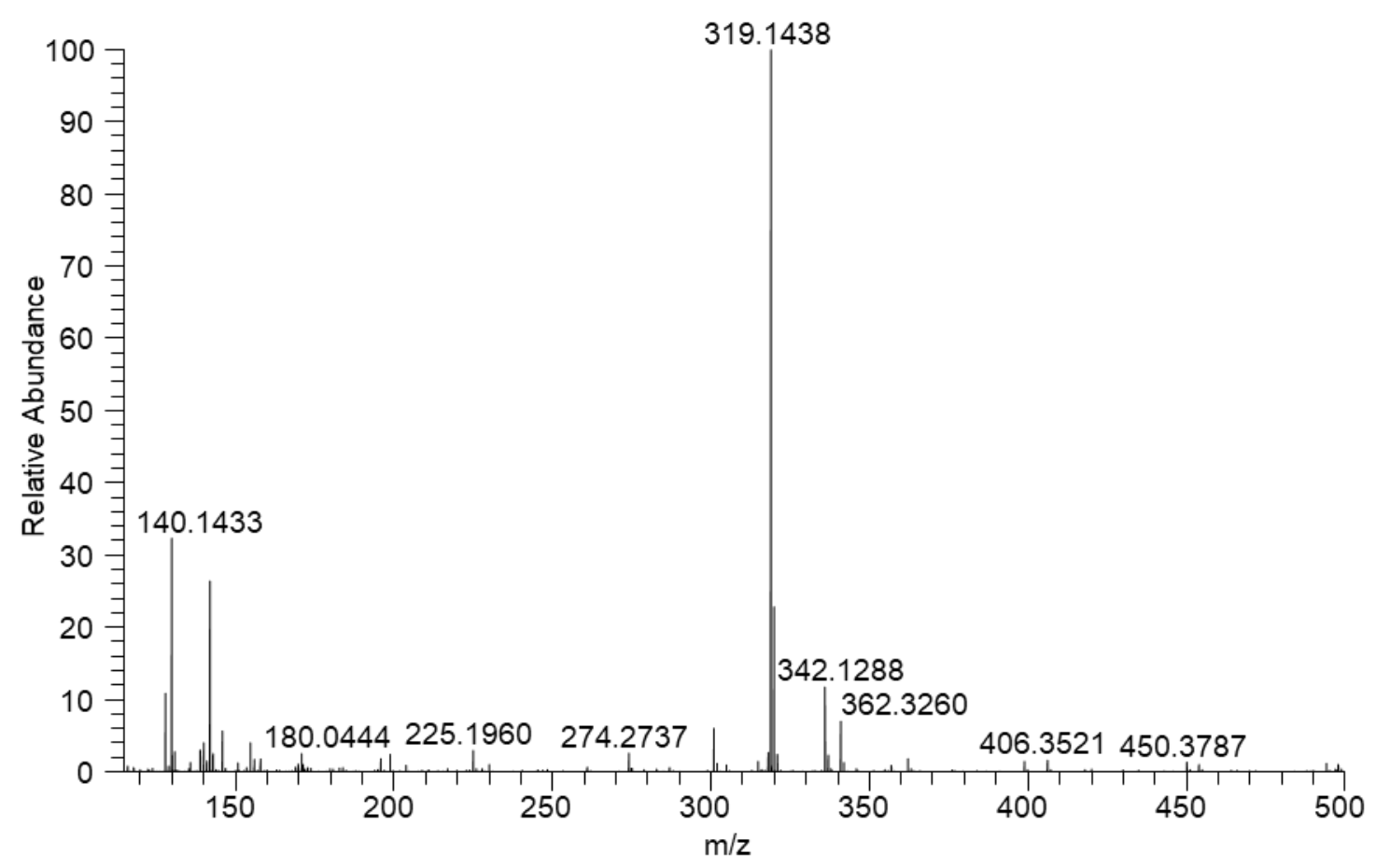

Figure S63. HR-ESI-MS spectrum of compound 9 measured in positive mode.

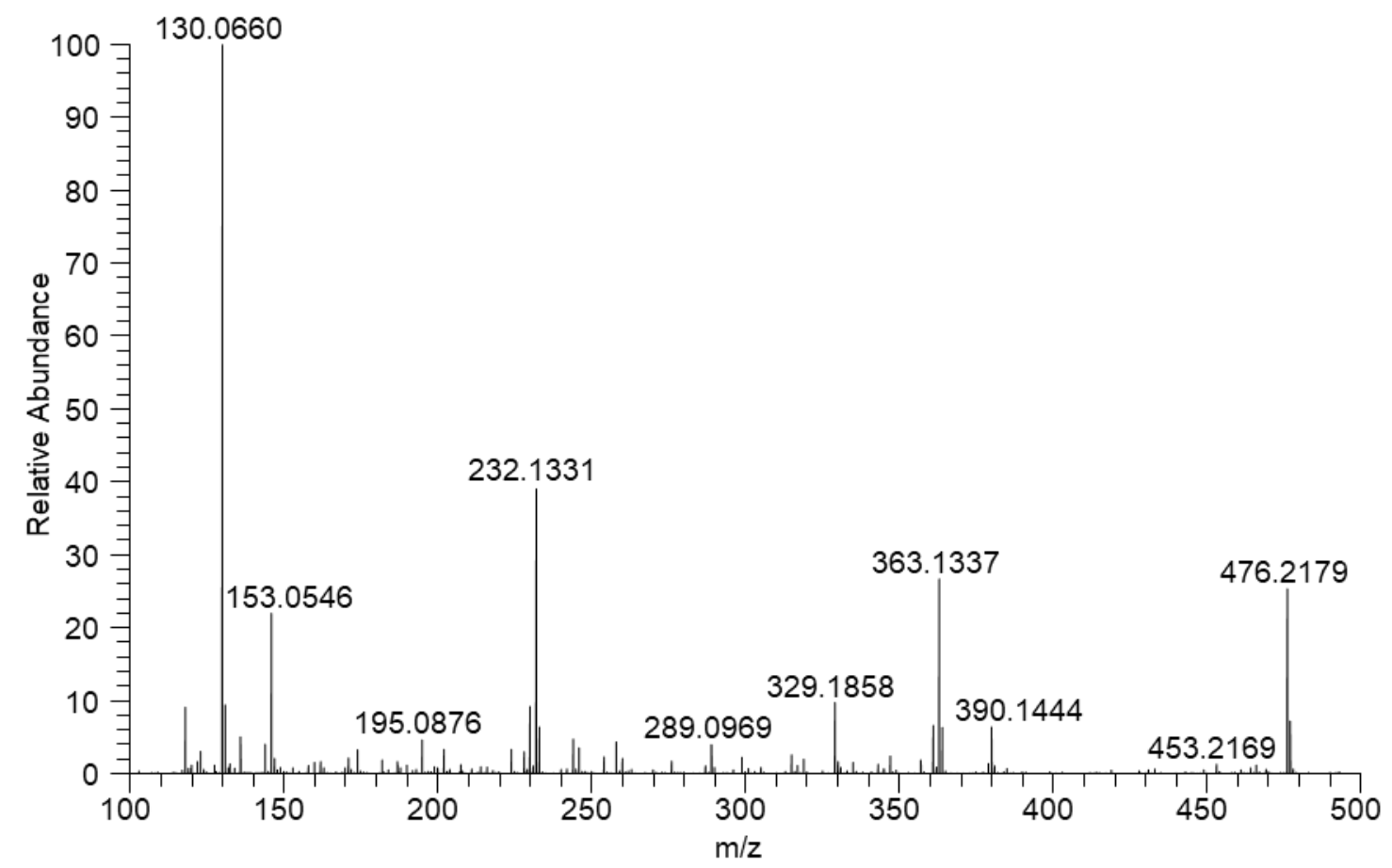

Figure S64. HR-ESI-MS spectrum compound 11 measured in positive mode. 


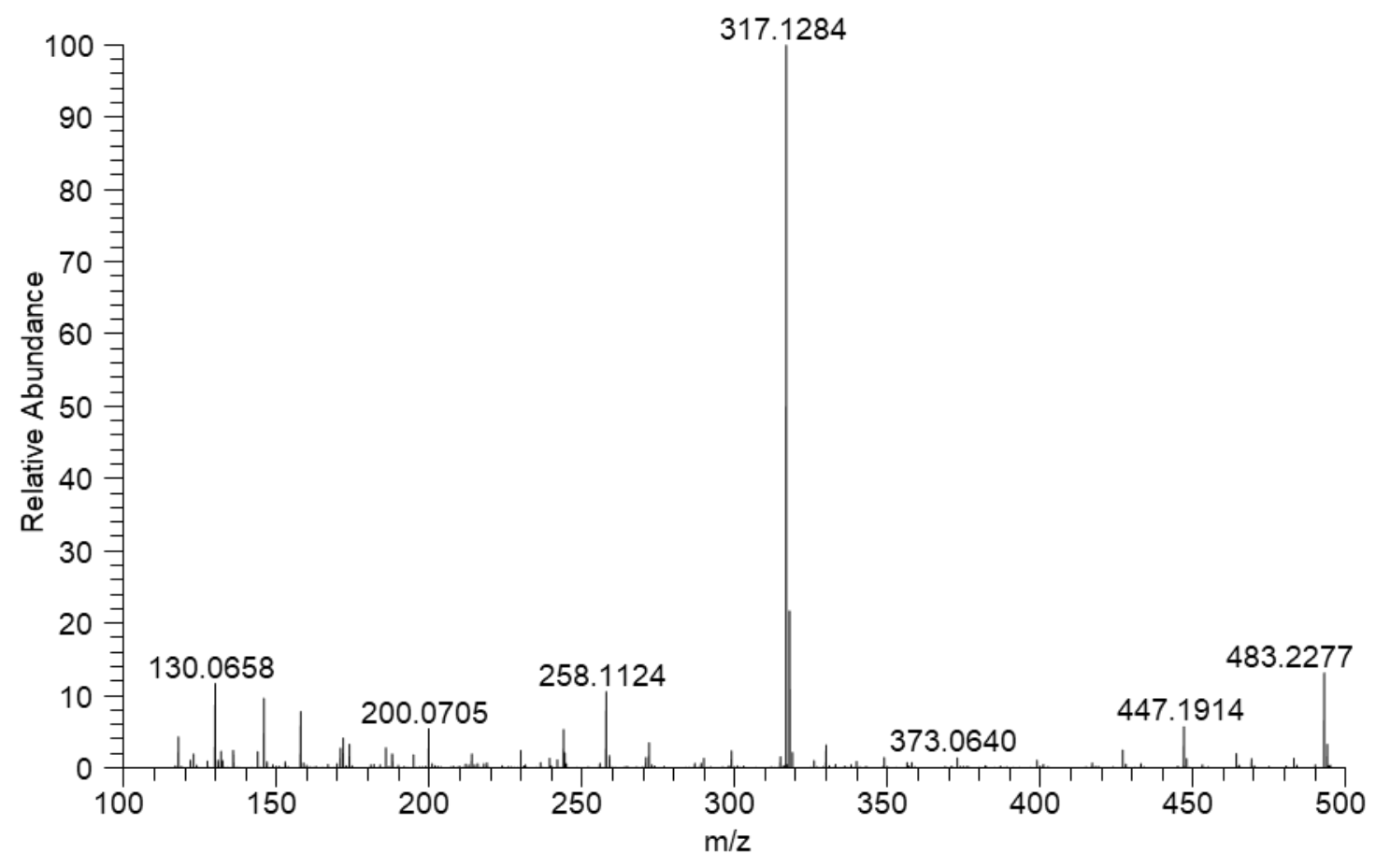

Figure S65. HR-ESI-MS spectrum compound 12 measured in positive mode. 


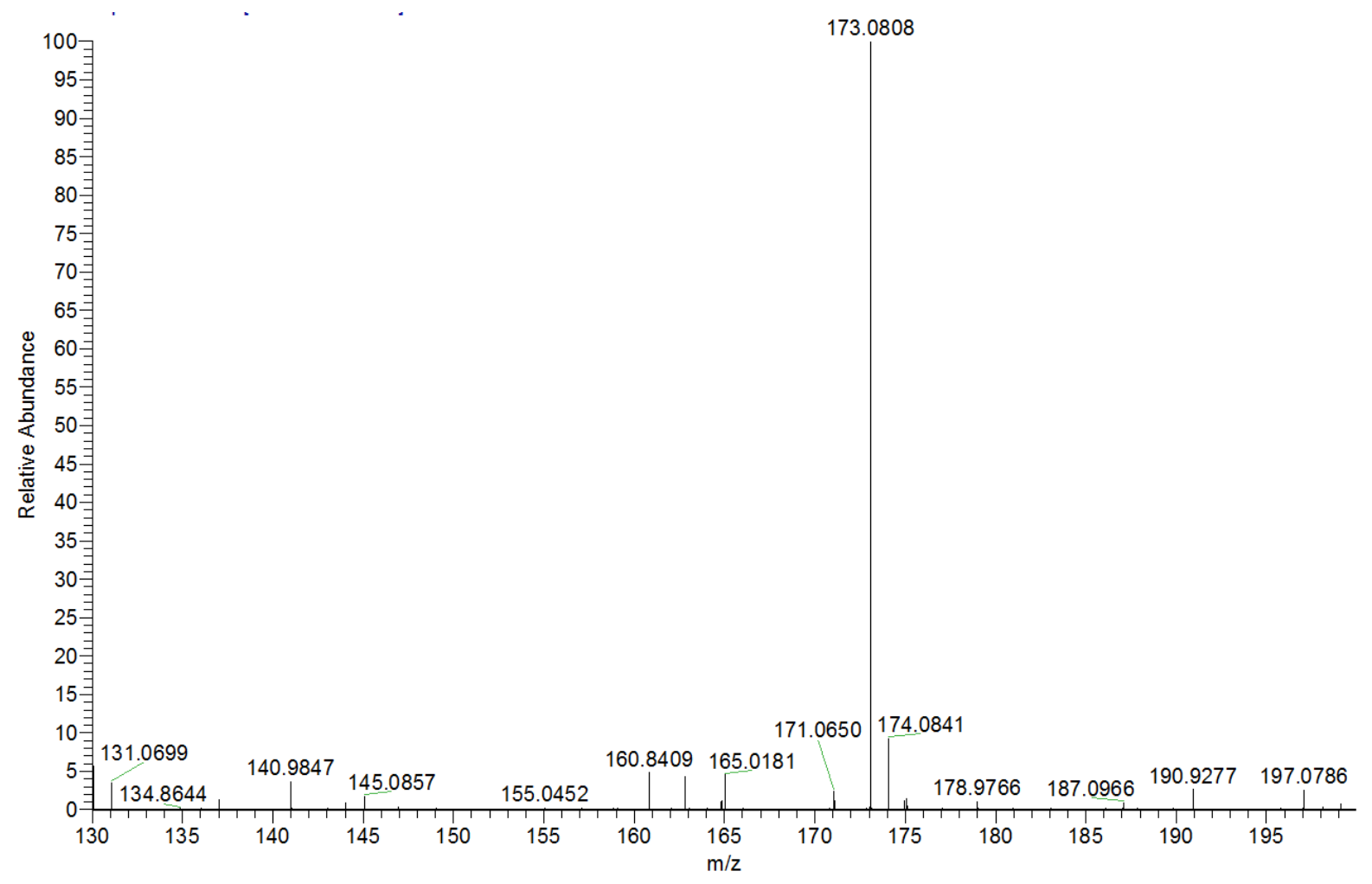

Figure S66. HR-ESI-MS spectrum of 13 measured in negative mode.

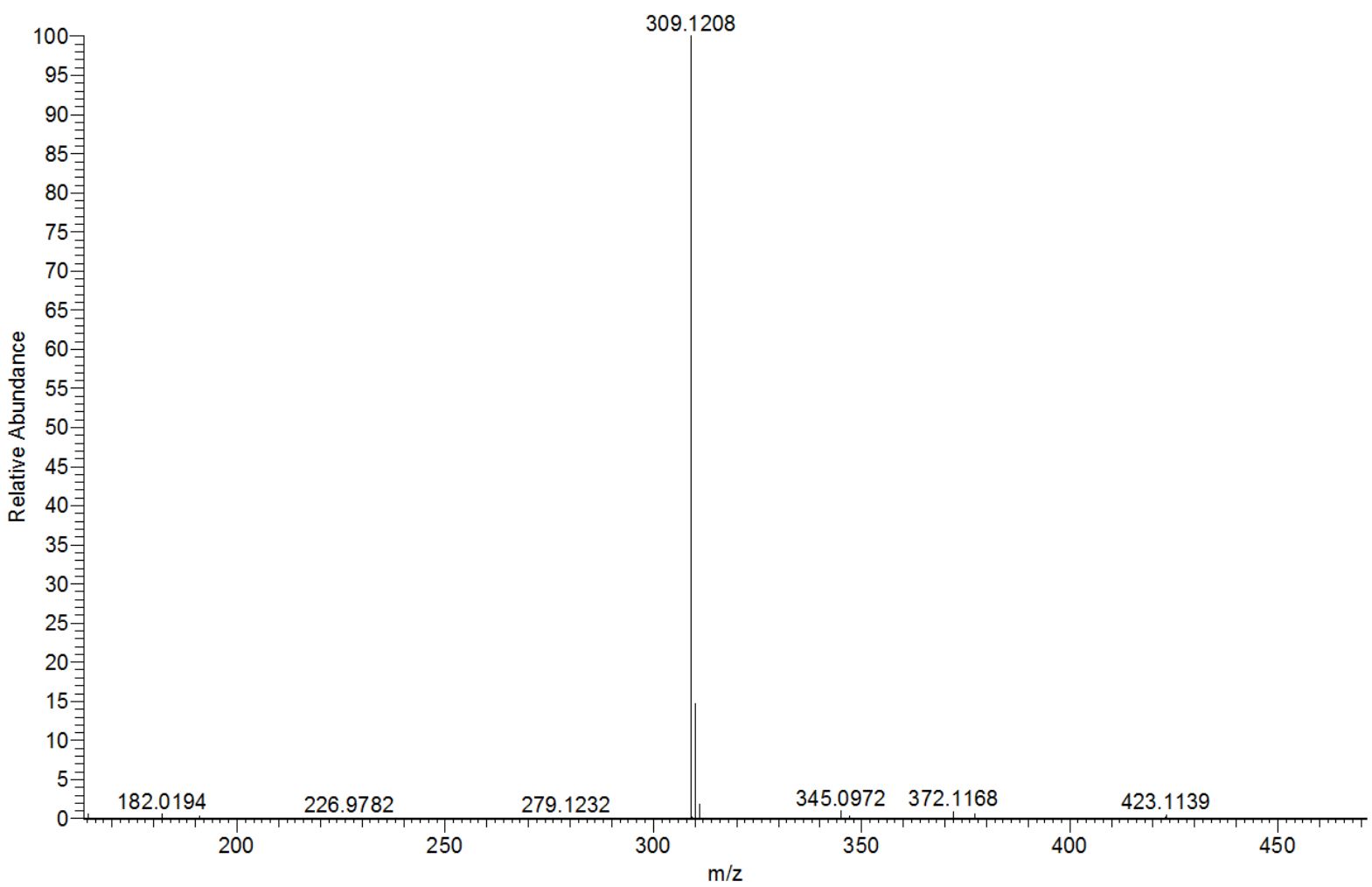

Figure S67. ESI-HR-MS spectrum of compound 14 measured in negative mode. 


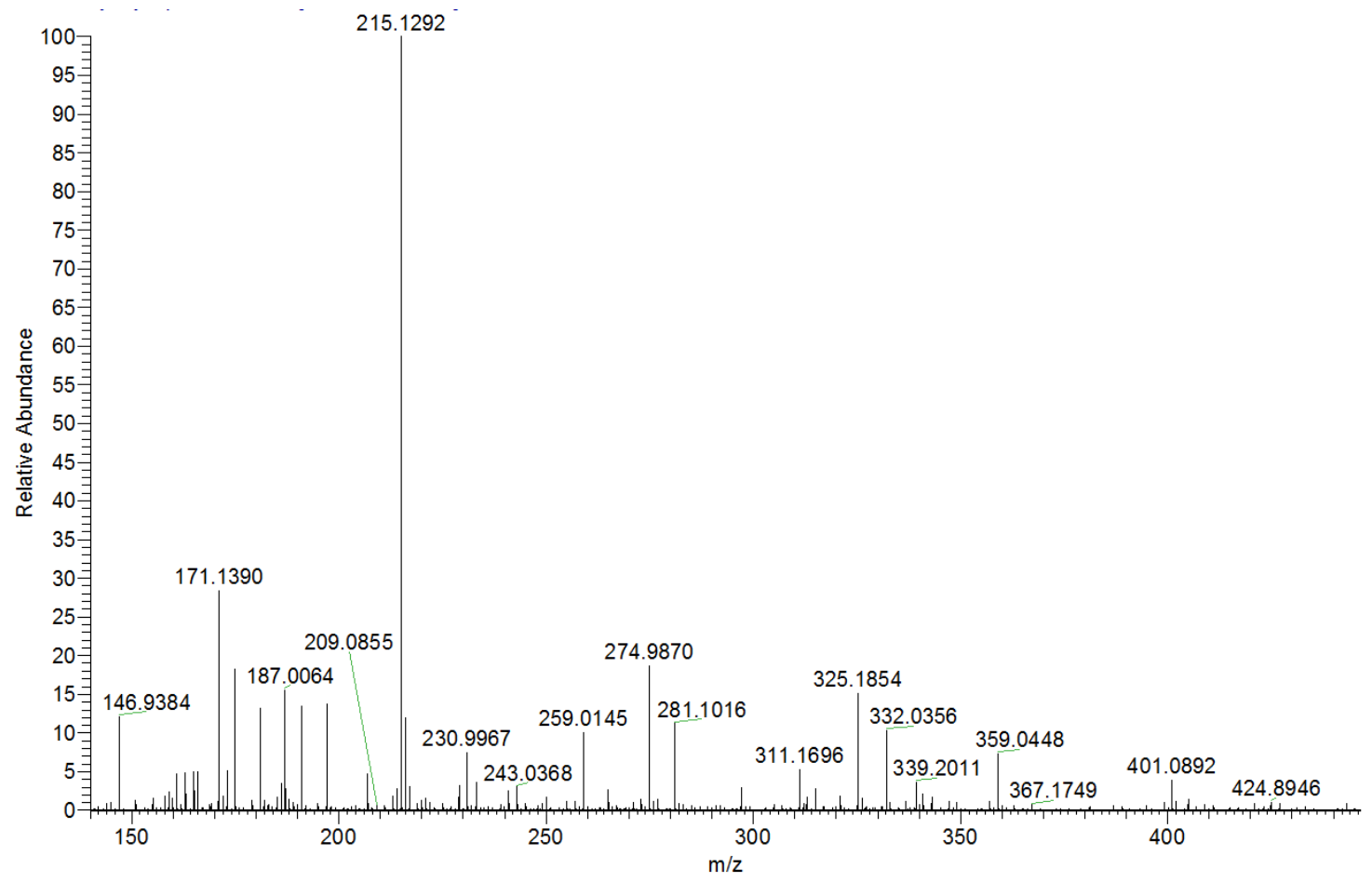

Figure S68. HR-ESI-MS spectrum of 2-hydroxy-2-isobutyl-4,4-dimethyl-3-oxopentanoic acid (15) measured in negative mode.

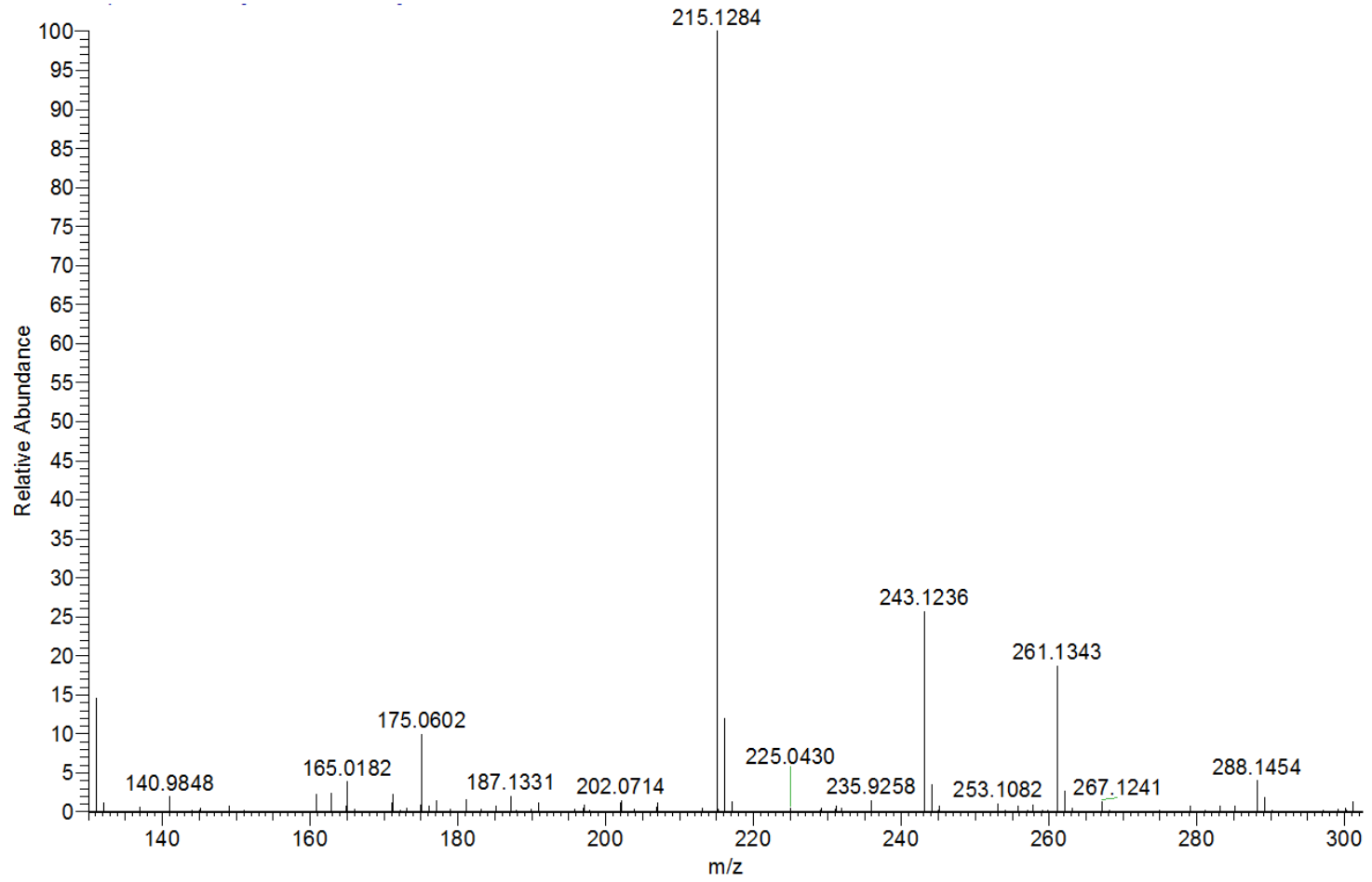

Figure S69. HR-ESI-MS spectrum of 2-hydroxy-2-isobutyl-4-methyl-3-oxohexanoic acid (16) measured in negative mode. 


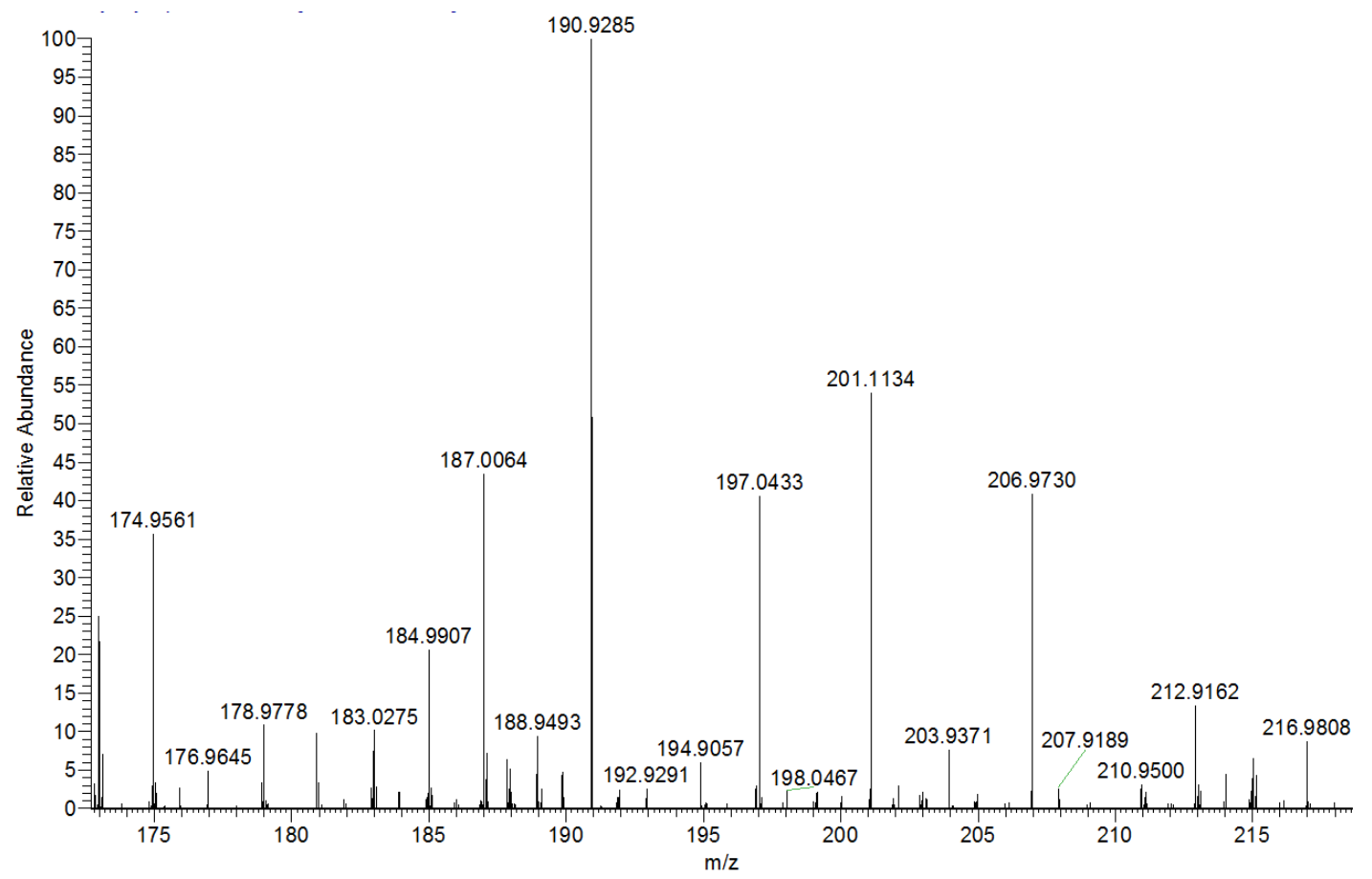

Figure S70. HR-ESI-MS spectrum of 2-hydroxy-2-isobutyl-4-methyl-3-oxopentanoic acid (17) measured in negative mode. 


\section{Supporting References}

1. Monot, F.; Martin, J. R.; Petitdemange, H.; Gay, R. Acetone and butanol production by Clostridium acetobutylicum in a synthetic medium. Appl. Environ. Microbiol. 1982, 13181324.

2. Bankevich, A.; Nurk, S.; Antipov, D.; Gurevich, A. A.; Dvorkin, M.; Kulikov, A. S.; Lesin, V. M.; Nikolenko, S. I.; Pham, S.; Prjibelski, A. D.; Pyshkin, A. V.; Sirotkin, A. V.; Vyahhi, N.; Tesler, G.; Alekseyev, M. A.; Pevzner, P. A. SPAdes: a new genome assembly algorithm and its applications to single-cell sequencing. J. Comput. Biol. 2012, 455-477.

3. Seemann, T. Prokka: rapid prokaryotic genome annotation. Bioinformatics 2014, 2068.

4. Katoh, K.; Rozewicki, J.; Yamada, K. D. MAFFT online service: multiple sequence alignment, interactive sequence choice and visualization. Brief Bioinform. 2017.

5. Nguyen, L. T.; Schmidt, H. A.; Haeseler, A. v.; Minh, B. Q. IQ-TREE: a fast and effective stochastic algorithm for estimating maximum-likelihood phylogenies. Mol. Biol. Evol. 2015, 268-274.

6. Kalyaanamoorthy, S.; Minh, B. Q.; Wong, T. K. F.; Haeseler, A. v.; Jermiin, L. S. ModelFinder: fast model selection for accurate phylogenetic estimates. Nat. Methods 2017, 587-589.

7. Minh, B. Q.; Nguyen, M. A. T.; Haeseler, A. v. Ultrafast approximation for phylogenetic bootstrap. Mol. Biol. Evol. 2013, 1188-1195. 